\title{
EL '98 EN AMÉRICA. ÚLTIMOS RESULTADOS Y TENDENCIAS RECIENTES DE LA INVESTIGACIÓN*
}

POR

A Julio Le Rieverend, maestro

In memoriam

\author{
ANTONIO SANTAMARÍA GARCÍA Y CONSUELO NARANJO OROVIO \\ Centro de Estudios Históricos, C.S.I.C.
}

«El 98 en América» es un estudio exhaustivo de la reciente producción historiográfica sobre las últimas colonias ultramarinas españolas en las últimas décadas del siglo XIX y primeras del XX. En la primera parte del texto se analizan las obras clásicas sobre el tema, lo que permite explicar, en la segunda parte, cuáles son las principales aportaciones de esa producción historiográfica reciente al conocimiento y sus carencias que deben resolverse en el futuro. El trabajo termina con una relación bibliográfica que incluye todo lo escrito últimamente y las referidas obras clásicas dedicadas al asunto.

* Trabajo financiado por el proyecto PB 96-0868 (DGES) y, también, en el caso de Antonio Santamaría García, por una Beca Postdoctoral en el Extranjero del Ministerio de Educación y Cultura Español en St. Antony's College, University of Oxford, gracias a la cual colaboró en el referido proyecto durante los meses de agosto y septiembre de 1998. Queremos agradecer los comentarios y sugerencias de los licenciados Luis Miguel García Mora y Margarita Lillo González y de los doctores José Antonio Piqueras Arenas, Christopher Schmidt-Nowara, Alejandro García Álvarez, Óscar Zanetti Lecuona y María Antonia Marqués Dolz. Así como los asistentes al «Seminario Permanente de Investigación» del Instituto Universitario Ortega y Gasset, y especialmente a los doctores Carlos D. Malamud Rikles, Marcela A. García Sabstiani y Laura Ruiz Jiménez. Debido al volumen de la Bibliografía, este artículo no sigue las normas de la Revista de Indias. En su lugar empleamos el sistema denominado de Boston o norteamericanos (en el texto y las notas se refiere la inicial del nombre y el apellido del autor y el año de publicación de la obra entre paréntesis, lo que permite localizarla luego en la bibliografía final). 


\section{INTRODUCCIÓN}

Más como pretexto que como razón, el centenario de 1898 ha generado una vasta producción científica. Como pretexto, pues al menos desde 1986, cuando se celebró la abolición de la esclavitud, se mantiene con intensidad un flujo constante de publicaciones que estudian en un sentido amplio la coyuntura finisecular en los últimos reductos del imperio español en América. Tanto es así que en un trabajo reciente, con intención similar al que aquí nos ocupa, E. Hernández Sandoica (1998f: 15) afirma: «Sólo hace diez años, parecía imposible que el ámbito de los estudios referidos a $\mathrm{Cu}$ ba, escritos desde España, habría de convertirse en un tema mayor»; no obstante también es cierto, y eso explica tanto su esfuerzo como el nuestro, que «aunque felizmente esto ha sido así, hay que advertir que no se han emprendido todavía las síntesis que permitan dar cuenta, a un público más amplio que el procedente del más estricto americanismo, de los avances producidos».

Como E. Hernández Sandoica, y para empezar, digno es reconocer el esfuerzo realizado desde España y por españoles, y la calidad y el rigor científico de la mayoría de los trabajos resultantes, poco habitual en un panorama historiográfico nacional caracterizado, hasta hace relativamente poco tiempo, más bien por su aislamiento y alejamiento de los debates internacionales (con honrosas excepciones, por supuesto), defecto que, sin embargo, se va superando. Reconocido esto, que es necesario para explicar la amplia presencia de autores españoles escribiendo sobre el tema que nos ocupa, debemos decir, empero, que el criterio de selección de este artículo no es la nacionalidad, sino la actualidad y el estado de la cuestión, ajeno a rígidas y ortodoxas posiciones nacionalistas que reducen el sentido de la historia y la historiografía a los estudios realizados dentro de determinadas fronteras; criterio que por lo general se aplica también a las fuentes. Este modo de proceder suele mermar el valor de unos resultados que, como consecuencia, no obedecen en absoluto a una realidad en la que son continuos los intercambios académicos y el mutuo conocimiento que los investigadores tienen del referido debate internacional.

El incesante flujo de publicaciones recientes sobre la coyuntura finisecular en América ha generado un buen número de análisis historiográficos que, como el citado antes, tratan de organizar un debate desbordado por las voces que están participando en él. Todos ellos han quedado rápidamente desactualizados, incluso algunos que todavía están en prensa, ya que desde finales de 1996 se han editado mas de ciento veinte obras que, por lo general, son compilaciones y reúnen en su interior casi seiscientos artículos 1 .

1 Entre los estudios recientes ver los de E. Hernández Sandoica (1996, 1997a, 1998b y f), centrados básicamente en la producción española y sobre españoles, especialmente en Cuba, igual que los de M. Espadas (1996), L. Álvarez (1997) y E. Camacho (1998-99), aunque los dos últimos no atienden sólo a la historiografía acerca de América. Los textos de M. de la Torre (1985), C. Almodóvar (1987, 1988 y 1989), L.A. Pérez (1988b y 1995a y b), J. Ibarra (1995c) y J. James (1995) son de carácter general (no analizan únicamente la coyuntura finisecular) y se concentran en lo editado por cubanos y norteamericanos sobre la Gran Antilla. Lo mismo puede decirse del de A. Gaztambide y S. Álvarez Curbelo, eds. (1996) para Puerto Rico. El más compensado en ese sentido es el de M.T. Cortés (1995). Aparte de los citados, otros trabajos examinan problemas más específicos como, por supuesto, el 98 en un sentido amplio, o en lo concerniente a la guerra colonial y a la intervención de los EE.UU. en ambas islas, de ello se ocupan F. Pérez Guzmán (1985), J.E. Hernández (1997), T.G. Paterson (1997), C. Rosario (1997), C. Almodóvar (1997b y c), D. Trask (1997a y b) y L.A. Pérez (1998). Por su parte, los artículos de C. Almodóvar (1993), A. Santamaría (1994b y 1996b), L.M. García Mora (1995), M.A. Castro (1997a), M.R. Cancel (1998a) y E. López Mesa (1999) examinan lo escrito en relación con la formación del Estado y la identidad nacional, y los de O. Zanetti (1985 y 1994), M.C. Barcia (1994 y

\section{R. I., $1999, \mathrm{n}^{\circ} 215$}


Como ya dijimos, el criterio de selección de este estudio es la actualidad, y específicamente se centra en lo publicado desde finales de 1996. La elección de tal fecha responde a dos razones. La primera es la aparición en el otoño de ese año de algunas de las obras más representativas del nuevo debate en torno al 98 en América, especialmente de la compilada por uno de nosotros, C. Naranjo, M.A. Puig-Samper y L.M. García Mora, eds. (1996), La nación soñada: Cuba, Puerto Rico y Filipinas ante el 98 (Aranjuez, Doce Calles). Los comentarios de que ha sido objeto avalan nuestra propuesta: «contiene, a no dudarlo, muestras de calidad historiográfica extraordinaria [...] Nadie podrá doblar la esquina del 98 alegando ignorancia sobre las colonias y mucho menos falta de información» [E. Hernández Sandoica (1998a: 145)]. La segunda razón es que tanto el contenido del referido libro como el de los trabajos que lo precedieron se examina en los estudios historiográficos citados anteriormente, de manera que analizando lo que ha aparecido después de él, nuestro artículo completa y complementa estos últimos.

Aparte de cronológicas, este artículo tiene limitaciones temáticas y muestrales. Su título expresa las primeras: El 98 en América. Aquí no analizaremos más que de soslayo otros noventa y ocho, como el filipino o el denominado desastre español, que dejamos para especialistas en el tema, pues nosotros no lo somos. Sí haremos breves referencias, por contra, a otros países americanos, aparte de los que surgieron de las últimas colonias de España, incluidos los EE.UU $\mathrm{UU}^{2}$. La limitación muestral se debe a que, pesar de la cantidad de obras examinadas en las páginas que siguen a continuación, quedan excluidos de nuestros comentarios por razones de espacio y de contenido algunos trabajos editados fuera de las compilaciones dedicadas específicamente al tema ${ }^{3}$.

Gran parte de las obras examinadas aquí, como hemos dicho, reúnen estudios de diversos autores y temas ${ }^{4}$. Algunas, además, y para tratar de evitar la citada rápida

1997b), G. García Rodríguez (1995), F. Iglesias (1995), C. Naranjo (1995), J.A. Uribe (1995), A. Santamaría (1996b y 1998a) y A. Santamaría y C. Naranjo (1999), con la sociedad y economía de Cuba. Finalmente, estudios de J. Opatrný (1995), W.L. Bernecker (1998b), J.A. Piqueras (1998b) y A. Sánchez Andrés (1998a) se interesan por la historiografía más reciente, un texto de M.A. Puig-Samper (1995) por la historia de la ciencia, y otro nuestro, A. Santamaría (1994b), y casi todos los citados anteriormente de E. Hernández Sandoica, por la continuidad o ruptura en las relaciones entre españoles y cubanos después de 1898.

2 Para Filipinas, aparte del monográfico compilado por uno de nosotros, C. Naranjo, coord. (1998) y del editado por la Revista Española del Pacífico (1997 y 1998), varias de las obras analizadas aquí contienen estudios, sobre todo las de M.R. Rodríguez, coord. (1997); En torno al 98 (1998); J.P. Fusi y A. Niño, eds. (1996 y 1997); S. Juliá, dir. (1997-98) o Hispania (1997). En las tres últimas y en las de S. Juliá, coord. (1998) y dir. (1997-98); A. Llopis, ed. (1998), J. Pan-Montojo, coord. (1998) o J. Tusell y F. Portero, eds. (1998), el lector interesado puede profundizar también en el tema de la crisis española subsiguiente a la pérdida del imperio.

3 Muchas revistas han publicado artículos sobre el tema, incluso monográficos en otros momentos. Por ejemplo, y aparte de las citadas en notas anteriores o posteriores, en España, Baluarte, Boletín Americanista, Revista Española de Estudios Norteamericanos o Tebeto; en Cuba, Bohemia, Economía y Desarrollo, Islas o Revista de la Universidad de La Habana; en Puerto Rico, Boletín Histórico de Puerto Rico, Revista de Ciencias Sociales, Revista de Historia de Puerto Rico o Revista del Instituto de Cultura Puertorriqueña; en EE.UU., Latin American Research Review; en Gran Bretaña, Journal of Latin American Studies o Latin American Bulletin, y en Francia-Guayana, Espace Caraïbe.

4 Por orden alfabético, las obras analizadas son: 1898: ¿desastre... (1998); El 98 (1998); El 98... (1998); El 98 visto... (1998); D. Abad (1996); L. Agrait y A. Cubano, coords. (1997); C. Almod6var, comp. (1997); C. Almodóvar, ed. (1998); S. Álvarez Curbelo et al., eds. (1998); J.B. Amores (1998); R. Aparicio (1996); A. Bahamonde, coord. (1997); M.C. Barcia (1998b); M.C. Barcia et al. (1998); M. Bejarano (1996); J. Belnap y R. Fernández, eds. (1998); W.L. Bernecker, ed. (1998); M. Bizcarrondo, ed. (1998); E.M. Burgos (1997); En busca... (1997); G. Cabrales (1996); J.G. Cabrera (1997); G. Cardona y J.C. Losada (1997); Casa de las... (1998); J. Casanovas (1998a); J. Casanovas, coord. 
desactualización que han padecido casi todos los ensayos como éste publicados últimamente, están aún en fase editorial, pero gracias a sus editores y/o autores, hemos podido tener en primicia el manuscrito, o al menos el índices, que en casos fue suficiente para comentar su contenido, debido al conocimiento previo que uno de nosotros tenía del mismo por haber asistido a los eventos que dieron lugar a muchas de las monografías analizadas. Aun así, somos conscientes de que en breve saldrán algunos estudios que ni siquiera por el procedimiento anterior hemos podido incorporar ${ }^{6}$.

El debate en torno al 98 en América se ha expresado fundamentalmente en obras que contienen trabajos de varios autores debido a la forma en que éste se ha desarrollado, fundamentalmente a través de reuniones de carácter internacional. Tal procedimiento tiene sus pros y sus contra, pero creemos que el saldo será positivo. A corto plazo puede crear confusión y desorden por lo mucho que en esos foros se ha podido decir - y luego publicar - pero a medio y largo plazo, una vez eliminemos lo su-

(1997); Y. Castillo et al. (1998); J.G. Cayuela, coord. (1998); J. Cervera (1998); J. Companys (1998); Contracorriente (1997); M.T. Cortés et al., eds. (1998-99); Cuadernos... (1998); Cuba/España (1996); Cuba Theme... (1996); A. Díaz Quiñones, ed. (1997); A.D. Dye (1998); A. Elorza y E. Hernández Sandoica (1998); España 1898... (1998); P. Estrade (1998a); Estudios de Historia Social.. (1998); Estudios Migratorios (1996); R. Fermoselle (1998); L. Fernández-Martínez (1998b); J. Figuero y C. García Santa Cecilia (1997 y 1998); J.M. Fradera (1999); J.P. Fusi y A. Niño, eds. (1996 y 1997); J.A. Galbán, ed. (1997); A. García Álvarez y L.M. García Mora, eds. (1998); A. García Álvarez y C. Naranjo, coords. (1998); A. García González y R. Álvarez (1999); C. García del Pino (1996); A. Gaztambide y S. Álvarez Curbelo, eds. (1996); P. Gómez, coord. (1996); M.D. González-Ripoll (1997); M.D. González-Ripoll y L.M. García Mora (1997); L.E. González Vales, ed. (1997); M. Guicharnaud-Tollis (1996); M. Guicharnaudd-Tollis, ed. (1999); A. Gutiérrez y M.L. Laviana, coords. (1998); A. Gutiérrez y M.L. Laviana, eds. (1998); J.E. Henández, ed. (1998); E. Hernández Sandoica, coord. (1998); O. Hevia (1996); Hispania (1997); Hispanic... (1998); Historia y Sociedad (1997); P.A. Howard (1998); Ibero Americana Pragensia (1998); F. Iglesias (en prensa); IHC (1996); S. Juliá, coord. (1998); S. Juliá, dir. (1997-98); M. Leguineche (1998); L. y M. Lopez Baralt (1998); M.P. Maza (1997); C. Mellizo y L. Núñez, coords. (1998); A. Llopis, ed. (1998); S.E. Morales (1998a); S.E. Morales y A. Sánchez Andrés (1998); C. Naranjo y C. Serrano, eds. (1999); L. Navarro (1998c); R. Núñez (1998); G. Ojeda, ed. (1998); Op. Cit. (1998); R. Orozco y N. Bolívar (1998); S. Palazón y C. Saiz Pastor, eds. (1998); J. Pan-Montojo, coord. (1998); J. Paniagua y J.A. Piqueras, eds. (1998); M. de Paz y F. Guerra (1998); L.A. Pérez (1998); F. Pérez Guzmán (1997a y 1998b); J.P. Pérez Llorca (1998); R.F. Pino (1998); J.A. Piqueras, coord. (1998); J. A. Piqueras, ed. (1998); G. Placer (1997b y 1998b); J.A. Plaza (1997a y b); F. Portela et al. (1998); Puerto Rico... (1996); Race, Society... (1998); A. Remesal (1998); A.R. Rodríguez (1997 y 1998a y b); M.R. Rodríguez, coord. (1997); R. Rodríguez (en prensa); I. Roldán (1998); A. Smith y E. Dávila, eds. (1998); La sociedad... (1997); H. Thomas (1998); L. Toledo (1998b); En tomo al 98 (1998); M. de la Torre (1998a); J. Tusell y F. Portero, eds. (1998); Un último... (1998); C. Xixirey y J.R. Campos (inédito); O. Zanetti (1998c); O. Zanetti y A. García Álvarez (1998) y M. Zeuske (en prensa).

5 Agradecemos especialmente la colaboración en este sentido de I. Balboa, W.L. Bernecker, M. Casado, M.T. Cortés, A. Cubano, A.D. Dye, C. Estepa, P. García Santamaría, L.M. García Mora, A. Gutiérrez, E. Hernández Sandoica, M.L. Laviana, C.D. Malamud; A. Morales, J. Opatrný, L.A. Pérez, J.A. Piqueras, L. Ruiz Jiménez, M. Röhrig Assunçao, I. Roldán, R. Sevilla, J.A. Uribe, O. Zanetti y de la Editorial Pablo Iglesias.

6 Que sepamos, las compilaciones de D. Aranguren, ed. (en prensa) y P. Tedde, ed. (en prensa); una obra editada por C. Parcero (título sin determinar); los monográficos que preparan la revista y Debates Americanos, 5 (1998); el tomo III de IHC (1994-); la selección de textos de J. Martí preparada por A.M. Fernández para la Univ. de Oviedo; un CD-Rom sobre la esclavitud y la abolición que publicará la Universidad de Harvard, y las actas de los congresos celebrados en Puerto Rico y Canarias en agosto y octubre de 1998. Somos conscientes, además, de que nuestro conocimiento de los trabajos más recientes o que saldrán próximamente en los EE.UU. es menor que el de lo editado o en prensa en España, Europa en general, México, Puerto Rico y Cuba.

R. I., 1999, n. $^{\circ} 215$ 
perfluo, procesemos, valoremos y ordenemos las diversas contribuciones, lo que quedará será una semilla de diálogo y sana discusión, que esperamos permanezca como rasgo distintivo de esta historiografía. Obviamente, todo ello ha sido posible gracias al esfuerzo de personas e instituciones que convocaron, organizaron, buscaron financiación, moderaron el debate y editaron los libros ${ }^{7}$. Sin menospreciar a las demás, pues son muchas las entidades que han abierto espacios de discusión, es justo destacar la cooperación entre las Universidades Complutense y Autónoma de Madrid, Jaume I de Castellón, de La Habana, de Puerto Rico (Recinto de Río Piedras), Michoacana San Nicolás de Hidalgo (México) y el CSIC (España), que además de haber dado buenos resultados, explica la presencia de tantos historiadores mexicanos en las obras que aquí comentamos y la importancia concedida al tema del 98 en México ${ }^{8}$.

Aparte de exponer sus límites y alcances, esta introducción pretende apuntar brevemente la estructura del trabajo. Empezaremos examinando el estado del conocimiento acerca del 98 en América inmediatamente antes de la aparición de las obras objeto de estudio, haciendo hincapié en los avances producidos en los últimos años, de los cuales, como dijimos, son continuación los más actuales. Seguidamente analizaremos la aportación de éstos, tratando de obtener algunas conclusiones en torno a lo que hemos avanzado recientemente para mejorar lo que se sabe sobre el tema, a las carencias que todavía debemos completar y a las tendencias que parece apuntar la investigación para un futuro próximo. El texto se completa con unas ideas finales que no son exactamente conclusiones, y con una extensa bibliografía, en la que se detallan exhaustivamente los libros, monográficos de revistas, artículos y capítulos publicados

\footnotetext{
$7 \mathrm{Al}$ ser fruto de tales reuniones muchas de las obras analizadas aquí tienen ese carácter implícitamente, ya hemos mencionado varias, concretamente, El 98... (1998); C. Almodóvar, comp. (1997); D. Aranguren, ed. (en prensa); W.L. Bernecker, ed. (1998); Casa de las... (1998); J.G. Cayuela, coord. (1998);; M.T. Cortés et al., eds. (1998-99); A. Díaz Quiñones, ed. (1997); Estudios de Historia Social... (1998); J.P. Fusi y A. Niño, eds. (1996 y 1997); L.E. González Vales, ed. (1997); M. Guicharnaurd-Tollis, ed. (1999); A. Gutiérrez y M.L. Laviana, coords. (1998), A. Gutiérrez y M.L. Laviana, eds. (1998) eds. (1998); C. Naranjo et al., eds. (1996); C. Naranjo y T. Mallo, eds. (1994); C. Naranjo y C. Serrano, eds. (1999); J. Opatrný, ed. (1995); las actas de los congresos celebrados en Puerto Rico y Canarias y el libro de C. Parcero citados en la nota 6; S. Palazón y C. Saiz Pastor, eds. (1998); J. Paniagua y J.A. Piqueras, eds. (1998); P. Tedde, ed. (en prensa) y J. Uría, ed. (1994), aparte de la de M.R. Rodríguez, coord. (1997), resultado del «Simposio internacional 1898: naciones emergentes y transición imperial» (Univ. de La Habana, 1994), organizado por O. Zanetti y A.M. Fernández. En Cuba tuvieron lugar, además, la «III conferencia internacional en torno al 98-época de transición» (Univ. de La Habana, 1997) y el ciclo «Enseñanzas del 98» (Embajada de España, 1997). En Nueva York, A. Quiroz preparó el evento «A war in perspective, 1898-1998» (New York Public Library, 1998). En España, C. Naranjo, aparte de los referidos, convocó en Madrid el seminario «1898, ¿Ruptura o continuidad?» (CSIC, 1996); J.A. Piqueras, en Castellón, los simposios «De súbditos del rey a ciudadanos de la nación» y «Memoria histórica del 98» (Univ. Jaume I, 1997 y 1998); P. Cagiao, en Santiago de Compostela, el curso de verano «Visiones do 98» (Univ. de Santiago de Compostela, 1998). En Cáceres tuvo lugar el seminario «Las Antillas españolas de siglo a siglo: Puerto Rico» (Univ. de Extremadura-CEXECI, 1996); en Valencia, «Adiós al Imperio. La crisis del 98» (UIMP, 1997), y en Vigo, «El significado del 98 en la historia cubana. Su transcendencia en las relaciones Galicia-Cuba» (Univ. de Vigo, 1998). Otras instituciones como la Univ. de Oviedo o la Univ. Hispanoamericana Santa María de La Rábida, también han habilitado diversos espacios de discusión. Finalmente, para finales de 1998 estaban previstos al menos otros seis encuentros en Madrid, El Escorial, Barcelona, Valencia, Salamanca y Nueva York.

8 Somos conscientes de que a pesar del esfuerzo realizado para evitarlo, algunas personas, trabajos o instituciones no estarán incluidos o no se sentirán adecuadamente representados en este estudio. Rogamos disculpas por ello.
} 
desde finales del 1996, junto con las principales obras clásicas y algunos otros trabajos recientes, aunque sin el mismo ánimo de exhaustividad.

\section{ESTADO DE LA CUESTIÓN ANTES DE FINALES DE 1996. APORTACIONES MÁS RECIENTES}

Antes de mediados de los años ochenta, el debate historiográfico en torno a la coyuntura finisecular en la América española se había caracterizado por un diálogo escaso entre las partes con historias implicadas debido a problemas como el status puertorriqueño dentro de los EE.UU., las difíciles relaciones norteamericanas con Cuba, los cambios interpretativos comunes en las investigaciones cubanas por razones políticoideológicas, como señala C. Almodóvar (1989: 173-191 y 1993: 62-71), o el citado aislamiento intelectual español. Varios de esos inconvenientes persisten, pero -como dijimos- el efecto de las celebraciones en este caso ha sido positivo $\mathrm{y}$, al menos desde que se conmemoró el centenario de la abolición, las cosas han variado. A continuación revisamos lo que sabemos sobre el tema y cuáles han sido los avances más relevantes en la última década. Para no hacer tediosa la lectura, cuando sea posible citaremos otros trabajos en los que el lector interesado, y sólo él, pueda encontrar las referencias bibliográficas precisas 9

\section{Abolición, inmigración, conflicto racial y una historia social escasa.}

Empezando por la abolición de la esclavitud, los estudios acerca del tema, en especial en Cuba, habían insistido sobre todo en sus causas y consecuencias políticoinstitucionales, además de laborales, hasta que los trabajos de R. Cepero (1947), continuados luego por M. Moreno (1978 y 1983) modificaron la perspectiva de investigación. Ambos vincularon el problema con la evolución de la industria azucarera, sosteniendo que el sistema esclavista entró en crisis por su incompatibilidad con la modernización de los ingenios durante la Segunda Revolución Industrial. Nuevas obras escritas en las décadas de 1980 y 1990 cuestionaron dicha tesis. Por ejemplo, R.J. Scott (1985) mostró que también había que ver las cosas desde el otro lado e indagó en las luchas de los negros por su liberación, óptica retomada recientemente por G. García Rodríguez (1996), que examina desde el punto de vista de los siervos, sus reivindicaciones y las relaciones que se establecieron en el seno de la plantación, aunque sus conclusiones son quizás algo exageradas por el tipo de fuentes que usa (demandas judiciales reclamando algún privilegio o mayor grado de libertad fundadas en la fuerza y tradición de esas relaciones). L.W. Bergad (1990), por otra parte, intentó probar el trabajo de éstos no sólo no fue incompatible con la mecanización de las fábricas de dulce, sino que además resultó más rentable que el de los obreros asalariados. El mismo autor, L.W. Bergad et al. (1995), nos ha proporcionado también recientemente, y tras una ingente labor de búsqueda y selección en los archivos y de procesamiento del material conseguido, una nueva reconstrucción del precio de los esclavos, cuyo pro-

9 Como señalamos anteriormente, la relación de obras citadas a continuación no es exhaustiva; sólo pretende ofrecer una muestra de las investigaciones realizadas, por lo que generalmente mencionaremos los principales estudios de referencia, las compilaciones de varios trabajos y los análisis historiográficos donde el lector interesado pueda encontrar más información.

R. I., $1999, \mathrm{n}^{\circ} 215$ 
blema, no obstante, es que no incluye en la muestra utilizada Matanzas, la región azucarera más importante de Cuba en el siglo XIX ${ }^{10}$.

Como la del ciprés, la sombra de la esclavitud es alargada. Partiendo de ella es posible abarcarlo casi todo en el Caribe finisecular. Así, se puede encontrar una perspectiva más humana del problema o análisis sobre sus implicaciones culturales y antropológicas ${ }^{1}$. No por casualidad se habla en las Antillas de una sociedad esclavista y de una sociedad postesclavista, aunque de esta última sabemos poco. Contamos con buenos estudios parciales, algunos recientes, acerca del movimiento obrero, del bandolerismo, la prostitución, la criminalidad o la masonería, y en relación con ciertos grupos como la elite socio-económica hispano-cubana o los chinos y yucatecos, y con varias obras generales que se hacen eco de esas carencias, pero no las resuelven ${ }^{12}$.

En relación también con la sociedad postesclavista en un sentido amplio, muchas obras han analizado en los últimos años la inmigración que fluyó hacia Ultramar, sobre todo de España a Cuba, aunque no solamente. Aparte de compilaciones y obras de carácter general, como las de F. Iglesias (1988a), C. Alonso (1993), C. Naranjo, coord. (1990), J. Maluquer (1992) o C. Yáñez (1994a), y de los trabajos que han reconstruido

10 Ver el estudio de M.C. Barcia (1994) para lo publicado acerca de la esclavitud y la abolición, aunque sólo en América, y el citado libro de L.W. Bergad et al. (1995), que incluye un buen estado de la cuestión. Por la cantidad de artículos que reúnen y/o su actualidad ver, además, las compilaciones de M. Moreno et al., eds. (1985); J. Le Riverend, ed. (1986); A. Vieira, coord. (1996) [especialmente de ésta, el trabajo de F.W. Knight (1996) sobre la relación azúcar-esclavitud en Cuba]; la tesis doctoral de Ch. Schmidt-Nowara (1995) y las obras de M.C. Barcia y E. Torres-Cuevas (1994); G. García Rodríguez y O. Gárciga (1994) y E. Torres-Cuevas y E. Reyes (1986), esta última, como la citada de G. García Rodríguez (1996), muy valiosa por su colección documental. Finalmente, ver también el libro de M.C. Barcia (1987), que frente al anterior y al de R.J. Scott (1985) ofrece la visión de los amos frente a la abolición, y los trabajos de J. Pérez de la Riva (1970), pionero en el estudio de la contradicción trabajo libre-esclavo; de M. Moreno et al. (1983), donde se ensaya otra reconstrucción del precio de los siervos, y de F. Iglesias (1986), que reexamina la relación azúcar-esclavitud-tecnología. Para Puerto Rico, aparte de la tesis de Ch. Schmidt-Nowara, ver el libro de F.A. Scarano (1984).

11 Acerca de estos temas, ver el trabajo de F. Solano y A. Gimerá, coords. (1990); los de J. Pérez de la Riva (1985 y 1987), estudios clásicos también sobre los aspectos económicos del problema, y el de F. Ortiz (1916 y 1987b).

12 Para la historiografía existente, ver los trabajos de O. Zanetti (1985 y 1994) y nuestros artículos, C. Naranjo (1995) y A. Santamaría y C. Naranjo (1999), especialmente este último, donde profundizamos con más detalle en lo que se ha escrito recientemente sobre la historia social cubana finisecular. Acerca de la sociedad postabolicionista, ver el estudio R.J. Scott (1987); sobre el movimiento obrero, las obras clásicas de J. Rivero Muñiz (1961 y 1962); S. Aguirre (1965) y J. Dumoulín (1965 y 1974), y las más actuales de O. Cabrera (1985 y 1993); IHC (1987); J. Stubbs (1989) y J. Casanovas (1995b y c y 1996); respecto al bandolerismo, las de M. Poumier (1986); L.A. Pérez (1989); R. Schwartd (1989); M. de Paz et al. (1993-94) y M. de Paz (1994), y para la prostitución, la criminalidad y la masonería, las de A.J. Gullón (1996), F. Ortiz (1916 y 1987b), J. Ibarra (1985a) y A. Miranda (1931). En lo referente al análisis de determinados grupos, ya hemos hablado de los negros y más adelante examinaremos otros, como los inmigrantes. Ejemplos de esos análisis son los trabajos de A. García Álvarez (1990); A. Bahamonde y J.G. Cayuela (1992) y A. Calavera (1996), dedicados a la elite económica hispano-insular, o los de J. Jiménez (1963 y 1983); J. Pérez de la Riva (1985) A. García Álvarez (1993b) o P. Estrade (1994) acerca de los chinos y yucatecos, llevados a Cuba para resolver los problemas de falta de mano de obra que ocasionó la prohibición de la trata. Respecto a la sociedad cubana finisecular en general, ver los textos de S. Aguirre (1968); F. López Segrera (1980 y 1989a y b); F. Iglesias (1982); J. Ibarra (1992 y 1995a); IHC (1994), M. Moreno (1995) y la tesina de L.M. García Mora (1994a), que incluye un buen estado de la cuestión sobre el tema. La sociedad puertorriqueña de la época está mejor estudiada que la cubana. Aparte de investigaciones clásicas como las de J.H. Steward et al. (1974) y F.A. Scarano et al. (1981), dispone de análisis recientes como los de A.G. Quintero (1988) y A. Ramos (1988). 
las cifras de ese flujo, como los de B. Sánchez Alonso (1990 y 1995) y C. Naranjo (1993) y los dos últimos citados antes, varios estudios han indagado en aspectos vinculados con la historia de las mentalidades [C. Naranjo (1987 y 1988)], en el examen de casos concretos [A. García Álvarez (1994), D. González (1994) o M.A. Marqués (1996a)], o en los efectos económico-sociales del fenómeno migratorio, como las remesas retornadas por los que se fueron [J.R. García López (1992 y 1994)], la reubicación profesional de los españoles en Cuba [C. Naranjo (1994)], la formación de redes familiares y de paisanaje [M. Llordén (1992) y J. Casanovas (1995a)] y su influencia en el mercado de trabajo y en el movimiento obrero [A.F. Losada (1995) y O. Cabrera (1993)], o las diferencias de renta entre la población local y la que llegó de fuera, que J. Maluquer (1994: 148) encuentra bastante elevadas a favor de la segunda, lo que pudo ser motivo de conflictos entre ambas. Éstos son, por otro lado, los temas menos conocidos y que se deben investigar más. Diversas obras, por otro lado, coincidiendo con la configuración del Estado Autonómico español, han examinado la relación específica de sus regiones con Cuba y Puerto Rico. Finalmente, mención aparte por su contenido merece el análisis de la emigración cubana a los EE.UU. de R. Álvarez (1986) ${ }^{13}$.

La demografía histórica también se ha enriquecido recientemente con estudios de carácter general que completan las obras clásicas, como por ejemplo el de J.L. Luzón (1989), que examina la relación economía-población-territorio, y con aportaciones más cualitativas que - según E. Hernández Sandoica (1997a: 154) - predominan actualmente. Lo cierto es que los citados esfuerzos de cuantificación no se agotan en sus resultados, al menos no deben hacerlo, sino que tienen como fin sentar las bases para discutir con mayor precisión sobre aspectos más genéricos y, por ende, más integradores, multidisciplinares y atractivos para el lector no especialista. En ese sentido, el debate abierto más interesante gira en torno a los problemas raciales y de diferenciación social; temas relacionados, por supuesto, con la definición socio-política de los Estados y con la economía, pues en definitiva, fue el crecimiento de ésta la razón que convirtió a Cuba en un país receptor de esclavos y, luego, de población foránea en masa. La política migratoria, el control de la inmigración, que por los motivos citados era en parte de carácter golondrino e indeseable desde muchos puntos de vista, pero idónea para realizar faenas agrícolas poco especializadas en época de cosecha, así como la discriminación de las minorías, sobre todo de color, ha sido objeto de infinidad de análisis y fuertes controversias, por ejemplo, entre A. Helg (1995) y A. de la Fuente $\left(1995\right.$ y 1996) ${ }^{14}$.

13 Para un examen de lo escrito sobre inmigración, pues las obras citadas son sólo una muestra, ver E. Hernández Sandoica (1996 y 1997a). Por su contenido y por situar el debate en términos más generales, que es como se ha producido (la emigración española en general), ver también la compilaciones de N. Sánchez-Albornoz, comp. (1998) e Historia general... (1992). Ejemplos de la relación entre determinadas regiones españolas y Cuba o Puerto Rico, son los estudios de J. Maluquer (1988), C. Yáñez (1994b) y B. Sonesson (1995) acerca de los catalanes; M. de Paz y M. Hernández (1992), A. Macías (1992) y Migraciones canarias.. (1995) de los canarios; R. Anes (1993), P. Gómez (1994) y J. Uría, ed. (1994) de los asturianos; E. Fernández de Pinedo (1993) de los vascos; J.R. Campos (1993-94) de los gallegos (casi todos ellos dedicados a Cuba), y A. Cubano (1993) de los mallorquines que fueron a Puerto Rico. Finalmente, ver el trabajo clásico de B. Morejón (1981) acerca de las migraciones cubanas y las obras de J.A. Portuondo (1937); L. Álvarez (1994) y C. Naranjo y A. García González (1996b) respecto a otros contingentes de inmigrantes, como los franceses, y a un proyecto de colonización alemana.

14 La obra clásica de demografía histórica cubana es La población... (1976); otros estudios recientes son la compilación La demografía... (1992) y la tesis de A.F. Losada (1994). Para la política migratoria posterior a 1902, ver D. González Suárez (1988); sobre la inmigración indeseable de coolies chinos e indios yucatecos cuando aún estaba vigente el régimen esclavista, y de antillanos negros tras

\section{R. I., 1999, n. $^{\circ} 215$}


La controversia sobre la discriminación social por razones de color, sexo o procedencia enfrenta dos posturas tan irreconciliables como, paradójicamente, complementarias, pues en definitiva se refieren a cuestiones distintas, una a la estructura del sistema social; la otra, a los cambios en su interior, destinados a preservarlo, pero que a la postre pueden llegar a alterarlo. Así, por ejemplo, el hecho de que con el tiempo se evidencien mejoras en la situación de determinados grupos marginados, como señala A. de la Fuente (1996), no excluye, sino más bien prueba su marginación dentro de dicho sistema, que defiende A. Helg (1995), lo que, a su vez, explica contradicciones como la convivencia de esas mejoras con demostraciones de violencia política. De estas reflexiones se derivan infinidad de posibilidades de investigación, algunas de las cuales han sido exploradas. Verbigracia, una tesis extendida acerca de la finalización del dominio español en las Antillas no se pregunta por qué acabó en 1898, sino por qué no lo hizo antes, y una respuesta probable es que la existencia de la esclavitud hasta mediados de los años ochenta desalentó la causa independentista en las elites insulares por el temor a que la emancipación provocase cambios revolucionarios en el status quo racial. Obviamente, aparte de la población de color, también preocupaban en ese sentido sectores más integrados, como las clases medias o el naciente movimiento obrero. Otra perspectiva de investigación se ha interesado más por la forma en que se justificó la discriminación y por sus resultados en términos de control socio-poblacional, en especial de la inmigración. Al ser esa justificación principalmente científica o pseudocientífica, en los trabajos sobre el tema han colaborado profesionales de distintas disciplinas, como la biología o la medicina, que también han experimentado avances importantes en sus estudios históricos recientemente, algunos de los cuales han conducido hasta la referida colaboración ${ }^{15}$.

\section{Construcción y definición de la identidad nacional en el contexto internacional de fin de siglo.}

La preocupación por preservar el status frente a los cambios políticos que supuso el fin del dominio español es parte consustancial del tema que ha articulado el debate en torno al 98: la construcción nacional en territorios que hasta entonces fueron colonias y cuya emancipación no desembocó en independencia plena. Por otra parte, así es como ha sido abordado el problema, desde una perspectiva amplia y multidisciplinar,

la abolición, J. Jiménez (1963); J. Pérez de la Riva (1979 y 1985); J. Rodríguez Piña (1990); A. García Álvarez (1993b); P. Estrade (1994) y la compilación de M. Moreno et al. (1985).

is Sobre la polémica en torno a los aspectos raciales y de discriminación social y su relación con la inmigración, ver E. Hemández Sandoica (1996 y 1997a), R.J. Scott (1995 y 1996) y C. Naranjo (1996 y b); acerca de la vinculación esclavitud-mantenimiento del Estado colonial, C. Saiz Pastor (1990 y 1994), y los trabajos de A. Ferrer (1995a y b), que explican la existencia de aquélla en el contexto de la primera guerra de independencia cubana (1868-1878) como el principal límite de la nacionalidad insular. Para la política seguida respecto al movimiento obrero y su participación en las luchas de liberación, J. Casanovas (1996) y C. Planos (1995). En cuanto a los avances en historia de la ciencia, los artículos de M.A. Puig-Samper (1995) y R. García Blanco (1996) ofrecen buenas visiones de conjunto y el monográfico Ciencia en Cuba (1991) permite profundizar en varios temas. Finalmente, el estudio pionero sobre racismo en Cuba en el siglo XIX es el de V. Stolke (1992), y los análisis clásicos de la Guerra de Razas de 1912, los de R. Conté y J.M. Capmany (1912) y R. Fermoselle (1998), reeditado recientemente. Acerca de la justificación científica del racismo y de la referida discriminación social en general, uno de nosotros es coautor de algunas de las obras más recientes. Ver C. Naranjo y A. García González (1996a y b); C. Naranjo (1996a y b), y A. García González (1994, 1995 y 1996). Para estos mismos aspectos en el caso puertorriqueño, ver J. Hinsbruner (1996). 
en algunas obras colectivas como la citada de C. Naranjo et al., eds. (1996). La discusión se ha desarrollado, además, en el ámbito de una renovación de las interpretaciones globales sobre el desenvolvimiento de las sociedades antillanas coloniales y postcoloniales, de la que son muestras las obras Historia de Cuba (1989-), J. Ibarra (1992 y 1995a), L. Bethell (1993), IHC (1994-) o M. Moreno (1995) para Cuba, y F. Picó (1988), B.G. Silvestrini y M.D. Luque (1992) o F.A. Scarano (1993) para Puerto Rico. Más que novedades temáticamente hablando, todas ellas coinciden en tratar los problemas dentro del contexto internacional, a largo plazo y en términos comparativos, aunque con diferencias destacables. Así, se puede decir que las de J. Ibarra son las más continuistas, y que la de M. Moreno es la que alberga mayores pretensiones de ruptura con los estudios precedentes, no obstante luego no se materializan en el resultado en la misma media en que se nos presentan. Las otras son más compensadas ${ }^{16}$.

El contexto internacional del 98 es referencia ineludible para entender la finalización del dominio hispano, la creación de nuevos espacios políticos en las ex-colonias y el reparto de áreas de influencia entre las potencias mundiales. Precisamente ésa fue en su momento la principal aportación española a la historiografía sobre el tema, con obras como las de J. Pabón (1963), R. Mesa (1967), J. Salom (1967 y 1988), o J.M. Jover (1979), que completaron las tesis clásicas de J.A. Hobson (1902) o V.I. Lenin (1939), continuadas luego por autores como R. de la Torre (1988), L. Álvarez (1988 y 1996), C. Robles (1996) o F. García Sanz (1996), incluso por norteamericanos como A. Pagden (1990). A. García Álvarez (1995a) es quien ha precisado mejor la relación entre todos esos factores para el caso de Cuba. Dice que su tardía independencia la libró de los problemas de inmadurez republicana que sufrieron otros países latinoamericanos. Frente a ellos, afrontó su guerra de liberación con un proyecto de nación, pero la coyuntura en que se dirimió aquélla impidió materializarlo, frustrado por los intereses expansionistas de los EE.UU. que, coincidiendo con los de parte de la burguesía local, determinaron el futuro de nuevo Estado ${ }^{17}$.

Dentro del contexto descrito anteriormente, el problema de la construcción de la identidad nacional ha sido abordado desde dos perspectivas complementarias, intelectual y político-institucional. Dentro de la primera, además, encontramos estudios generales y análisis de aspectos concretos, en particular, de determinadas obras. De especial relevancia por su significado son los trabajos de J. Ibarra (1980), P. Estrade (1987 y 1995b), N. Martínez Díaz (1986), M.L. Laviana (1988), M.L. Laviana, ed. (1988), O. Ette y T. Heydenreinch, eds. (1994), R. de Armas (1994), F. López Civeira (1995) o A. Elorza (1996), dedicados a J. Martí, cuya muerte se conmemoró en 1995; los de J. Ferres (1990), A. López Cantos (1991), M. Maldonado-Denís (1992), A. Ruano (1993), M.D. González-Ripoll (1996) o P. Estrade (1993 y 1996) sobre los puertorriqueños E.M. de Hostos y R.E. Betances, considerados, junto a J. Martí, padres de la patria y del Antillanismo (proyecto de Confederación Antillana formulado en la década de 1890); los de M.C. Simón (1986), F. Laguna (1991), U. Vicente (1992), L.M. García Mora (1993a), E. Hernández Sandoica (1994b) o A. Serrano de Haro (1996) acerca del español R.M. de Labra, defensor de la abolición, el autonomismo y la reforma colonial, entre otras cosas; incluso el más genérico de J. Ibarra (1972) que indaga en la ideología mambisa, y los de L.M. García Mora (1996a) y T. Mallo (1996),

16 Entre las obras generales clásicas de historia de Cuba, que son las más renovadas ver, sobre todo, las de R. Guerra (1925) y R. Guerra, comp. (1952); H. Thomas (1973); J. Le Riverend (1973); L. Marrero (1973-1992); J. Ibarra (1985b) y O. Pino (1984), y entre las de historia de Puerto Rico, por ejemplo, la de M. Maldonado-Denís (1980).

17 A. García Álvarez (1995a: 4-10). Ver también las obras clásicas sobre el tema de J.L. Franco (1967-69) y R. Guerra (1974) y una reciente de P. Tornero (1996).

\section{R. I., $1999, \mathrm{n}^{\circ} 215$}


quienes analizan instituciones como el Ateneo de Madrid, uno de los foros en que se debatió la cuestión colonial española. Respecto a los estudios generales, lo más interesante quizás es una controversia implícita - pues los autores eluden la polémicaentre los que creen que el conocimiento del tema ha avanzado gracias a las discusiones teórico-metodológicas, y los que piensan, como apuntaba C. Almodóvar (1989: 173191), que precisamente tales discusiones han impedido hasta ahora ir más allá del planteamiento de interrogantes. Ejemplos de ambas posturas son los trabajos de J. Opatrný (1994), quien sostiene que la dialéctica criollo-europeo, sesgada a favor de lo segundo, definió la idiosincrasia de los nacionalismos antillanos, y de E. Torres Cuevas (1993), quien dice que el examen del problema debe abordarse mediante la interacción de tres conceptos clave: patria, pueblo y revolución, que J. Martí sintetizó y el marxismo permitió instrumentalizar $\left[\right.$ sic ${ }^{18}$.

C. Almodóvar (1995) muestra que proyectos concretos como el de J. Martí no fueron únicos e indiscutibles en su momento, impresión de la que es culpable en gran parte la historiografía. Por ejemplo, E. Trujillo, J.I. Rodríguez o E. Collazo mantuvieron posiciones distintas, incluso enfrentadas con las de aquél. No obstante, polémicas aparte sobre su delimitación específica en uno u otro autor, hay un acuerdo amplio acerca de que los fundamentos intelectuales de la nacionalidad están representados en las obras de los referidos J. Martí, E.M. de Hostos o R.E. Betances y se definen a través de elementos contrapuestos, a veces complementarios, a veces antagónicos, algunos ya citados y que hunden sus raíces en un pasado más o menos remoto (criollo versus europeo, negro versus blanco); otros más novedosos o cuya importancia aumentó en la coyuntura finisecular (natural versus inmigrado, hispano versus anglosajón). Todo ello caracterizó a sociedades que habían alcanzado cierto grado de identidad nacional, mayor sin duda en el caso cubano, aunque aún estaban en proceso de formación poblacional y cultural. Sobre algunos de esos problemas ya hemos analizado lo que sabemos. Por haberlos dejado para más tarde, los otros no son menos relevantes, pero tal vez si más candentes debido al carácter internacional que está teniendo el debate en torno al 98.

\section{Españoles, cubanos y puertorriqueños. Estado colonial y relaciones post ' 98 .}

Entender la evolución de las relaciones cubano-españolas después del 98 requiere hablar antes del Estado colonial. Las citadas obras de E. Hernández Sandoica (1982 y 1994a) - iniciadora e impulsora de esos estudios - , de C. Saiz Pastor (1990 y 1994) y A. Bahamonde y J.G. Cayuela (1992), y las de I. Roldán (1991, 1994 y 1996), J.A. Piqueras (1992 y 1996), J.G. Cayuela (1993, 1994 y 1996) o L.M. García Mora (1993b, 1994a y b y 1996b) insisten en lo peculiar de sus fundamentos. J.G. Cayuela opina que, por su debilidad, el mercado peninsular no absorbió la producción insular, así que su nexo con la metrópoli no lo proporcionó éste, sino la consolidación de una elite económica con poder a ambos lados del Atlántico. Los cambios en el comercio y en las relaciones internacionales a finales del siglo XIX, el fracaso de las reformas que

18 Para más detalles sobre esa controversia, ver uno de nuestros estudios bibliográficos, A. Santamaría (1994b: 224-5) y, además de los citados, los trabajos de J. Opatrný (1986) y G.E. Poyo (1989). Menos polémicos son los estudios de J. Ibarra (1981) y A. García Álvarez (1991), que analizan la relación nación-sociedad-cultura; los de T. Muñoz (1996) y M. Fernández Sosa (1996), que examinan los fundamentos filosóficos e ideológicos de la construcción de la nacionalidad, así como los de F.W. Knigth (1978) y D. Matto, coord. (1994), referidos a todo el Caribe, no sólo a Cuba. Las tesis de E. TorresCuevas tienen antecedentes en las obras de F. López Segrera (1980 y 1989a y b) y M. Moreno (1983). 
implementó dicho Estado para hacerles frente - -según I. Roldán y L.M. García Mo ra- y, en opinión de este último, su incapacidad para mediar entre los distintos intereses implicados en los asuntos de Ultramar, debido - dice E. Hernández Sandoica- a su falta de autonomía frente al poder económico, explican políticamente la independencia. Todos esos estudios destacan, además de por su contenido, por su excelente factura teórico-metodológica, incorporando al debate instrumentos recientes de análisis historiográfico a nivel mundial, como el concepto de Estado-mediador o la teoría de los grupos de presión. Con una proyección más socio-económica que la de los anteriores, destacan en la aplicación de esa teoría los trabajos de M.C. Barcia (1993) y J.A. Piqueras $(1996)^{19}$.

El colonialismo decimonónico español fue tan peculiar en el caso puertorriqueño como en el cubano, pues, paradójicamente, en el primero las formas de explotación metropolitana respondieron a pautas más convencionales (el café era su principal artículo exportable y su mercado estaba en Cuba y España), pero el control metropolitano fue más débil. La razón estriba, seguramente, en la menor potencialidad de su economía y, por ende, de los intereses económicos implicados. Ahora bien, los estudios sobre el tema insisten igualmente en que el Estado no supo adaptarse a los cambios que conllevó la coyuntura internacional y aunque la revolución independentista tuvo poco éxito, también se desarrolló un sentimiento nacional similar al de la mayor de las Antillas, sustentado en los sectores medios y populares y en la burguesía azucarera ${ }^{20}$.

Sea como fuere, la historiografía ha destacado que en Puerto Rico, y aún más en Cuba, las relaciones entre españoles e insulares se restablecieron tras el 98 , predominando los elementos de continuidad sobre los de ruptura. Como razones se han señalado el carácter anticolonial, pero no antiespañol con que J. Martí concibió la independencia; la inmigración peninsular, que siguió con más fuerza en el siglo XX; el hecho de que la guerra no acabase con la rendición de un bando frente al otro, sino ante un tercero, los EE.UU., cuya intervención provocó la identidad de ambos en una especie de victimismo (derrota metropolitana, pero también de los proyectos independentistas isleños), además de otro factor, de más raigambre, e igualmente vinculado con la identidad y reforzado por dicha intervención: el sentido de lo hispano por oposición a lo anglosajón ${ }^{21}$. Como en otros casos, la investigación ha indagado sobre la dimensión práctica e intelectual de esas categorías. Así, autores como C. García del Pino, (1993) aunque refiriéndose a un momento anterior, han señalado la conexión entre los levantamientos cubano, puertorriqueño y español (Revolución Gloriosa) en 1868 y, en un sentido más amplio, el citado estudio de J.A. Piqueras (1996), han intentado dilucidar hasta qué punto se puede decir que intereses coincidentes en la metrópoli y las colonias hicieron causa común en determinadas circunstancias tratando de imponerse, pues el hecho de que, por ejemplo, el Estado colonial tomase una decisión y no otra sobre

19 Aparte de las obras citadas, ver los monográficos Estudios de Historia Social (1988) y Raices históricas... (1991 y 1993), nuestros estudios bibliográficos, A. Santamaría (1994b y 1996b), y el de E. Hernández Sandoica (1998b y f).

20 Sobre las formas de explotación colonial en Puerto Rico, ver los trabajos de L.W. Bergad (1983) y J. Maluquer (1974 y 1988). Para la historiografía reciente de carácter general sobre la isla en la coyuntura finisecular, los de A. Cubano (1990 y 1996); F. Picó (1987); T. Martínez-Vergne (1992); P. Barbosa (1996); L. Agrait (1996) y J. Ibarra (1996).

21 Ver el estudio E. Hernández Sandoica (1998b) para la historiografía sobre el continuismo en las relaciones entre españoles, cubanos y puertorriqueños después de 1898, además de los trabajos de A.M. Fernández (1988 y 1996), quien lleva años investigando este asunto, y de J.A. Giusti (1996) para Cuba y Puerto Rico respectivamente.

\section{R. I., $1999, \mathrm{n}^{\circ} 215$}


un asunto y que esa decisión favoreciese a ciertos grupos no prueba en sí mismo la existencia de una acción de presión colectiva consolidada y consciente.

La historia intelectual ha destacado también la conexión entre aquellos grupos que, en Latinoamérica y España, abogaron por modernizar sus sociedades y romper con el pasado más atávico, motivo por el que iniciaron una reflexión en busca del sentido de lo nacional y específico de su cultura. Para ellos, la coyuntura finisecular fue un hito, pues evidenció el atraso y debilidad de sus países, fundamentalmente frente a la expansión de los EE.UU. En opinión de uno de nosotros, esa reflexión tuvo como principales referentes en América las obras de J. Martí (1891) y J.E. Rodó (1900) y fue dentro de ella donde se definieron nuevos significados de sus componentes étnicoculturales, tanto indígenas como hispanos ${ }^{22}$.

\section{Guerra, Revolución e injerencia externa. La construcción de dos Estados de soberanía limitada.}

Recobrando el hilo troncal del discurso, que la complejidad del debate historiográfico obliga a perder en más de una ocasión, debemos recordar lo que dijimos acerca de que el problema de la construcción nacional tenía una dimensión intelectual y otra político-institucional. El análisis de esta última quedó pendiente. Ya anotamos que el fin del dominio colonial en Cuba y Puerto Rico no desembocó en una independencia plena debido en parte a la coyuntura en que se produjo la guerra de liberación. No hay acuerdo acerca de si en 1898, tras tres años de conflicto hispano-cubano, éste estaba a punto de acabar. Estudios recientes sugieren que no está claro que los mambises lo tuviesen ganado cuando intervinieron los EE.UU., lo que tampoco implica que las tropas metropolitanas estuviesen en condiciones de vencer; por tanto, también se sigue discutiendo si tal intervención fue definitiva, sobre sus motivos o sobre la descompensación entre las fuerzas norteamericanas y españolas que lucharon en el Caribe. No insistiremos en esos asuntos pues requieren un grado de conocimiento técnico que no tenemos, pero, además de citar otros trabajos donde se puede encontrar más información, es preciso comentar que el debate al respecto se ha ampliado últimamente, analizando temas colaterales de lo militar, pero de gran importancia socio-política, económica o poblacional, como la presencia de españoles en las filas rebeldes, la función del ejército como vía migratoria o las consecuencias de ciertas acciones de la guerra como las deportaciones ${ }^{23}$.

22 La obra clásica sobre el tema es la de J.L. Abellán (1972). Para más detalles y nuestra opinión, ver el artículo A. Santamaría (1993).

23 Algunos estudios clásicos sobre las dos guerras de independencia cubanas son los de V. Millis (1931), Porter Vilá (1941), F.J. Ponte (1944), H. P. Azcárate (1968), J. Miró (1970), J.L. Franco (1975), P.S. Foner (1978), R. Guerra (1972), E. Buznego et al. (1986) y C. García del Pino (1988). Respecto al conflicto en Puerto Rico, ver los de A. Rivero (1972) y F. Picó (1987), y para lo publicado acerca de ambos temas, los de F. Pérez Guzmán (1985); T.G. Paterson (1997) y D.F. Trask (1997a y b). De especial relevancia por los trabajos que reúnen son las monografías III Jornadas... (1995) y La presencia... (1996). Ver, además, las obras recientes de F. Pérez Guzmán (1996), que ofrece una visión de conjunto de la guerra de 1895-1898; las de M.D. Domingo (1992), J. Abreu (1993), Y. Díaz (1994), R. Zulueta (1995) y M. de Paz (1996b), dedicadas a distintos aspectos de las dos contiendas de liberación, como las expediciones de apoyo a los sublevados, la respuesta española a las rebeliones, las estrategias militares, el ejército norteamericano, y los alzamientos respectivamente, y las de $O$. Céspedes (1995) y M. de Paz (1996a) en relación con personalidades como C.M. de Céspedes y J. Sanguily. Ejemplos de estudios colaterales de lo militar son los de M. y J.J. Moreno (1993) sobre las tropas coloniales como vía migratoria; los de M.D. Domingo (1994 y 1996) y J.A. Blanco y C. Alonso (1996) 
Aparte de un hecho militar, la intervención de los EE.UU. en la guerra hispanocubana fue trascendental para la evolución socio-política y económica de Cuba y Puerto Rico. Tras la rendición española, aquéllos impusieron a la primera un gobiemo de ocupación que sentó las bases de un futuro protectorado, e incorporaron la segunda con un status impreciso, que aún es fuente de problemas, no obstante se delimitó mejor años después. En ambos casos, pues, un tercer país determinó en mayor o menor grado la construcción político-institucional del Estado, hecho que la historiografía ha calificado con nombres como la revolución pospuesta [R. de Armas (1975)], el '98 incesante [M.A. Castro (1997a)] o la búsqueda de la nación concreta [J.A. Giusti (1996)]. El programa revolucionario, más o menos definido en cada caso, tuvo que modificarse en función de esa injerencia externa, aunque - y en ello estamos de acuerdo la mayoría de los autores - con la aquiescencia de parte importante de la oligarquía local. Además, si bien es cierto que en las dos islas hubo tradicionalmente movimientos anexionistas (a los EE.UU.) con fuerza variable dependiendo de la coyuntura, que junto a los incondicionales (de España), autonomistas e independentistas agruparon las distintas posiciones políticas en la colonia, no sólo los primeros apoyaron dicha injerencia, la cual provocó una redefinición de intereses que explica, por ejemplo, la preservación del poder económico de los españoles al que nos referimos anteriormente ${ }^{24}$.

La anexión de Puerto Rico a los EE.UU., matizada y no bien definida, pero anexión al fin y al cabo; el protectorado que impusieron a Cuba; sus relaciones con ambas islas y la construcción político-institucional del Estado neocolonial, han gozado tradicionalmente del interés de la investigación ${ }^{25}$ y —como cabía esperar - cuentan con estudios recientes numerosos y de gran calidad, como los de L.A. Pérez $(1986,1988$ a, 1990 y 1991), J.M. Hernández (1992) o C. Planos (1995) para la segunda, y de F. Picó (1987), A. Cubano (1990) o P. Barbosa (1996) para la primera; sin embargo, no insistiremos ahora más en estos aspectos, pues volveremos sobre ellos más adelante. Entonces abundaremos también en otras contribuciones de diversa índole que han quedado fuera de esta apretada síntesis por razones de espacio, a cambio de insistir en lo más general. Para concluir ese propósito sólo nos queda hablar de la economía.

acerca de la presencia española en las fuerzas insurrectas cubanas; el de C. Serrano (1996), que analiza la guerra gráfica, o los M.C. Barcia (1996a) y R. Núñez (1996a) que examinan el problema de los deportados y de los repatriados.

24 Sobre los intereses de parte de la oligarquía local en el régimen impuesto a Cuba por los EE.UU., ver la obra de J. Ibarra (1984), excesivamente maniquea, y la de C. Planos (1995), más compensada; sobre el agrupamiento de las distintas posiciones políticas en la colonia, los trabajos de $\mathrm{A}$. Calavera (1996), L.M. García Mora (1993a, 1994a y b, 1995 y 1996b), A. Cubano (1996), I. Roldán (1991), A.G. Ramos (1987), I. Hidalgo (1992) y D. Abad (1995) estudian, respectivamente, el independentismo cubano, el autonomismo en Cuba y Puerto Rico, el incondicionalismo cubano, el anexionismo puertorriqueño y el Partido Revolucionario Cubano (las dos últimas). Los autores que han estudiado el tema afirman, por ejemplo, que parte de dichos autonomistas cubanos se mostraron favorables al gobierno de ocupación norteamericano, por convicción o, simplemente, aceptando los hechos consumados.

25 Las obras clásicas sobre el tema para Cuba son las de Ch. E. Chapman (1926); L.H. Jenks (1928); R. Martínez (1929); P.H. Wright (1931); M. Márquez (1941); H. Portell Vilá (1941); R.F. Smith (1960); E. Roig (1961 y 1973); S. Nearing y J. Freeman (1973); J. Le Riverend (1973); P.S. Foner (1973 y 1978); R. de Armas (1975) y J.R. Benajamín (1977). Para Puerto Rico, ver C. Coll y Toste (1985); R. Bothwell, comp. (1979) y M. Maldonado-Denís (1980).

R. I., 1999, n. ${ }^{\circ} 215$ 
Economía. Azúcar, tabaco, café y sectores vinculados. La ausencia de los grandes agregados.

Según E. Hernández Sandoica (1997a: 149), la economía ha sido una de las privilegiadas de la historiografía reciente, al menos en España; pero tal impresión se debe a la abundancia de estudios sobre la inmigración, los negocios peninsulares en las Antillas y el comercio hispano-insular. Por otro lado, es indudable que el tema cuenta con obras excelentes sobre esos y otros aspectos, antiguas y actuales, y también que los mejores profesionales cubanos le han dedicado su esfuerzo en algún momento, labor en la que les acompañan cada vez más españoles y estadounidenses. Algo similar sucede en el caso de Puerto Rico. Además, de lo dicho en páginas precedentes se deduce que los factores económicos son esenciales para entender el 98 , pues por mucho que se quiera matizar, toda relación colonial o neocolonial implica formas de explotación. Nadie discute que su especialización en producir azúcar, cuya venta se concentró progresivamente en el mercado norteamericano desde mediados del siglo XIX, es clave para explicar la guerra de independencia y el protectorado impuesto en Cuba por los EE.UU., que tuvo como contrapartida un tratado comercial que favorecía dicha venta. Tampoco se duda que los beneficios económicos que implicaba la integración en ese último país fue una razón importante para que los puertorriqueños la aceptasen.

Por buenos y abundantes que sean los trabajos para otros temas y a pesar del acuerdo sobre su importancia, el análisis de los factores económicos del 98 es muy deficitario. Citando a la propia E. Hernández Sandoica, cuando analizamos los estudios migratorios dijimos que tras disponer de la necesaria evidencia numérica, el debate ha crecido, transitando hasta latitudes más cualitativas. Con la economía ocurre al revés. La discusión se asienta sobre un enorme vacío al carecer de estimaciones para los grandes agregados (renta, precios, salarios reales, términos de intercambio), en especial para el siglo XIX, incluso de una reconstrucción de la estadística comercial, pues sólo a través de ellas podremos precisar cuán cierto es eso que repetimos tantas veces de que la crisis antecedió a la guerra de independencia de Cuba. Disponer de tal conocimiento seguramente no cambiará lo que ya sabemos grosso modo, pero aportará solidez al debate, le permitirá madurar y abrirá nuevas perspectivas de investigación, como ha sucedido en otros casos ${ }^{26}$.

Antes de mediados de la década de 1980 contábamos con buenas obras descriptivas de carácter general y, además de las citadas sobre la inmigración, la esclavitud, la relación colonial y con los EE.UU. y el movimiento obrero, con excelentes estudios acerca de la industria azucarera esclavista, la manufactura tabacalera, las finanzas y el comercio en el siglo $\mathrm{XX}^{27}$. En los últimos años se ha avanzado más en el conocimiento

26 Contamos con una estimación del PIB para varios años con ciertas deficiencias metodológicas de P. Fraile et al. (1993), con una serie de renta líquida hasta la década de 1870 publicada en IHC (1994) y estadísticas acerca del comercio con España y los EE.UU., sobre todo de exportación, reconstruidas por M. Moreno (1978) para el siglo XIX. Para el XX disponemos también de la estimación del PIB de J. Alienes (1950) y con las series de comercio exterior de O. Zanetti (1975 y 1989) y de precios y salarios de O. Zanetti y A. García Álvarez (1976).

27 Las obras clásicas de carácter genérico son las de O. Pino (1984) y J. Le Riverend (1985). Para el siglo XIX ver también las de H. Friedlaender (1944) y L. Marrero (1973-1992). Sobre la industria azucarera, los estudios generales de L.V. de Abad (1945), R. Guerra (1946 y 1970), N. Deerr (1950), F. Ortiz (1973) y M. Moreno (1983); los dedicados al siglo XIX de R.T. Ely (1963), G. Tortella (1964) [que examina la relación azúcar-guerra], F. Goizueta-Mimo (1974) y M. Moreno (1978), y los referidos al siglo XX de A. García Álvarez et al. (1972), R.B. Hoernel (1976) y O. Zanetti y A. García Álvarez (1976). Acerca del tabaco, ver el trabajo de J. Rivero Muñiz (1964); respecto al crédito, los de 
de todos esos aspectos gracias en parte a tesis doctorales, aunque no solamente, que han mejorado lo que sabemos de las referida industria tabacalera en el largo plazo; de la azucarera, particularmente para las primeras décadas del siglo XX; del comercio y las finanzas en el siglo XIX, y de otros sectores como el ferroviario. Además, de modo incipiente pero sólido, se han empezado a usar metodologías historiográficas bastante novedosas, como la econometría aplicada a la historia económica, y se han realizado interesantes aportaciones en ámbitos de conocimiento explorados desde hace pocas décadas, como la citada historia de los grupos de presión, la historia económica de la empresa o la historia de la tecnología 28 .

En suma, aparte de la falta de estimaciones y de reconstrucciones estadísticas básicas, especialmente macroeconómicas, se puede decir que los estudios sobre la historia económica de Cuba se han concentrado tradicionalmente en el análisis del sector externo y de las actividades relacionadas con él y que, lo mismo que sucedía con la historia social, las últimas décadas del siglo XIX han sido mucho menos investigadas que las anteriores y posteriores. Estas conclusiones, son también aplicables al caso puertorriqueño. De hecho, en los trabajos citados a pie de página se observa una correspondencia temática casi mimética con los referidos al cubano. Del debate historiográfico sobre Puerto Rico, debemos destacar un grado menor de acuerdo reciente en torno a la continuidad o ruptura de las relaciones entre españoles e insulares y, en especial,

H.C. Wallich (1953) y F. Iglesias (1980); sobre la minería, los de A. Calvache (1944) y L.D. Soto (1981) y, en relación con el ferrocarril y la mano de obra, los de L.V. de Abad (1949) y C. Mesa-Lago (1972). Para más detalles ver los artículos acerca de la historiografía y las fuentes para el conocimiento del tema de G. García Rodríguez (1995), F. Iglesias (1995) y A. Santamaría (1998a).

28 Obras recientes de carácter general sobre la economía cubana son las de A. García Álvarez (1996) y A.F. Losada (1996); acerca del sector azucarero, ver las de F. Iglesias (1988b), R. Álvarez (1988), C.J. Ayala (1990, 1994 y 1995), L.W. Bergad (1990), M. Moreno (1991), H. Venegas (1995), A.D. Dye (1991, 1993 y 1994a y b), A. García Álvarez (1994) y A. Santamaría (1995b y 1996a); acerca del tabaco, las de J. Stubbs (1989) y D. González (1992, 1994 y 1996) [el último dedicado al efecto de la guerra en el sector]; para el ferrocarril, los estudios de O. Zanetti y A. García Álvarez (1987), de la Fundación de los Ferrocarriles españoles (1989), de E.L. Moyano (1991 y 1994) y de A. Santamaría (1995a); en relación con el comercio, los de O. Zanetti (1989) y A. García Álvarez (1990); respecto a los bancos y al sistema financiero, los de S. Fernández (1987), E. Collazo (1989 y 1996), I. Roldán (1990 y 1995) y J.R. García López (1996), y sobre la minería, los de J.A. Uribe (1995). A.D. Dye (1991) y uno de nosotros, A. Santamaría (1995b), hemos aplicado técnicas econométricas y analizado la historia de varias empresas azucareras, estudios que ya habían merecido en Cuba la atención de autores como O. Zanetti y A. García Álvarez (1976) y O. Pino (1984), y que últimamente se han enriquecido con aportaciones como las de E. Hernández Sandoica (1989 y 1994a), M. Rodrigo (1996) y las citadas de A. García Álvarez (1994) y D. González (1994), dedicadas especialmente al examen de ciertos empresarios. El referido trabajo de A.D. Dye (1991) es clave también en el análisis de la historia tecnológica y demuestra, frente a tesis tan difundidas como la de A.W. Lewis ed. (1970), que las innovaciones en la industria azucarera cubana no fueron resultado de un flujo de un sólo sentido con origen en Europa y los EE.UU. y final en la isla, sino de un intercambio de doble sentido. Un trabajo dedicado a un tema no mencionado pero esencial para conocer las fuentes disponibles para la investigación de la economía urbana es el de G. García Rodríguez et al. (1987). Finalmente, aparte de las obras citadas en otros momentos sobre la esclavitud, las remesas de los inmigrantes, los negocios de los españoles en Cuba y Puerto Rico o los grupos de presión, por su importancia para entender las economías coloniales, pues ya hemos dicho que no íbamos a ocuparnos de España, ver el libro clásico de J. Nadal y G. Tortella, eds. (1974), y algunas contribuciones recientes de gran calidad, como las de J.M. Serrano (1987) y L. Prados (1988).

\section{R. I., 1999, n. $^{\circ} 215$}


al mantenimiento de la elite económica peninsular tras el 98. Las obras de J.A. Giusti (1996) y T. Martínez-Vergne (1992) son ejemplos de ambas posturas respectivamente ${ }^{29}$.

\section{ULTIMOS RESULADOS Y TENDENCIAS RECIENTES DE LA INVESTIGACIÓN}

Planteado el estado de la cuestión desde una perspectiva amplia, se puede decir sin que el lector menos versado tenga que hacer auto de fe, que los trabajos editados en los últimos meses son continuistas respecto a las tendencias historiográficas precedentes, aunque ciertas polémicas han pasado a segundo plano, han surgido otras, ha mejorado el conocimiento de varios temas y se han abierto unas cuantas líneas nuevas de investigación. En suma, el debate ha crecido y madurado con una rapidez que no hubiese sido posible sin disponer de tantos espacios de discusión.

\section{Generalidades, síntesis, historiografia y fuentes}

Una de las carencias historiográficas que señalaba E. Hernández Sandoica (1998f) era que no se habían emprendido trabajos de síntesis que diesen cuenta de los últimos avances a un público más amplio que el procedente del americanismo. Varios estudios de carácter general han visto la luz recientemente, unos breves, como los de J. Le Riverend (1997) o A. Cubano (1998c); otros de más envergadura, dirigidos a profesionales de cualquier campo de la historia y las ciencias sociales, a alumnos universitarios, como la compilación de J. Casanovas, coord. (1997), o a lectores meramente interesados, como los editados por S. Juliá, dir. (1997-98) o J. Figuero y C. García Santa Cecilia (1998) en El País y El Mundo. Entre ellos hay contribuciones de todo tipo, cubanas, españolas, puertorriqueñas o de otros países, como la de J. Opatrný (1998b) sobre la Guerra Hispano-Norteamericana en la prensa checa; con una perspectiva política, como la de A. Elorza y E. Hernández Sandoica (1998); social y militar, como las del IHC (1996) o G. Ojeda, ed. (1998). Incluso hay quien ha repensado el 98 desde la óptica del presente, sobre todo para Puerto Rico [L. Agrait (1998b y 199899), M.A. Castro (1997a), G.L. García (1998-99) o D. Sommer (1997)], pues los problemas iniciados entonces (su status y la situación de sus inmigrantes en los EE.UU. o el bilingüismo) siguen siendo temas candentes, pero también intentando extraer lecciones para retos como la integración de los mercados caribeños, lo que preocupa a $P$. Pérez Herrero (1996). Hay que decir, finalmente, que alguno de esos estudios generales ha procurado generar polémica. Por ejemplo, Ch. Schmidt-Nowara (1998a) cree

29 Entre los estudios clásicos de carácter general sobre la historia económica de Puerto Rico, ver los de J. Stewart et al. (1974) o R.J. Toro (1982); entre los recientes, los de J. Dietz (1986); A.G. Quintero (1988) o T. Martínez-Vergne (1992); sobre la relación colonial, ver las obras de J. Maluquer (1974) y L.W. Bergad (1983); para el café, esta última y la de F. Picó (1981); para el azúcar, los trabajos clásicos de A. Gayer et. al (1938); S. Mintz (1974a y b); S. Mintz, ed. (1974), o F.A. Scarano (1984), y los más actuales, de F.A. Scarano (1990), A. Ramos (1988), C.J. Ayala (1990 y 1994) o J.A. Giusti (1994 y 1996). Respecto a la esclavitud y las migraciones, los de F.A. Scarano et al. (1981), A. Cubano (1993) o Ch. Schmidt-Nowara (1995), y en relación con otros sectores y la historia empresarial, los de G. Baralt (1993), T. Cochram (1959), A. Tío (1973) el de y uno de nosotros, A. Santamaría (1994a), analizan la banca, los hombres de negocios puertorriqueños y los ferrocarriles (los dos últimos).

R. I., 1999, n..$^{\circ} 215$ 
que el colonialismo español post-Ayacucho fue un proyecto moderno y de gran escala, aunque sus argumentos para probarlo son poco convincentes ${ }^{30}$.

Aún hay mucho que hacer para que el reciente esfuerzo de investigación llegue a los manuales, y aún más para que deje su huella en la cultura, en la opinión y en mentalidad popular, pero las obras citadas anteriormente son un primer paso bastante sólido y además continúan y completan la renovación historiográfica que apuntamos se inició en años precedentes, caracterizada por abordar los problemas desde una perspectiva amplia, menos prejuiciada que la de algunos de sus antecedentes, comparativa y metodológicamente más refinada. A esa labor coadyuvan, asimismo, los análisis historiográficos, que también son esfuerzos de síntesis, aunque con intenciones más profesionales, y un buen número de trabajos destinados a proporcionar instrumentos que faciliten la investigación, como las bibliografías de Y. Castillo et al. (1998), F. Moscoso (1998) e I. Roldán (1998), la reedición de textos de R.M. de Labra y otros y de M. Gómez publicadas por M. Bizcarrondo, ed. (1998) y C. Almodóvar, ed. (1998) y la que prepara A.M. Fernández acerca de J. Martí (ver nota 6), y los $C D$-Rom de la propia A.M. Fernández, ed. (1998) sobre el 98 en la mayor de las Antillas y de A. García Álvarez y L.M. García Mora, eds. (1998), que incluye una bien elegida colección documental (fuentes y estudios de época) para la historia de Cuba hasta $1930^{31}$.

Ingenios por centrales $y$ esclavos por colonos. Blanquear la población y preservar el status

Empezando por la abolición, para seguir el mismo orden del apartado anterior, los últimos trabajos muestran que el debate aún está abierto. Uno de nosotros, A. Santa-

30 Además de los citados, ver los estudios, reflexiones y ensayos generales de distinta índole de D. Abad (1996), E. Acosta (1997), M. Barnet (1997), J. Cantón et al. (1997), R. Cepeda (1997), C.M. de Céspedes (1997), A.M. Fernández (1997c), E. Leal (1997), O. Loyola (1997), R. Rodríguez (1997), L. Toledo (1997a y 1998a), E. Ubieta (1997), O. Zanetti, M.C. Barcia et al. (1997), «Algunas reflexiones...» (1998), J.B. Amores (1998), O. Loyola (1998), M. Moreno (1998), L. Navarro (1998b), O. Pino (1998), F.J. Pizarro (1998), P.P. Rodríguez (1998), C. Vitier (1998) y O. Zanetti (1998d y e), para Cuba; los de S. Álvarez Curbelo (1997), M.A. Castro (1997b y 1998-99), I. Fernández (1997), L. Agrait (1998a), F. Pic6 (1997b y 1998), E. Rodríguez (1998), M. Rodríguez Castro (1998) y V.M. Torres y C. Buitrago (1998) para Puerto Rico; los de D. Casteañeda (1998), A. Díaz Quiñones (1998a y b), F.W. Knight (1998), J.G. Cayuela (1998b), P. Estrade (1998b) y E. Hernández Sandoica (1998e) para ambas islas, y el H. Bianchi (1998) para una valoración más internacional. Otra monografía de divulgación es la de M.D. González-Ripoll y L.M. García Mora (1997) y otras perspectivas desde el presente se encuentran en los artículos de J.L. Abellán (1996) y A. Moncada y J. Olivas (1996), A. Cristóbal (1997), L. Agrait (1997 y 1999), A. Díaz Quiñones (1997-98) y L. Toledo (1998d). Finalmente, para una perspectiva más ponderada del imperio español post-Ayacucho, ver los estudios de J.M. Fradera (1997 y 1999).

31 Para los estudios historiográficos editados en las obras comentadas ver la nota 1. Aparte de las citadas, ver las selecciones documentales de R. Alegría, ed. (en preparación) y "Carta Autonómica..." (1998) sobre Puerto Rico [la primera similar a la editada por A. García Álvarez y L.M. García Mora, eds. (1998) para la mayor de las Antillas], y las de G. Cabrales (1996) y «Documentos-monumentos» (1997) sobre Cuba. Los artículos de L.M. García Mora y C. Naranjo (1997), M.D. Luque (1997b), R.J. Scott (1997b), F. Alía (1998) y A.R. del Valle (1998), por otra parte, examinan las fuentes existentes en archivos de ambas islas, de España y de los EE.UU. para estudiar el 98 . Esos trabajos, aunque en el apartado anterior no pudimos referirlos todos, tienen antecedentes recientes en obras como las de $\mathrm{M}$. Mena y S. Hernández (1994), R. Ramos (1994), A. García Carranza (1995), G. García Rodríguez (1995), F. Iglesias (1995) o G. García Rodríguez et al. (1997), y lo mismo puede decirse de los repertorios bibliográficos; entre ellos ver, por ejemplo, los de M.D. Domingo (1991), C. Naranjo et al. (1996); En tomo al 98:... (1995) y el muy general, aunque sumamente incompleto de J. Stubbs et al., comps. (1996).

R. l., $1999, \mathrm{n}^{\circ} 215$ 
maría y L.M. García Mora (1998b), tras analizar los dos censos azucareros cubanos de 1860 y 1877 , sostenemos que aquélla se explica fundamentalmente por las presiones externas, que coincidieron con un proceso de modernización de los ingenios, sin que por ello se pueda hablar a priori de una relación causa-efecto entre él y la supresión de la esclavitud, mucho menos de la contradicción que decían M. Cepero (1947) o M. Moreno (1978). Ahora bien, obras como la de L.W. Bergad (1990) tampoco prueban satisfactoriamente que aquélla fuese más rentable que el trabajo libre, pues usa datos de salarios en una economía esclavista, poco válidos como contrafactual, de modo que sus cálculos indican dicha mayor rentabilidad, pero no demuestran su hipótesis. En última instancia, además, nuestro trabajo, que es un antecedente de otro más exhaustivo en fase de realización [L.M. García Mora y A. Santamaría (inédito)], apunta algo que la historiografía ha omitido hasta ahora y que es una evidencia de peso a favor de las tesis que defendemos, y es que la industria azucarera decimonónica en la mayor de las Antillas no reemplazó los esclavos con asalariados, al menos no exactamente, sino que inició una profunda transformación tecnológico-organizativa que, al mismo tiempo, centralizó la producción y descentralizó la oferta de caña [ver A.D. Dye (1998) y A. Santamaría (1995b)].

Lo que se deduce de conclusiones como la anterior es que la abolición y la modernización de la industria azucarera cubana deben estudiarse dentro de un contexto amplio en el que interactuaron múltiples factores, los mismos que explican el 98 tal y como aquí lo entendemos. El peculiar proceso de transformación de esa industria, único en el mundo, a pesar de lo que sostiene J.A. Piqueras (1998a: 169), respondió a la necesidad de abaratar costes para mantener su competitividad internacional, optimizando el uso de los recursos disponibles: la abundancia de tierra y de materia prima y la escasez de trabajo. Para resolver dicha escasez se acudió a la inmigración que, además, seleccionada adecuadamente podía blanquear la sociedad para reducir la importancia del elemento negro heredada de la esclavitud. En A. Santamaría y L.M. García Mora (1998a) y en función de todos esos parámetros, analizamos el colonato, institución resultante de la referida descentralización de la oferta de caña, esgrimiendo que la coincidencia de intereses económicos y socio-políticos se mantuvo mientras no obstaculizó la rentabilidad del sector, pues atrajo inmigrantes blancos, dotándolos de tierra, ligó a ella a los cultivadores y impulsó seguir en el negocio a antiguos hacendados venidos a menos y a algunos ex-esclavos; pero también impulsó el crecimiento de la producción cuando acabó la guerra y se dispuso del mercado norteamericano para venderla, lo cual, con el inconveniente añadido de la merma poblacional que significó el conflicto, agravó el problema de la falta de brazos, y obligó a recurrir al inmigrante indeseable (negros antillanos principalmente) que, además, ofrecía más barato su servicio, deprimía los salarios y era menos conflictivo al no estar integrado en organizaciones obreras $^{32}$.

32 Es interesante la forma en que en C. Planos (1995) vincula el problema de la falta de brazos en un momento en que había que aumentar la oferta de dulce ante la perspectiva de la firma de un tratado comercial con los EE.UU., con la actitud más o menos permisiva del gobierno de ocupación norteamericano ante esa inmigración indeseable, según conviniese favorecer a los propietarios azucareros o a los obreros. Sobre la esclavitud hay varias contribuciones recientes aparte de las citadas y de un $C D$-Rom que prepara la Universidad de Harvard; por ejemplo, M.C. Barcia (1998c) sintetiza lo que sabemos del desarrollo de la institución en Cuba; Ch. Schmitd-Nowara (1998b) analiza su relación con las economías de esta última isla y de Puerto Rico y la oposición a su abolición; M. Lucena (1996) estudia el Reglamento de Esclavos y H. Thomas (1998) la trata en general, Por su parte, B. Potthast-Jutkeit (1998), M. Barcia Paz (1998) y L. Fernández-Martínez (1998b) se interesan por el problema desde un ángulo similar al que preocupaba a R.J. Scott (1985) o a G. García Rodríguez (1996). Investigan, 
Por las razones citadas, todos los que hemos estudiado la coyuntura finisecular en Cuba acabamos tropezando con el desconocimiento de la sociedad y aportando alguna contribución necesaria para nuestro trabajo. Así se ha ido completando un panorama que, sin embargo, aún es muy deficitario. Precisamente, el interés de los autores de este artículo coincide en el colonato. Uno llegó desde la economía; la otra desde la inmigración y la política socio-poblacional, aspectos en los que hemos seguido profundizando [C. Naranjo (1996a y b y 1998c); C. Naranjo y A. García González (1998), y A. García González y C. Naranjo (1998)], especialmente en la relación inmigraciónhigiene racial como elemento configurador de una identidad nacional en formación y transformación y que, por tanto, podía determinarse políticamente, elaborando un proyecto justificado científicamente. La relevancia de esos temas, además, parece clara para la historiografía, pues ha atraído a muchos investigadores recientemente. La última obra publicada sobre el asunto, que además es una de las de mayor valor historiográfico, es el libro de A. García González y R. Álvarez (1999). Su título resume con precisión los términos del debate: En busca de la raza perfecta. Eugenesia e higiene en Cuba.

A. Helg (1998), sin proseguir explícitamente su polémica con A. de la Fuente, dice que los negros se sumaron masivamente a la insurrección cubana esperando mejoras con su triunfo que luego se frustraron, lo que ayuda a entender la connivencia entre la burguesía insular y el gobierno de los EE.UU. a la hora de establecer un régimen de protectorado que preservase el status quo de eventuales pretensiones revolucionarias. Autores como M. Zeuske (1997, 1998a y b) se manifiestan en el mismo sentido, y en sus trabajos sobre Puerto Rico, F. Picó (1997a, 1998-99 y 1999) señala que la otra parte implicada vio las cosas de modo similar. Opina que proteger lo puertorriqueño de lo español justificó la intervención norteamericana, pero en la práctica ésta protegió lo español frente a lo negro, considerado inferior, ergo, incapaz de asimilar la cultura y civilización anglosajona. Estudios como los de P. Tornero (1998a y c) y S. Labrador (1997) llevan esa perspectiva hasta sus últimos extremos, entendiendo que la estructura económica y la burguesía esclavista y posteslcavista fueron un obstáculo para el desarrollo de la nacionalidad cubana que -cree S. Labrador siguiendo a P. Deschamps (1979)_-, es negra antes que blanca. Más ponderada, R.J. Scott (1997a), propone un nuevo punto de vista para este aspecto del debate. Se pregunta cómo fue posible la unidad interreacial del movimiento insurgente de la que habla A. Helg (1998) y, sólo doce años después, una guerra de razas, y estima que explicarlo implica revisar la manera en que hemos construido la historia de los problemas raciales en Cuba, insistiendo, precisamente, en ver lo blanco y lo negro como dos extremos, pues quizás, ni la unidad en 1895-1898, ni el sentimiento anti-negro en 1912 fueron tan intensos ${ }^{33}$.

respectivamente, las relaciones familiares de los siervos en el Caribe y su resistencia y sus luchas en la plantación y en las ciudades, particularmente en La Habana. Esa perspectiva más social del tema parece que va cuajando en la historiografía, incluso hay autores que se han interesado por la cimarronería en las literaturas caribeñas o por la relación azúcar-esclavitud en el cine o en la música [ver los artículos de S. Monet-Descombey (1999), L. Pérez (1999) y T. Escribano (1998)]. Finalmente, el colonato ha sido analizado tradicionalmente en Puerto Rico mejor que en Cuba. Ver los trabajos de $\mathrm{S}$. Mintz (1974a y b) y F.A. Scarano (1990). Para la mayor de las Antillas, ver las obras clásicas de R. Guerra (1948 y 1970) y F. Ortiz (1973), y las de C.J. Ayala (1995), A.D. Dye (1994b y 1998) y A. Santamaría (1996a), que lo estudian jurídica y económicamente, y las de I. Balboa (1998c y e) y L. Fernández Prieto (1999 y en prensa), que abordan el asunto en relación con temas como la política agraria o las protestas rurales. De ambas autoras esperamos en el futuro sendas tesis doctorales; además, uno de nosotros, A. Santamaría, junto a L.M. García Mora, pensamos en la actualidad en un proyecto para mejorar lo que sabemos de los colonos.

33 Para la visión estadounidense de Puerto Rico ver también los trabajos de G.L. García (1997b y c); acerca de la relación esclavitud-racismo y de los problema raciales, los de A. Ferrer (1998), T.

\section{R. $1 ., 1999, \mathrm{n}^{\circ} 215$}


La relación entre la ciencia y la formación de la sociedad y de la identidad nacional, donde decíamos coincidían los intereses de varias disciplinas, continúa mereciendo la atención de la investigación. Dice M.A. Puig-Samper (1995: 143) que el camino por el que desde hace tiempo avanzan los estudios, tendencia que sigue actualmente, es el de la historia de la pequeña ciencia, muy próxima la historia social, alejada de los problemas planteados en los países de los que proceden los grandes descubrimientos, por la ausencia de éstos, exceptuando casos como el hallazgo de la causa de la fiebre amarilla por el cubano C.J. Finlay [ver el libro de J. López Sánchez (1987)] o las aportaciones a la neurología de S. Ramón y Cajal en España [ver el artículo de L. Carandell (1997-98d)]. Aparte de las citadas, entre las obras recientes destacan trabajos de carácter general [P.M. Pruna (1997)]; sobre las grandes polémicas [M.A. Puig-Samper (1998-99) y A. García González (1998b y 1999)], acerca de la relación entre ciencia, regeneracionismo, construcción nacional o ideología revolucionaria en Cuba y España [R. Huertas y R. Campos (1998-99), M.T. Cortés (1998-99) y M.A. Puig-Samper y C. Naranjo (1998)], además de los mencionados antes que abordaban el problema de la justificación de ciertas posiciones xenófobas y favorables al control de la inmigración. En estos últimos, finalmente, es donde más se aproximan el estudio de la ciencia y de la sociedad, como lo hacen la antropología física y social, de modo que también es posible hablar aquí de investigaciones dedicadas a personalidades como J.E. Varona [C. Naranjo (1998-99)] o F. Ortiz [R. Quiza (1998), S. Palmié (1998), F. Moulin-Civil (1999) y M.A. Puig-Samper y C. Naranjo (1999)], junto a otras interesadas por científicos más convencionales, como $\mathrm{F}$. de Albear, R. Baldorioty y $\mathrm{E}$. López Giménez [R. García Blanco (1997) y M.T. Cortés (1998-99) y M. y L. López Baralt (1998)]. De los textos referidos, los de M.T. Cortés y de M. y L. López Baralt son, además, los únicos que analizan el caso puertorriqueño. Esperamos que sean los antecedentes de más investigaciones para un tema que ha interesado poco en la isla.

\section{Una historia social en construcción parcial. Fuentes y perspectivas poco ex- plotadas}

Los estudios cuantitativos sobre la inmigración apenas gozan de espacio en las obras comentadas aquí debido a la exhaustiva labor realizada en fechas precedentes, pero tampoco abundan los referidos a aspectos que requerían más investigación, como el envío de remesas, si exceptuamos un artí́culo de P. Pascual (1998a), el examen de casos, o las diferencias de renta entre la población local y la que llegó del exterior. Más interés ha despertado el tema de la formación de redes familiares o de paisanaje y el asociacionismo del inmigrante en general. V. Erice (1996), M. Llordén (1996) y J.C. Cabrera (1997) analizan el tema y C. Xixirey y J.R. Campos (inédito) preparan actualmente un libro, aunque esos trabajos se refieren únicamente a los asturianos, canarios y gallegos y sólo el tercero se centra exclusivamente en el caso cubano. Más concreto, pero dedicado a un asunto similar, es un artículo de C. González Pérez (1996) acerca de una sociedad de instrucción creada por coruñeses en La Habana.

Pedraza (1997-98); M. Röhrig Assunçao y M. Zeuske (1998); R.J. Scott (1998), y el monografico Race, Society... (1998). Por otra parte, ya mencionamos anteriormente la reedición de uno de los trabajos clásicos sobre la Guerra de Razas, el de R. Fermoselle (1998). También hay que citar un nuevo estudio publicado por A. de la Fuente (1997) en el que examina los vínculos racismo-inmigraciónmercado de trabajo. Finalmente, sobre la historia de los negros, ver los artículos de O. Hevia (1997), R.A. Duharte (1998), y la obra clásica de T. Fernández (1990). 
Aparte de los citados anteriormente, las obras comentadas aquí incluyen algunos estudios de carácter genérico sobre la inmigración. R. Grosfoguel (1998) la analiza en relación con la geopolítica, y $\mathrm{R}$. Serra examina la política española al respecto en sus archipiélagos balear y canario. Precisamente el flujo migratorio entre este último y Cuba es el que más cantidad de trabajos ha generado últimamente. Aunque todavía autores como A.P. Sánchez (1996) y M. Hernández (1997 y 1998) siguen abordando el tema en términos generales, lo que más abunda son perspectivas peculiares - como la selección de fotografías editada por M. de Paz y F. Guerra (1998), cosa que también existe para los españoles en general [Un último... (1998)] - o investigaciones concernientes a asuntos poco explorados hasta ahora por la investigación, como la dimensión antropológica del problema. En este sentido, los artículos de C.M. Barreto (1997b), M.C. Mateo (1997) y J.C. Rosario y G. Sierra (1997) se preocupan por las tradiciones rituales vinculadas a los procesos sociales, a la medicina popular y a las festividades; los de G. Galbán (1997b), el propio C.M. Barreto (1997a) o M. de Paz (1997), por cuestiones de identidad y adaptación socio-cultural o por la percepción que los isleños tenían de si mismos en Cuba, y los de J.L. Cruz (1997), J.A. Galbán (1997a y c) y M. López Isla (1997) por aspectos menos abstractos, como la inserción laboral de los recién llegados, particularmente en la agricultura y la industria del tabaco, que fue uno de los principales sectores de ocupación de los canarios en la mayor de las Antillas; o la vida cotidiana de éstos en localidades como Cabaiguán. ${ }^{34}$

De lo anterior se deduce que los estudios sobre la inmigración han experimentando avances muy significativos y se encuentran en una fase de consolidación en la que cobran importancia los aspectos concernientes a su integración en la sociedad del país receptor. Sin embargo, hay que decir también que esto es aplicable únicamente al caso de la española, y especialmente de la procedente de algunas regiones, particularmente de Canarias, que ha seguido generando un abundante flujo de publicaciones cuando se ha reducido la cantidad de estudios sobre otros casos. El estudio de los demás contingentes que llegaron a Cuba, en especial de los antillanos, los más numerosos tras los hispanos, muchos de los cuales, además, lo hicieron sólo con carácter temporal (durante la época de zafra azucarera) apenas ha pasado de meramente cuantitativo y ha recibido muy pocos aportes que completen los estudios clásicos mencionados en el apartado precedente.

En relación también con la inmigración o los movimientos de población, A. Bahamonde (1998a) y A. Bahamonde y J.G. Cayuela (1997) han seguido analizando la elite española en Cuba; M.D. González-Ripoll (1998b) ha examinado la comunidad cubana exiliada en los EE.UU. - cuyo estudio clásico es quizás el de J. Rivero Muñiz (1958)—, específicamente los intentos de los cónsules de España por neutralizar su apoyo a los insurrectos durante la Guerra de 1895-1898, y M.C. Barcia (1997a) el caso de los rebeldes de las colonias deportados a Africa y la solidez y mantenimiento de las relaciones que iniciaron allí. Finalmente, algunos autores se han preocupado por el desarrollo de la población en general [F. González (1998)] y por el efecto devastador que en ella tuvo la Guerra de Independencia [A. Marchena (1998), P. Tornero (1998b)

34 Otros estudios recientes sobre inmigración, además de los mencionados anteriormente que abordan el problema en relación con el blanqueamiento de la sociedad y el racismo, son los de $S$. Palazón (1998), que examina en términos generales el flujo migratorio entre España y Cuba en el siglo XIX; el de uno de nosotros, C. Naranjo y A. García Álvarez (1998), que vincula el tema con la rápida y relativamente cordial reanudación de las relaciones entre españoles y cubanos después de la Guerra de 1895-1898, y la compilación de P. Gómez, coord. (1996), en la que se aborda el caso de los asturianos desde muy distintos ángulos.

R. I., $1999, \mathrm{n}^{\circ} 215$ 
y F. Iglesias (1997)], aunque sin aportar muchas novedades respecto a lo señalado por J. Pérez de la Riva (1975).

Trabajos como los anteriores suponen pequeñas aportaciones parciales y muy desarticuladas para el conocimiento de la sociedad cubana finisecular, pues -como decimos - falta un estudio que la abarque en su conjunto. M.C. Barcia (1996b, 1997b y 1998e) se ha aproximado al tema y lo resuelve de nuevo lamentando las carencias e intentando un acercamiento desde el examen de sus manifestaciones culturales. Más ambicioso es el libro de la anterior y otras autoras, M.C. Barcia et al. (1998) [ver, además, una síntesis del mismo en G. García Rodríguez et al. (1997) y el artículo de ésta última, G. García Rodríguez (1998a)], aunque en él se abordan también sólo algunos aspectos del problema. De momento, por lo tanto, debemos conformarnos con lo que hay y formarnos una idea a través de esas aportaciones parciales, que al menos han mejorado lo que sabemos de lo que L.M. García Mora (1998b) llama la transición de una sociedad de castas a una sociedad de clases, de los inmigrantes, de la población negra, de los colonos y de algunos otros temas, unos cuantos bastante descuidados hasta ahora, como determinados colectivos llegados a la isla, verbigracia, la comunicada hebrea o los chinos, analizados por M. Berjarano (1996) y J. Guanche (1997b), o la mujer.

Las investigaciones sobre la mujer han despertado recientemente mucho interés, particularmente en el caso cubano, aunque también cuentan con algunas aportaciones para el puertorriqueño, como por ejemplo las de A. Cubano (1998b) o N. Agosto (1998), que examinan los problemas de ésta en relación con la cultura política y con el discurso religioso respectivamente. Para el primer caso, los estudios de A. Cairo $\left(1997^{2}\right.$ ), J.C. González (1998), I. Guerrero (1998), B. Pastor (1998) o R. Vinat (1998a y b) abordan el problema desde distintas perspectivas. Particularmente se interesan por la participación de las mujeres en el movimiento independentista, por el papel desempeñado por determinadas figuras, como E. Casanova, o por su acción en la defensa de ciertos intereses, especialmente colectivos, y el efecto que ello tuvo en la toma de conciencia de su situación y posibilidades en el seno de una sociedad machista, lo que se agravaba en muchas ocasiones con otros factores discriminarios, como el color de la piel, asunto que ha interesado a M.C. Barcia (1998f), quien analiza la revista Minerva, uno de los órganos de expresión de las cubanas negras en las últimas décadas del novecientos. Estas investigaciones cuentan también con algunos antecedentes recientes, aunque escasos, por lo cual no los mencionamos anteriormente, como el artículo de $\mathrm{L}$. Fernández-Martínez (1995) acerca de la elite femenina decimonómica, nativa y foránea, en la mayor de las Antillas.

El estudio del movimiento obrero ha seguido despertando el interés de historiadores como G. García Rodríguez (1998b), J. Casanovas (1997 y 1998a, b y c) o C. del Toro (1997 y 1998). Los trabajos de este último examinan su reorganización tras la Guerra de Independencia y la historiografía cubana sobre el tema; los de la primera y el segundo analizan a los trabajadores y a los artesanos urbanos, argumentando que su importancia socio-política aumentó progresivamente tras los cambios que supuso la paz del Zanjón (con la que terminó en 1878 la Guerra de los Diez Años) y la abolición de la esclavitud, y se materializó en la creación de muchas asociaciones, en las que según J. Casanovas- el anarquismo reemplazó al reformismo como principal corriente ideológica. Normalmente esto se había justificado por la fuerte presencia de inmigrantes, sobre todo españoles [ver O. Cabrera (1993 y 1999)], tesis de la que dicho autor disiente, esgrimiendo que eso fue así porque aquél ofreció soluciones adecuadas para sus problemas. Finalmente, J. Casanovas entiende que aunque los cambios políticos de la década de 1890 redujeron la referida importancia política de los obreros, aunque se sumaron al proyecto martiano y fueron determinantes en la transformación de la socie- 
dad. Las investigaciones sobre el colonato y la inmigración selectiva como alternativa también frente a la proletarización laboral, y sobre la preservación del status quo como explicación para la ocupación norteamericana confirman esas tesis.

La complejidad de una sociedad en formación y transformación al mismo tiempo es sin duda la causa por la que nadie se ha atrevido a analizarla globalmente. La guerra, además, agravó las cosas con su efecto movilizador -que A. Helg (1998) y M. Zeuske (1998a y b y en prensa) explicaban para el caso de los negros- y militarizador, aumentando la presencia de soldados cuya vida, por ejemplo, estudian C. Alonso (1996), B. Frieyro (1996), L. Carandell (1997-98c) o Y. Díaz (1998-99). A esos problemas se unieron las consecuencias de determinadas políticas de represión, exilio y reconcentración, que han merecido la atención de M.C. Barcia (1997a), M.C. Barcia y M. Hernández (1996), F. Pérez Guzmán (1997b, 1998a, b y c) o M. López (1998), y del bloqueo norteamericano, cuya secuela en la vida cotidiana habanera también examina M.C. Barcia (1998a). ${ }^{35}$ En relación con esto, las acciones bélicas y el ejército han seguido generando trabajos, pero por desconocimiento técnico, salvo en lo referente a los aspectos anteriores, que transcienden de lo meramente marcial, nos limitamos a enumerarlos ${ }^{36}$.

35 El estudio de la vida cotidiana en 1898 cuenta en Cuba con la obra clásica de M. Poumier (1975). Para Puerto Rico, específicamente sobre lá ciudad de Caguas, disponemos también de un trabajo de I. Acosta (1998).

36 Además de los citados, sobre la guerra en general (tanto sobre la de 1868-1878, como sobre la 1895-1898), ver los trabajos de D. Abad (1996); E. Buznego el al. (1996 a y b y 1997); C. García del Pino (1996); F. Pérez Guzmán (1996 y 1998-99); F. Pérez Guzmán e I. Hidalgo (1996); E. Torres Cuevas et al. (1996); J.A. Plaza (1997a); R. Rojas (1997-98b), F. Marín (1998); L. Navarro (1998c); G. Placer (1997b y 1998a); M. Moreno (1997-98a y b); A.R. Rodríguez (1998a y b) y R.F. Rodríguez (1998). Por otro lado, los estudios de Y. Díaz (1996a); M. Espadas (1997); J. Figuero y C. García Santa Cecilia (1997); R. Núñez (1998) y F. Portela et al. (1998) analizan el ejército español en general, y los H. O'Donell (1997), G. Placer (1997a), E. Hernández Sandoica (1997-98), M. Rodrigo (1997-98) y A.R. Rodríguez (1996 y 1997) la marina, la política naval y el desastre en el mar. Autores como $\mathrm{H}$. Otero (1997), L. Carnadell (1997-98b), H. Thomas (1997-98), G. Placer (1998b) o A. Remesal (1998) se han ocupado de la voladura del Maine; J.A. Plaza (1997b) del conflicto con los EE.UU.; C. Navajas (1996) de los presupuestos de guerra; J.P. Pérez Llorca (1998) de la estrategia del desastre; V. Batista (1997-98) de la altemativa negociar o perder; J. Díaz (1997-98b) de la rendición; R. Núñez (1996b) de los conflictos entre las jurisdicciones civil y castrense, y C. Serrano (1999) e Y. Cordoví (1998) de hechos concretos de la contienda, como la batalla de Caney o la campaña de Reforma. La tendencia reseñada en años precedentes a ampliar el examen de lo marcial a aspectos de mayor alcance historiográfico prosigue en trabajos como los referidos acerca de la reconcentración, el bloqueo norteamericano o la vida del soldado. Aparte de ellos, la moda biográfica en otras ramas de la historia, nunca abandonada en los estudios militares, ha deparado recientemente libros y artículos como los de G. Cardona y J.C. Losada (1997), F. Pérez Guzmán (1998c), J. Díaz (1997-98a), J. Cervera (1998), dedicados a V. Weyler (los dos primeros) y P. Cervera (los dos últimos), o los de R. Aparicio (1996), L. Carandell (1997-98a), Y. Díaz (1998a) y C. Almodóvar, ed. (1998), que indagan en las figuras de A. Maceo (los dos primeros), C. García y M. Gómez. Del mismo carácter que el último trabajo mencionado (una selección documental comentada) es el Epistolario de héroes de G. Cabrales (1996). Otros temas de interés son las medidas españolas frente a las expediciones filibusteras, que preocupa a C. Parcero (1998); el papel y/o valor de ciertas ciudades y/o de sus fortificaciones en el conflicto, investigado por F. Pérez Guzmán (1997a) en el caso de La Habana, y E. Vivoni (1998) y J.M. Zapatero (1998) en el de San Juan de Puerto Rico; los cuerpos de voluntarios formados en apoyo de las fuerzas coloniales en la contienda de 1868-1878, en lo que abunda M.D. Domingo (1997); los españoles residentes en el Río de la Plata que fueron a luchar a Cuba, analizados por I. García (1998); la repatriación de las tropas tras la rendición, que examinan Y. Díaz (1996b y 1998b) y J. Pan-Montojo (1997-98), o los proyectos de establecimiento de colonias militares para prevenir y contrarrestar el movimiento independentista antes de estallar la rebelión de 1895, estudiados por I. Balboa (1998c). Finalmente, B.E. Marfil (1998) e Y.

\author{
R. I., $1999, \mathrm{n}^{\circ} 215$
}


En relación también con lo militar, aunque con connotaciones políticas y sociales, un trabajo de R. Rodríguez (1998) examina la disolución del Ejército Libertador $\mathrm{Cu}$ bano tras el inicio del gobierno de ocupación norteamericano en la isla, asunto al que dio prioridad dicho gobierno para mantener el orden y para lo cual entregó un préstamo con el fin de facilitar el licenciamiento. De hecho, el país no contó con una milicia regular hasta después de la segunda intervención estadounidense en el mismo (19061909). Ésta y su papel socio-político en las primeras décadas del siglo XX, aparte de la que le brinda algún estudio antiguo como el de M. Chang (1975), apenas han merecido la atención de la investigación.

Dentro de lo que cabe conocemos mejor la sociedad urbana que la rural, exceptuando la vinculada a la producción de azúcar y tabaco. I. Balboa (1998d y e) intenta resolver esa carencia analizando las protestas campesinas, contraparte de la lucha obrera en las ciudades, aunque con problemas y métodos distintos. Paradójicamente, además, aunque esto está bien estudiado en otros países, aún en situaciones de escasez de brazos y fuerte inmigración como la cubana, sobre todo en momentos de crisis económica, alteración del orden, guerra, vacío de poder o débil control estatal, al menos en ciertas zonas, proliferó el bandolerismo - que también preocupa a I. Balboa (1998b) - aún entre los inmigrantes, lo que en el Caribe tuvo antecedentes en fenómenos como el de los cimarrones durante la esclavitud, tema que cuenta con la obra clásica de M. Barnet (1966), sobre la que reflexionan M. Zeuske (1998a) a la luz de la documentación disponible para la guerra de 1895-1898, M. Barcia Paz (1998), y S. Monet-Descombey (1999), este último en todo el espacio caribeño y usando como fuente la literatura. Esos trabajos entroncan con una larga tradición de estudios antropológicos en Cuba, iniciada por F. Ortiz (1916, 1975 y 1987a y b) y L. Cabrera (1970 y 1993), cuyas aportaciones más relevantes examinan la cultura y mentalidad de los negros -esclavos y liberados-y las sociedades secreta ñáñiga o abakúa. En las obras comentadas aquí, autores como R. Quiza (1998), M.A. Puig-Samper y C. Naranjo (1999) y F. Moulin-Civil (1999) prosiguen esa tradición indagando en el pensamiento del primero ${ }^{37}$.

Obras como las de L. Cabrera (1992), M. Barnet (1966), S. Monet-Decombey (1999) o P. Hulme (1997), que reflexiona sobre la etnología indígena puertorriqueña, tema que también ha interesado a M. Ballesteros (1996) y a A. Esteban y A. Moreno (1998) - a estos últimos para el caso cubano-, están a medio camino entre la antropología y la literatura, que la historiografía aún ha explotado poco como fuente, a pesar de que hay quien sitúa el origen de la moderna literatura hispanoamericana, valga la redundancia, en R. Darío y J. Martí [ver el libro de L. Sáinz (1989)]. No obs-

Díaz (1998c) investigan también la sanidad militar y ambos preparan sendas tesis doctorales en relación con estos y otros aspectos del ejército.

37 Acerca de la sociedad rural ver, asimismo, los estudios de A. Ferrer (1998) y R.J. Scott (1998), ambos dedicados, además, a la población negra fundamentalmente. Para el estudio de estas última, aparte de las obras de F. Ortiz y O. Cabrera, ver la novela de A. Carpentier (1989), los libros relativamente recientes de M. Poumier (1993) y N. Bolívar (1989), así como que acaban de publicar R. Orozco y N. Bolívar (1998). Este mismo año se organizó también una reunión en Gran Bretaña, con la participaron investigadores noveles, como $\mathrm{K}$. Hasing, cuyos trabajos esperamos más adelante. Finalmente, con un carácter menos antropológico que los anteriores, sendos estudios de O. Hevia (1996) y P.A. Howard (1998) examinan las asociaciones creadas por los cubanos de color en las últimas décadas del siglo XIX, obligados por el Estado (Cabildos de Nación) o libremente, a través de las cuales expresaron sus reivindicaciones. Sobre este asunto, no obstante, volveremos más adelante. 
tante, las obras comentadas aquí reúnen buenos trabajos sobre el tema ${ }^{38}$. Igual se puede decir del cine, la fotografía, la música, el arte o el urbanismo, que por razones de espacio en estas páginas sólo reseñamos ${ }^{39}$, y de otras aportaciones más o menos atrevidas en sus propuestas metodológicas y fuentes, algunas de las cuales son objeto de controversia desde hace tiempo. Entre ellas debemos citar la historia oral, otrora frecuentada por muchos investigadores, pero bastante ajena al debate actual; el análisis de la religiosidad en sí misma y como manifestación simbólico-cultural, que sí ha merecido alguna atención en dichas obras, o la opinión pública y la prensa, que tradicionalmente han despertado mucho interés y mantienen su atractivo. Por ejemplo, aunque se discute en qué grado, nadie duda de su papel determinante en la intervención de los EE.UU. en la guerra de Cuba. Para España, R. Sevilla (1996 y 1998a, b y c) ha mostrado de nuevo en trabajos recientes las limitaciones que tiene la segunda para conocer la primera. Dice que incluso en un momento en que se estaban convirtiendo en vehículo de expresión de la burguesía y había libertad para expresar en ellos diversas ideas, los diarios

38 Sobre el uso, por ejemplo, del teatro bufo para analizar la formación de la cultura y nacionalidad cubana y sus raíces hispanas y norteamericanas, ver el estudio de J. Ibarra (1995b). Acerca de la literatura finisecular en América Latina en general y de la influencia y/o el tratamiento del 98 en ella, los artículos de M. Barchino (1998) y M. Caballero (1998b), y para eso mismo en Cuba, los de L. Álvarez Álvarez (1998), S. Bueno (1997), E. Sosa (1998) y L. Toledo (1998b). Sobre aspectos más concretos, los trabajos de J.B. Sánchez (1998) y A. Benítez (1997) examinan las narraciones de esclavos y la cuestión del negro en el nacionalismo literario de la mayor de las Antillas; los de A. Bansart (1999), A. Vásquez (1999) y J. Durnerin (1999) y J.P. Pauté (1999) la temática azucarera en el Caribe en general, en Puerto Rico y, específicamente (los dos últimos) en las novelas de A. Carpentier; los de A. Oria (1997) y M. Guicharnaud-Tollis (1999b), los problemas emancipación y antiespañolismo en la literatura cubana, y el de M. Caballero (1998c) las repercusiones del 98 en la narrativa actual puertorriqueña. Finalmente, A. Sicard (1999) investiga la relación entre J. Lezama y F. García Lorca, y M. Caballero (1996 y 1998a), W. Binder (1998), S. Álvarez Curbelo (1999), J. Herrero (1998), T. Barrera (1998b), C. de Mora (1998) y J.C. Rovira (1999), analizan obras concretas como El entierro de Cortijo, del boriqueño E. Rodríguez; El arpa y la sombra; los vínculos literatura-política en los también boricuas L. Muñoz Rivera y J. de Diego; la poesía y la prosa de los cubanos J. del Casar y N. Guillén; el libro Espejo de Paciencia de S. Balboa, y la estética de V. Piñera respectivamente.

39 Los trabajos de N. Chanan (1998), J.J. Sánchez (1998) y L. Pérez (1998a y b y 1999) examinan el problema del 98 , el intervencionismo estadounidense, la manipulación de la realidad histórica y de la sociedad y la relación azúcar-esclavitud en el cine; los de M.A. Bretos (1996), M. de Paz y F. Guerra (1998) y Un último... (1998) ofrecen una nueva perspectiva de la imagen de Cuba y de la inmigración canaria y española en general a través de la fotografía; los de Z. Lapique (1997), M.T. Linares (1997) y T. Escribano (1998) abordan temas vinculados con la música y la danza; por ejemplo, en su relación con la nacionalidad o el efecto que sobre ella tuvo la esclavitud -aspectos que cuentan con buenos análisis clásicos, como el de F. Ortiz (1974)-. Por otra parte, las obras de N.G. Menocal (1996), F. Martín (1998), J. Andreo (1999), S. Mègevant (1999) o M.T. Richard (1999) indagan en el arte contemporáneo, en el reflejo del país real e imaginario, de la vida cotidiana o de la identidad nacional en el gravado y la pintura, o en la iconografía azucarera. Todas ellas se refieren a Cuba. El urbanismo es un asunto que tradicionalmente ha merecido la atención de la historiografía en el caso de la Gran Antilla. Ver, por ejemplo, el libro de F. Pérez de La Riva (1973) sobre el hábitat rural, el de E. Álvarez (1989) sobre la urbanización burguesa o el artículo M.D. Arriaga y A. Delgado (1995) respecto a la vivienda pobre en La Habana. Recientemente se han editado muchos estudios y de buena factura, especialmente para esa última ciudad [C. Venegas (1996), C. Otero (1998) y N. Pérez (1998)], la de San Juan de Puerto Rico [J.M. Zapatero (1996) y E. Vivoni (1998)], las de Mayagüez y Santurce [M.R. Cancel (1998b) y J. Damiani (1998)], y para la arquitectura norteamericana, de vanguardia y de algunos centrales azucareros en Cuba [J.A. Gelabert-Navia (1996), E.L. Rodríguez (1996) y F.J. Préstamo (1998)]; incluso contamos con investigaciones de las conexiones urbanísticas en los principales centros de exilio y emigración cubana (Tampa, Key West y Miami) y del trabajo de A. Thayer, escritos por P. Harper (1996) y I. Jaramillo (1999) respectivamente.

R. $I, 1999, \mathrm{n} .^{\circ} 215$ 
sevillanos no fueron transmisores del sentir popular ante el conflicto colonial, más preocupado por la sangría humana que por la humillación nacional, incluso denunciaron su pasividad ${ }^{40}$.

\section{Ruptura y continuidad. Transformaciones políticas y relaciones sociales e in- telectuales}

De lo dicho hasta ahora se deduce que entre los trabajos comentados aquí pocos estudian la sociedad finisecular en Puerto Rico. Los autores se han concentrado en los problemas políticos, aunque, como veremos más adelante, al abordarlos examinan marginalmente aquélla. Buen ejemplo de ello es un artículo de A. Cubano (1998d) que indaga en los vínculos sociedad-identidad nacional en sí mismos y en comparación con el caso de la Gran Antilla. Para terminar con la historia social, pues, sólo queda hacer referencia a las relaciones entre españoles y cubanos y puertorriqueños tras el 98, que han seguido generando muchas obras y nuevas polémicas. Autores como A.M. Fernández (1998c y d), I. Balboa (1998a) y uno de nosotros, C. Naranjo y A. García Álvarez (1998) y A. García Álvarez y C. Naranjo (1998) perseveramos en la idea de que la inmigración y la tradición hispana, reforzada por la intervención estadounidense, permitieron un rápido restablecimiento de dichas relaciones y el retorno de la convivencia. Frente a ello, E. Hernández Sandoica (1998b) señala que insistir en el continuismo ha impedido ver los elementos de ruptura. Empero, a lo que ésta se refiere luego para avalar su tesis es a las transformaciones políticas, y en su libro, A. Elorza y E. Hernández Sandoica (1998: 17), se manifiesta de acuerdo con los anteriores. Ade-

40 La historia oral ha sido aplicada principalmente al estudio del movimiento obrero, la antropología y la inmigración. Ver, por ejemplo, las obras de O. Cabrera (1985), L. Cabrera (1970 y 1993), A. García Álvarez (1993a) y las de uno de nosotros, C. Naranjo (1987 y 1988). Casi todos los análisis antropológicos ya mencionados de la cultura negra [verbigracia, el libro de R. Orozco y N. Bolívar (1998)] exploran el tema de la religiosidad; para una perspectiva más amplia y sobre otros aspectos, ver los artículos de J. Corbea (1996), L. Fernández-Martínez (1998a), O. Portuondo (1998) y J. Ramírez (1998) referidos a Cuba y el de M. Rosario (1998) dedicado a Puerto Rico. También existe una investigación inédita de E. Torres Cuevas (inédito) acerca de la Iglesia Católica en aquella primera isla y sendos estudios de A. Dávila (1997) y M.P. Maza (1997) sobre el Vaticano y la crisis de 1898. Respecto a la opinión pública, además de los trabajos de R. Sevilla, ver los de M.J. Ruiz Acosta (1996 y 1998), A.M. Mota (1998), S. Núñez (1996), M.C. Seoane (1997-98) y L. Núñez (1998), que abordan un asunto similar, aunque los dos primeros se refieren a lugares concretos como Sevilla y Tarragona y los tres últimos a toda España. Ver, asimismo, los artículos recientes, pero anteriores a los que aquí comentamos, de C. Serrano (1996), A.M. Fernández (1996) en relación con la guerra colonial y la visión de los españoles en un diario cubano (el Diario de la Marina), tema que ocupa también a $I$. Balboa (1998a), y los más actuales de J.J. Sánchez Baena (1998), L. Fernández Prieto y R. Funes (1998-99), M. de la O y A. López (1997), J. Companys (1998), R. Figueroa (1998a), M. Leguineche (1998), J. Opatrný (1998b), I. Sánchez (1998) y P. Pascual (1998b) que analizan el imperialismo editorial norteamericano, la prensa legal y la revolución de 1895, el binomio prensa-patriodrama en la mayor de las Antillas, los periódicos españolistas en México durante la crisis del 98, la Guerra Hispano-Norteamericana en los diarios checos, el papel que jugó la prensa amarilla en ella, el valor de las publicaciones diarias para estudiar dicha crisis o la prensa independentista cubana en el exilio. Otras fuentes de estudio más o menos peculiares utilizadas en los trabajos que examinamos en estas páginas son las etiquetas de los puros habanos para indagar en los sucesos acontecidos en España y Cuba [Z. Lapique (1999)], lo editado en las revistas Social y El Cojo Ilustrado como acercamiento a la sociedad de esta última y a la confrontación latinidad versus imperialismo (M.L. Lobo y Z. Lapique (1996) y M. Belrose (1998)] o los relatos de viajeros acerca de aquella isla y de Puerto Rico [M. GuicharnaudTollis (1996) y L.M. González (1998)]. 
más de esas consideraciones de carácter general, varios artículos abordan temas más específicos, como la visión de España en las islas [A. Cubano (1997b) y C. Naranjo (1998d)]; la actitud de J. Martí ante los españoles explicada por la presencia de éstos en las filas mambisas [J.A. Blanco (1996)]; los referidos vínculos de Cuba con algunas regiones españolas, secuela de un aspecto objeto de abundantes trabajos años atrás por razones explicadas en páginas precedentes, o la Cámara Española de Comercio, analizada por M.A. Marqués (1998a) que, en la línea de las investigaciones de A. Bahamonde y J. Cayuela (1992) para el siglo XIX y de A. García Álvarez (1990) para el $\mathrm{XX}$, prueba que la posición de los integrantes de tal institución frente a distintas coyunturas y situaciones en esa última centuria da fe de su integración en la realidad insular postindependentista, pero no fue óbice para que preservasen fuertes lazos con España por motivos tanto mercantiles como de identidad ${ }^{41}$.

Independientemete de la situación en que quedaron los peninsulares en Puerto Rico tras $e l$ 98, que además varía en función de las diferencias entre ellos ${ }^{42}$ A. Cubano (1997b: 637) cree que la elite insular rechazó la España de las oligarquías y de los privilegios al tiempo que defendió su origen hispano frente a lo negro y lo norteamericano y justificó la invasión de los EE.UU. como un hecho impuesto por la razón. En esto coincide con los postulados tradicionales de la historia de las ideas a ambos lados del Atlántico, aunque el rechazo de lo negro (o lo indio en otras partes) no siempre está presente. Muchos trabajos recientes abundan en el tema. Verbigracia, J.L. Abellán (1998) vuelve a insistir en la obra de J.E. Rodó (1900) como símbolo de la construcción de una nueva identidad en los países latinoamericanos, cuyo sentido se encontraba en la defensa de los valores culturales hispanos frente a los materiales anglosajones y debía permitir combinar lo mejor de ambos mundos. De la misma forma se expresan J.M. Jover (1997), M. Belrose (1998) o A. Díaz Quiñones (1998b), quien ve en el pensamiento de M. Menéndez Pelayo el origen de esa nueva concepción de lo español. Resaltando la vigencia actual del problema, R.D. Molinary (1996a) y L.. Agrait (1999) hablan de Puerto Rico, en ese sentido, como frontera cultural y, de modo más tajante, incluso en ciertos aspectos opuesto a los anteriores, pero con el mismo problema de

41 Acerca de este tema se ha vertido mucha tinta recientemente. Aparte de las obras citadas, un trabajo de D. Castañeda (1998) examina los factores de ruptura y continuidad en el Caribe hispano, y otro de L. Toledo (1998a) la guerra y otros vínculos entre Cuba y España; estudios de A. Cairo (1998) y M. Guicharnaud-Tollis (1999b) analizan el antiespañolismo criollo en la Gran Antilla; los de uno de nosotros, C. Naranjo (1998a y b), la interconexión entre la construcción de los imaginarios nacionales, la defensa de la integridad nacional y la continuidad en las relaciones hispano-cubano y puertorriqueñas tras el 98, aspectos hacia los que está derivando actualmente el debate historiografico. Para los lazos específicos de determinadas regiones de España con las islas caribeñas, además de las obras mencionadas cuando hablamos de la inmigración, ver las de V. Erice (1996), A.M. Fernández (1997a), L. Mees (1997) y R.D. Molinary (1996b) sobre Asturias (los dos primeros), el País Vasco y Cuba, y sobre Galicia y Puerto Rico respectivamente. Con un carácter más genérico, pero en consonancia con ese mismo asunto, las investigaciones de E. Ucelay-Da Cal (1997) y S. Hilton (1998b) indagan en el efecto de la crisis finisecular en el nacimiento y desarrollo del nacionalismo y del federalismo en la península. Finalmente, en artículos recientes, A. Bahamonde (1998a), J. Cayuela (1997) y A. Bahamonde y J. Cayuela (1997) han seguido abundando en sus tesis acerca de la elite hispano-insular.

42 J.A. Giusti (1998) sigue manteniendo que el grupo vinculado a la industria azucarera preservó su posición privilegiada, mientras R.L. Cabrera (1998), analizando un entorno más específico y menos elitista, el corozaleño, califica la situación en que quedaron los peninsulares tras el 98 como el tránsito de un auge vulnerable a la supervivencia. Además de estos estudios, ver sobre el tema el trabajo de J.M. Pérez Rivera (1998) acerca del antiguo Casino Español de San Juan de Puerto Rico y el de M. Francés (1998) sobre resentimientos soterrados y ajustes de cuentas en la ciudad de Guayama.

R. I., $1999, \mathrm{n}^{\circ} 215$ 
fondo, F. Puell (1997) cree que el grito de Baire (inicio de la guerra de independencia cubana) supuso la frustración de una vocación europeísta ${ }^{43}$.

\section{cional}

Otros lugares, otros hechos. El 98 en América como acontecimiento interna-

De un modo u otro, ese 98 entendido en un sentido amplio afectó a muchos países; aunque a unos más que a otros y por razones distintas. Hubo vencedores y vencidos en conflictos coloniales; guerras (como en el caso español) o disputas por la hegemonía (como la británico-germano-estadounidense en Venezuela), entre potencias más o menos importantes o entre éstas y territorios supeditados o por supeditar. Ese fue el contexto general del fin de siglo al que ya nos referimos, el del reparto y redistribución del mundo entre unos pocos Estados que estudió J.M. Jover (1979). El nivel de acuerdo al respecto es grande, pero por pura coherencia, en momentos como el actual, con infinidad de espacios para debatir y publicar, deben estar presentes ciertas tesis y quienes las formularon, pues si además hablamos de historiadores de la talla de N. Sánchez-Albornoz (1998), siempre ofrecerán alguna novedad, en especial interpretativa. Aparte de él, han seguido indagando sobre esos asuntos, E. Baltar (1997), C. Robles (1997), M.D. Elizalde (1997-98 y 1998), F. García Sanz (1997-98), M. Espadas (1998), R. Mesa (1998), o los distintos autores incluidos en la compilación sobre el tema de A. Smith y E. Dávila, eds. (1998). Por ejemplo, R. de la Torre (1997a y b, 1997-98 y 1998-99) atrae la atención hacia latitudes más cercanas que el Caribe, explicando la política exterior española durante la crisis internacional de 1898 en función de la seguridad del Estrecho de Gibraltar [lo que también preocupa a L. Álvarez (1998)], y examina el intento británico de evitar la entrada de los EE.UU. en la guerra de Cuba y la paz con que ésta acabó. Por otro lado, L. Álvarez (1988 y 1998-99), que ya había analizado el problema del alzamiento cubano contra la metrópoli en 1868 en la diplomacia bismarkiana, continua viendo el 98 en la perspectiva ecuménica más amplia posible: la de España dentro del concierto de las naciones.

Junto a las citadas en el párrafo anterior, en las obras comentadas aquí encontramos también otras investigaciones temáticamente más novedosas, como un breve pero interesante artículo de A. Dávila (1997) y un libro de M.P. Maza (1997) acerca de El Vaticano y la crisis del 98 ; un trabajo de A. Navas (1998) sobre los precedentes diplomáticos de la cesión de Cuba y Puerto Rico, o sendos estudios de P. Estrade (199899) y A.M. Fernández (1998b) sobre el acercamiento cubano-filipino durante la contienda colonial y la diplomacia noventayochista vista desde Cuba. La historia diplomática, en la que de un modo u otro se incluyen casi todos los estudios referidos a lo que hemos llamado el contexto internacional del 98, y que cuenta con buenas aportaciones clásicas, especialmente para el caso de la mayor de las Antillas [ver los libros de H. Portell Vilá (1941) o M. Marquez (1975)], pues, ha seguido enriqueciéndose tanto con esas contribuciones, como con las escritas para examinar la intervención de

43 Aparte de los citados, ver el trabajo ya mencionado de H. Bianchi (1998) sobre las ideas-fuerza y el de J. Figueroa (1997) acerca de la dicotomía reformismo-revolución, que el autor examina desde una óptica más actual, pero que está en el trasfondo de esta discusión. Aunque interesado más por los proyectos políticos que por la historia de las ideas, J. Opatmý (1996) argumenta, al igual que F. Puell (1997), que el 98 supuso el fin de la época europea en América. Otra manera de expresar los dos extremos enfrentados en el debate es la dialéctica decadencia-modernidad, asunto que merece la atención de artículos como los de L.A. Ferrao (1996), O. Zanetti (1998e) y E. Subirats (1997) para Puerto Rico, Cuba y España respectivamente. 
los EE.UU. en la guerra hispano-colonial y en el futuro político de las ex-colonias españolas, tema que retomaremos más adelante; por ejemplo, S.E. Morales y A. Sánchez Andrés (1998) han publicado un texto acerca de Cuba y España en el horizonte latinoamericano del 98. Dilomacias en conflicto, e H. Otero (1998) un artículo en relación con J.A. de la Campa, que representó al gobierno de la isla en España, Japón o México.

El Caribe fue un espacio especialmente importante en la reorganización de las relaciones internacionales. El referido conflicto germano-estadounidense (1902-1903) merece estudios de M. Zeuske (1998-99) y R. Fiebig-Von Hase (1998), que lo explica como resultado de la interacción de varios factores (además del enfrentamiento entre ambas potencias, los problemas internos de Venezuela y sus relaciones con cada una de ellas) y analiza los medios que usaron los EE.UU. para imponer sus intereses. Tan comunes como estas disputas en las zonas de reparto y redistribución colonial americanas, africanas y asiáticas, fueron las acciones de intervención de pequeños Estados por una potencia extranjera, como la de Nicaragua en 1911 o la de Haití en 1915 por los marines [en 1906 también asumieron por segunda vez el gobierno de Cuba, asunto acerca del cual contamos con la obra clásica de T. Yglesias (1977)]. A. Gutiérrez (1998-99) investiga el caso nicaragüense y L.F. Hoffman (1997) y W.L. Bernecker (1998a) examinan el haitiano, en el que la injerencia - afirma Bernecker- se justificó como medio para restablecer el orden socio-político interno y modernizar el país, pero respondió también a razones menos altruistas, como evitar que Alemania estableciese allí una base para su flota de guerra o romper la orientación hacia dentro de su economía, vinculándola a la norteamericana como productora de azúcar y tabaco.

Panamá es el único país latinoamericano donde la coyuntura finisecular fue tan determinante históricamente hablando como en Puerto Rico y Cuba. T. Fischer (1998) y A. Figueroa (1998) polemizan sobre su caso. T. Fischer dice que su independencia fue resultado de la Guerra de los Mil Días, que los EE.UU. mantuvieron una postura ambigua ante el conflicto entre liberales y conservadores colombianos, aprovechando la debilidad de los segundos con el fin de fortalecer su posición en el istmo, que había sido clave para comunicar sus costas Este y Oeste desde la apertura del Panamá Railroad en 1855 y era un lugar idóneo para construir un canal interoceánico [ver nuestro trabajo, A. Santamaría (1998b)], y sólo apoyaron su secesión después de que el Senado de Colombia anulase el tratado acerca de ese territorio entre ambos países haciendo una lectura nacionalista y errónea del mismo. A. Figueroa, por su parte, disiente de la visión rupturista del anterior, pues cree en la existencia de un germen independentista en Panamá, cuya identidad diferenciada se reforzó con la presencia extranjera en la zona tras la fiebre del oro de California y la incorporación a los EE.UU. de vastos territorios en su frontera occidental después de la guerra con México (1848), que aumentaron el valor estratégico de la región y su importancia como lugar de tránsito entre los océanos Atlántico y Pacífico. En ese sentido - piensa- la emancipación en 1903 fue una ruptura dentro de la continuidad.

Conociendo la contundencia de ciertas acciones, sus resultados y la especial consideración que el Caribe y el Pacífico tuvieron para los EE.UU. (algo así como una frontera en un sentido amplio) puede parecer lo contrario, pero no hay acuerdo historiográfico sobre su política exterior en el tránsito del siglo XIX al XX; sobre su naturaleza y objetivos, o acerca de si éstos últimos respondieron a un plan definido. Estudios recientes de E. Malefakis (1997 y 1997-98), J. Tabares (1997), J.B. Ruiz (1998) y E. Zulueta (1998) abordan el tema desde la perspectiva de la situación general del país en 1898; L. Martínez (1997), J. Díaz (1997-98c), J. de Ojeda (1997-98b), S. Hilton (1998a y c) o M.R. Rodríguez (1998-99) se hacen eco de esos problemas al examinar la expansión norteamericana en el Caribe antes del 98 , las figuras de sus principales presidentes del momento, W. McKinley y T. Roosevelt, el uso que hizo el primero de

\section{R. $1 ., 1999, \mathrm{n}^{\circ} 215$}


la Doctrina Monroe en 1898 , o su proyecto geopolítico finisecular, mientras otros investigadores polemizan respecto de este último.

R.R. Dorries (1998) opina que la guerra de Cuba no lo alteró el proyecto geopolítico de los EE.UU., pues éste fue concebido en términos estructurales y continentales, no caribeños y coyunturales. Por el contrario, R. Dietl (1998), de forma menos monolítica, cree que la proyección exterior del país fue objeto de controversia entre quienes abogaron por mantener una posición de fuerza y los partidarios del aislacionismo y la defensa ejemplar de los valores democráticos del pueblo norteamericano. El autor sostiene que ambas posturas estuvieron en liza hasta que el wilsonianismo las integró, justificando la intervención en Europa durante la Primera Guerra Mundial con la defensa de tales valores. Finalmente, T. Schoonover (1998) piensa que el conflicto hispano-cubano sí representó un hito, pues proporcionó a Washington la ocasión de impulsar una política imperialista en el Caribe y el Pacífico que aliviase los problemas internos de la nación, ideas en las que abunda W. Howard (1998) al hablar de las grandes perspectivas que parecía ofrecer una pequeña guerra (contra España en Cuba). La definición y el efecto de esa política en Centroamérica y especialmente en la Gran Antilla y en Puerto Rico han preocupado a M.T. Cortés y M.R. Rodríguez (1997), J.L. Offner (1997), F. López Civeira (1997), M. Toussaine (1998-99), R. Villena (1998), A. García Álvarez (1998a y b) o R. Barreto (1997), y asuntos más concretos, pero igualmente trascendentes, como las fundaciones culturales del imperio o el crecimiento y declive de las colonias estadounidenses han interesado a L. Thompson (1997), C.D. Deere (1998) y U. Guthunz (1998), piensa quien para el caso puertorriqueño que el dudoso éxito de su colonización cultural muestra que el control excesivo sobre un territorio tiene sus límites. En este último sentido, un trabajo de M. Quijada (1997) reflexiona sobre la contraposición entre lo latino y lo anglosajón en el fin de siglo norteamericano.

La historiografía considera la coyuntura finisecular como un momento de especial relevancia en casi todos los países latinoamericanos. Por muy alejados que estuvieran [J.E. Rodó, del que hablaba J.L. Abellán (1998), era uruguayo] hechos como la guerra de Cuba y la intervención norteamericana o las causas que los explican tuvieron alguna implicación en ellos. Así lo entienden E. Aquino (1998-99), E. González (1997) o M. Palacios (1998) que, además, y aunque de distinta forma, centran su atención en el surgimiento y desarrollo del nacionalismo en dichos países desde un punto de vista político (los dos primeros) y económico (el tercero), o A. Sánchez Andrés (1998b), que estudia el efecto de la crisis del 98 en las relaciones hispanoamericanas. Otros autores se ocupan de casos más específicos, como el conservadurismo chileno [F.A. García (1998-99)], el regeneracionismo y el 98 peruano [V. Peralta (1998-99) y C. Martín (1998)], la Guerra Federal y la ciudadanía política en Bolivia [M. Irurozqui (1998 y 1998-99)], la identidad nacional en el Caribe francés y la República Dominicana [M. Dash (1997) y S. Torres (1997)], la construcción nacional argentina [M. Quijada (1998)], o la lectura que de la crisis del imperialismo español y de la intervención estadounidense en sus colonias se hizo en determinados círculos políticointelectuales de Argentina y Uruguay [D.O. Lucía (1998) y M.E. Pérez (1998)] y en América Latina en general [C. D. Mafamud (1998)].

Más cercano geográficamente al conflicto hispano-colonial, México, que en 1848 se enfrentó también en una guerra con los EE.UU. y por la cual perdió buena parte de su territorio, es objeto de muchos análisis, por esa razón y por la citada activa participación de la Universidad Michoacana San Nicolás de Hidalgo en el debate sobre el tema. Entre ellos encontramos estudios de carácter genérico, como el de R. Marsiske (1998) y la universidad mexicana finisecular; trabajos acerca de las relaciones con España y Cuba, como los de R. Figueroa (1998b), M.D. González-Ripoll (1998a) y R. Rojas (1998) [este 
último examina un proyecto de anexión de la isla a esa República], e investigaciones que indagan en la percepción y/o reacción frente a dicho conflicto, la intervención norteamericana en el mismo y la independencia cubana, bien en términos generales [M.S. Herrera (1998), S.E. Morales (1998a y b)] o en los casos concretos de los grupos políticos [J.C. Quiroz (1998)], la prensa y la opinión pública [R. Figueroa (1998a), J.L. Lizardi (1998)] y la colonia española [S. Ortelli (1998) y R. Figueroa (1998a)].

Un estudio de C.D. Malamud (1998) revisa los cambios en las relaciones entre España y sus antiguas colonias americanas en el contexto de 1898 y explica que una mejora en las mismas y la evidencia de que los EE.UU. terminarían entrando en el conflicto hispano-cubano podría explicar por qué muchas de las Repúblicas surgidas de ellas no apoyaron a los independentistas cubanos. Esa misma simpatía, según M.D. Elizalde (1998), fue todo lo que el gobierno español pudo conseguir de otras potencias para su causa en el enfrentamiento con el norteamericano, entre otros factores, debido a la errónea política internacional de la Restauración, y particularmente de A. Cánovas, quien entendió que para preservar su status, el país debía desentenderse de los grandes conflictos mundiales.

\section{La construcción política e intelectual de la identidad y de la nacionalidad}

El problema de la construcción nacional sigue siendo pieza clave en la articulación del debate historiográfico en torno al 98 en Puerto Rico y Cuba, aunque quizás con menos preeminencia que en años anteriores. Al hablar de la inmigración, de la desigualdad social, de las relaciones entre españoles y cubanos y puertorriqueños, de la historia de las ideas o del antagonismo hispano-anglosajón adelantamos cuestiones vinculadas con ella. Los estudios más específicos continúan abordando el tema desde. una doble perspectiva, intelectual y político-institucional y, dentro de la primera, con una óptica general o centrada en obras concretas. Llama la atención, especialmente en los textos más generales, la prioridad que conceden a ese último antagonismo y a la oposición criollo-metropolitano en detrimento de la dialéctica negro-blanco (los tres elementos dicotómicos que definían los fundamentos de la nacionalidad), debido sin duda a que éste dispone de un menor acervo erudito-literario para analizarlo y es examinado esencialmente desde el punto de vista socio-antropológico. En ese sentido, autores como A. Gaztambide (1997), L.A. Pérez (1997), A. Cubano (1998d), M. Flores (1998) o R. Rodríguez (en prensa) investigan desde distintos ángulos la invención y definición de las identidades nacionales caribeñas; T. Muñoz (1998) y J. Santana (1997) la forja de la cubanidad en el pensamiento español y las ideas en mayor de las Antillas tras la independencia, y A. Cairo (1997b y 1998), P. Guadarrama (1999), L.M. García Mora y C. Naranjo (1997) y D. García Ronda (1998) y L.M. González (1996 y 1999) la intelectualidad criolla ante la cuestión nacional en las décadas finales del dominio colonial en esa isla (los cinco primeros) y en la de Puerto Rico.

Los estudios sobre los intelectuales cubanos han generado controversias relacionadas con la complejidad social de la que hablamos anterioremente. Así, siguiendo los postulados clásicos de la Historia de la Ideas, también comentados con antelación, J. Le Riverend (1997) señala que ciertos sectores en Cuba y en su metrópoli se acercaron en las últimas décadas del siglo XIX, unidos por sus propuestas de transformación de sus respectivas sociedades para terminar con el tradicionalismo atávico que ambas sufrían. En ese ideal se encontraron los pensamientos de la denominada Generación del 98 y de los regeneracionistas españoles y de cubanos como J.G. Gómez, M. Sanguily, E.J. Varona, J.A. Ramos o C. Loveira, aunque fue demasiado tarde para evitar la guerra colonial. La mayoría de los autores citados anteriormente abundan en estas

\section{R. I., $1999, \mathrm{n}^{\circ} 215$}


tesis, más convincentes para explicar interrogantes todavía no suficientemente aclarados, como la filiación autonomista de la mayoría de las grandes figuras de la intelligentsia insular que, por ejemplo, las ideas de A. Cairo (1997b), quien define su posición durante la mayor parte del siglo XIX como una humillación permanente.

Aunque en la misma línea que la de los autores mencionados en los párrafos precedentes, más precisa es la preocupación de E. Hernández Sandoica (1997b), quien estudia la incidencia que la política metropolitana tuvo en el origen y en el desarrollo de los nacionalismos antillanos, y la de J. Guanche (1997a), que examina los aspectos étnico-demográficos de la cubanidad. Mucho más genérico, por el contrario, es el interés de E. Torres Cuevas (1997), que sigue indagando en los fundamentos teóricos de ésta última, así como el de J. Ibarra (1997), el historiador cubano que conserva en estado más puro la tradición marxista, el cual explica la nacionalidad como crisol de los citados elementos dicotómicos y, refiriéndose a las herencias española y estadounidense, y matizando lo afirmado en otras ocasiones con respecto a la primera (a la que calificó como valladar para la consolidación de dicha nacionalidad), sostiene que mientras la influencia hispana es parte consustancial de la identidad popular, la norteamericana sólo fue absorbida parcialmente y en sus aspectos más relacionados con la vida material.

Algunos estudios en los que se está trabajando actualmente analizan las identidades nacionales de múltiples formas con el fin de esclarecer los factores que se solapan y transcurren en distintas esferas de la sociedad civil y las instituciones públicas y oficiales. Dichos trabajos contribuirán próximamente a enriquecer el debate sobre los elementos de continuidad y ruptura en la coyuntura finisecular, aportando nuevas claves interpretativas acerca de la constitución de la nacionalidad y del imaginario de los pueblos como resultado de la dialéctica de diversos elementos contrapuestos y mestizos. Ejemplos de estos estudios son los artículos de uno de nosotros, C. Naranjo (1998a) y C. Naranjo y C. Serrano (1999), de S. Álvarez Curbelo (1998), M. Rodríguez Castro (1998) o M. Valdés (1998), casi todos los textos compilados en C. Naranjo y C. Serrano, eds. (1999) y muchas de las de las ponencias presentadas al referido congreso celebrado en Puerto Rico en el verano de 1998 y que verán la luz próximamente en un libro de actas.

Los libros editados en los últimos meses reúnen también nuevos trabajos sobre el Antillanismo; sobre sus perfiles histórico-ideológicos y su definición concreta en obras como la de L. Pales Matos [R. Cassá (1998) y T. Barrera (1998a)]. Y si hablamos de autores concretos, J. Martí y E.M. Hostos siguen siendo los que más interés despiertan en la investigación, junto con S. Brau, E. Roig, J. Marinello, R.E. Betances, C.M. de Céspedes, P. Albizu, R.M. de Labra, F. Ortiz, J.E. Varona, L. Muñoz Rivera y J. De Diego. Quizás es en J.E. Varona donde mejor se aprecia la dicotomía reformarevolución que caracterizó el pensamiento cubano en las primeras décadas del siglo XX [ver C. Naranjo (1998-99)]. De la literatura y política de L. Muñoz Rivera y J. De Diego (actividades que combinaron), W. Binder (1998) opina que fueron reflejo de la situación en que quedó Puerto Rico tras 1898; en especial, del antagonismo españolnorteamericano. Ambos -dice-mantuvieron posiciones independentistas, pero en el uno prevaleció la resignación y en el otro un hispanismo belicoso, excluyente de los componentes culturales africanos y contrario a las reformas socio-laborales, exclusiones ambas que hemos analizado desde distintas ópticas como elementos básicos de los proyectos políticos de las elites insulares postcoloniales, radicalmente opuestos a la democracia de base popular en que creyó J. Martí y también E.M. Hostos ${ }^{44}$.

44 Sobre S. Brau, E. Roig, J. Marinello, R.E. Betances, C.M. de Céspedes y P. Albizu ver los trabajos de M.T. Cortés (1997), A. Conde (1997), R. Pupo (1997), C. Naranjo (1997-98), T. Pedraza 
La contradicción entre los conceptos de identidad y nacionalidad en E.M. Hostos o J. Martí y los proyectos de una parte de las elites cubanas y puertorriqueñas y de ciertos intereses extranjeros, como los norteamericanos en el Caribe, es lo que diferencia más el componente intelectual del político-institucional de ambos conceptos. De tal contradicción se hacen eco, entre otras cosas, los trabajos de D. Sommer (1997), C. Fell (1999) o M.D. González-Ripoll (1997, 1997-98, 1998c y 1999) para el primero, al que esta última se refiere con términos como las trampas de la utopía, y los de A. Díaz Quiñones (1997); S. López y M.C. Marial (1997); D. Ramos (1997); L. Toledo (1997b); C. Vitier (1997); R. Rojas (1997-98a), A. Anderle (1998), J. Belnap y R. Fernández, eds. (1998); J. Cantón (1998); P. Estrade (1998a) [edición revisada de su libro publicado en 1987]; M. Iglesias (1998); R.F. Pino (1998), o J. González (1998) para el segundo. Todos ellos se preocupan por la modernidad y/o el valor simbólicomitológico de la figura y del pensamiento martianos en oposición, pero también como complemento, de sus planteamientos y acción política, a lo que prestan más atención R. de Armas y P.P. Rodríguez (1996) o I. Sepúlveda (1996). Incluso hay análisis como el de J. Opatrný (1998a), que descubren premoniciones más o menos fundadas en dicho pensamiento; concretamente en su crítica a las posiciones defendidas sobre Cuba en el Congreso Panamericano por J.G. Blaine, Secretario de Estado de los EE.UU., contra las cuales esgrimió que la influencia económica de ese país en la isla durante la segunda mitad del siglo XIX podría acabar convirtiéndose en influencia política. Finalmente, más específicas son las investigaciones de M. Mourelle (1996) o A. Oliveros (1996) acerca de Hostos y Puerto Rico vistos desde España, o en torno al marco cultural y educativo en la trayectoria vital de este último, y de $\mathrm{A}$. Esteban y $\mathrm{A}$. Moreno (1998) e I. Guerrero (1998) sobre J. Martí, la raza indígena y la mujer respectivamente.

Antes de analizar la historiografía político-institucional en relación con el tema de la construcción nacional debemos referirnos a dos últimos aspectos asociados con el problema de la identidad. Uno de ellos, la cuestión de la lengua, por razones obvias, preocupa sobre todo en el caso puertorriqueño, aunque autores como $\mathrm{M}$. Domínguez (1998) o A.M. González y J.J. Fernández (1998) la examinen en el cubano vinculando la formación de la modalidad cubana del español con el proceso histórico de constitución de la nacionalidad. Casi todos los textos de una de las compilaciones comentadas aquí [Puerto Rico... (1996)], además de algunos otros, estudian aquél primer caso; los de M. Criado (1996) y V. García (1996) desde una perspectiva panorámica; los de G. Tribin (1996) y E.M. Burgos (1999) insistiendo en la citada conexión idioma-defensa de la identidad, y los de E. Suárez-Galbán (1996), I. Mansilla (1996), T. Calvo (1996) y E. Barnach-Calvo (1996) ocupándose de asuntos concretos como la polémica en torno a la poesía puertorriqueña en inglés, el intercambio linguíístico-cultural entre la isla y España, el habla como sangre común de los hispanos que viven en los EE.UU., o la dimensión educativa del problema.

El segundo aspecto al que nos referíamos en el párrafo anterior es la historia de la educación, que en las obras objeto de este estudio ha recibido más atención para el caso cubano que para el puertorriqueño. En los dos, no obstante, es un tema poco investigado, tanto en términos generales, como en su relación específica con la formación y desarrollo de la identidad nacional y los proyectos de aculturación que los gobiernos de ocupación norteamericanos ensayaron en ambas islas, asunto este último

(1997-98a) y J.J. Rodríguez (1998) respectivamente; acerca de R.M. de Labra, los de M. Bizcarrondo, ed. (1998) y M.D. Domingo (1998); para F. Ortiz, los de A. Cairo (1998), S. Palmié (1998), R. Quiza (1998), F. Moulin-Civil (1999) y los de uno de nosotros, M.A. Puig-Samper y C. Naranjo (1998 y 1999). Respecto a L. Muñoz Rivera ver también el artículo de S. Álvarez Curbelo (1999).

R. I., $1999, \mathrm{n}^{\circ} 215$ 
que acapara la atención de las obras más recientes, como sucedía con el tema de la lengua. En ellas destaca, además, un debate implícito entre quines piensan que la labor de tales gobiernos se caracterizó exclusivamente por su interés en usar la escuela como instrumento para la referida aculturación, y quienes piensan, de modo menos maniqueo, que además contribuyó a dotar a Cuba de un sistema educativo relativamente moderno que, paradójicamente, fue esencial, junto con la acción pedagógica de los maestros, para preservar las tradiciones y los valores autóctonos frente a los estadounidenses [ver, por ejemplo, los trabajos de A. Penabad (1997) y C. Almodóvar (1997a) respectivamente $]^{45}$.

Igual que dijimos en el capítulo anterior, entre los estudios recientes de historia política e institucional y por razones obvias, unos examinan los últimos años de la colonia y otros el inicio del período independiente. Aquéllos abundan más que éstos, pero en su mayoría, ambos se caracterizan por su buena factura teórico-metodológica. Las investigaciones con una perspectiva más amplia han seguido profundizando en tesis desarrolladas años atrás, como las causas por las que Cuba y Puerto Rico permanecieron fieles a España tras la emancipación del resto de su imperio americano, cuestión que analiza A.J. Kuethe (1998); la configuración del Estado colonial postAyacucho, que ha continuado preocupando a J.M. Fradera (1997 y 1999), J.G. Cayuela (1998a) y E. Hernández Sandoica (1998c y e), o las razones de la crisis de posesión en la mayor de las Antillas, en las que profundiza J.J. Figarola (1996).

Trabajos más específicos que los anteriores, como los de A. Sánchez Andrés (1996a y b, 1997a y 1998-99), M. Rodrigo (1997 y 1998b), M.C. Barcia (1998b y d), L. Fernández Prieto (1998), E. Hernández Sandoica (1998d), J.A. Piqueras (1997, 1998d y 1998-99), J. Maestre (1998b), P. Muñoz (1997-98), O. Zanetti (1998a, b, c y f) o A. Bahamonde (1998a) dedicados a Cuba, y los de Ch. Schmidt-Nowara (1997), M.A. Castro (1997b) y M.D. Luque (1997a) para Puerto Rico, aunque también profundizan en tesis desarrolladas años atrás, ofrecen más novedades. Los cinco primeros autores examinan los condicionantes de la política española usando metodologías relativamente recientes, sobre todo en su aplicación a la historia cubana, como la conexión sociedad civil-política, el proceso de toma de decisiones o la acción de determinados grupos de presión. El propio A. Sánchez Andrés y J. Maestre estudian el Estado colonial desde una perspectiva jurídica ${ }^{46}$; a $\mathrm{P}$. Muñoz le preocupa el caso concreto del Capitán General C. García de Polavieja, y a A. Bahamonde, J.A. Piqueras, M. Rodrigo y $O$. Zanetti la relación economía-política, e insisten en la importancia que en ella tuvo

45 Además de los mencionados, para una perspectiva general ver el trabajo de C. Pérez (1998); acerca de la Universidad al final del período colonial, el de H. Hernández (1997) y, más específico, referido al problema de la etnografía y el racismo en la enseñanza de la geografía, el de A. García González (1998a). En estudios recientes, aunque anteriores a las compilaciones comentadas aquí, estudios de C. Almodóvar (1996) y A. García González (1996) ya habían abordado asuntos similares, y artículos de J.F. González (1995) y J. Meza (1995) examinaban la relación pedagogía-poder y el proyecto educativo de E.J. Varona, responsable educativo del citado gobierno de ocupación estadounidense. Alguna obras clásicas acerca del tema son las de C. Génova (1958), E. Hernández Sandoica (1988) y R. de Armas et al. (1984), que analizan la fundación de la escuela cubana, la enseñanza superior y la Universidad de La Habana.

46 Aunque aquí no vamos a extendemos en esta perspectiva, hay que decir que los estudios de historia del derecho y, en términos más generales, las aproximaciones a diferentes problemas del pasado a través de la legislación y de su aplicación cuentan en el caso cubano con trabajos clásicos como los de A.S. Bustamante (1923) o F. Ortiz (1916) y no se limitan sólo al estudio de la política. Un texto de C.J. Ayala (1995), por ejemplo, examina el colonato azucarero desde ese punto de vista. Un artículo ya citado de R. Quiza (1998), finalmente, analiza, entre otras cosas, la evolución de algunos de esos asuntos en la obra del citado F. Ortiz.

R. I., $1999, \mathrm{n}^{\circ} 215$ 
la interacción de distintos intereses que, por ejemplo, en opinión del último, impidieron resolver los problemas que la isla tuvo que enfrentar a finales del siglo XIX para mantener y mejorar la posición de sus productores en el mercado mundial.

En concreto, O. Zanetti (1998b) intenta explicar la miopía política de A. Cánovas, quien -dice- evitó una reforma profunda que quizás habría permitido un desenlace menos cruento que la Guerra de 1895-1898. La tardanza en aplicar esa reforma y lo inadecuado de las medidas arbitradas en su ausencia para paliar las dolencias del régimen colonial se estudian en trabajos como los de M. de la Torre (1997a y 1998b) sobre los derechos políticos y el problema electoral. Abunda, asimismo, la historiografía que aborda el tema desde el otro lado, el metropolitano, que ya dijimos sólo comentaríamos aquí en su dimensión ultramarina. En ese sentido hay que reseñar aportaciones interesantes de carácter general, como las de A.M. Fernández (1997b y 1998a) o E. Hernández Sandoica (1998d), y contribuciones más específicas como las de J. Maestre (1998a) acerca de la vinculación de los dos 98 (guerra de Cuba y desastre nacional); L. Fernández Prieto (1998) y P. Pascual (1996) a propósito de la cuestión colonial (las reformas y la guerra) en el Parlamento; las de P.C. González (1997), C.E. Lida (1998) y S. Hilton (1998b) en torno a la referida posición de ciertos intereses como las derechas, los anticolonialistas o los federalistas, y las de J. Companys (1996), R. Sevilla (1998b), S. Hilton (1998c) y J. Pando (1996) sobre los intentos de paz previos a 1898, la visión de los EE.UU. en España y las conversaciones entre ambos países en relación con la mayor de las Antillas durante su primera guerra de independencia (1868-1870), cuyo estallido, finalmente, examina J.J. Moreno (1997-98).

La configuración del régimen colonial puertorriqueño, su reforma a finales del siglo XIX y su status político tras el cambio de soberanía, como apuntamos en páginas precedentes, han acaparado prácticamente toda la atención de la historiografía reciente. De hecho, buena parte de los citados trabajos generales sobre el 98 , como los de S. Álvarez Curbelo (1997), L. Agrait (1998a) o A. Cubano (1998c), abordaban el problema desde esa óptica. En concreto, es sugerente el modo en que Ch. Schmidt-Nowara (1997 y 1998a) plantea la interacción de los elementos que definieron un sistema de dominio político que, por un lado, fue más convencional y menos conflictivo que el cubano y, por otro, precisó reformas que no se aplicaron ni siquiera como estaba previsto y, además, se alternaron con demostraciones de fuerza contra aquéllos que, aunque sin excesivo peligro, cuestionaron el status quo o demandaron cambios en el mismo. Ni este autor ni los otros que han examinado el tema han llegado a conclusiones claras debido a la ambigüedad que el 98 tuvo en Puerto Rico en todos los sentidos. Ya dijimos que la isla jugó un papel secundario en el imperio ultramarino español, que su historia estuvo muy determinada por la de Cuba, que se levantó contra la metrópoli en 1895 cuando lo hizo esta última, pero la rebelión fue rápidamente sofocada, y que después, cuando la invadieron los EE.UU., apenas se opuso resistencia militar [«¿A qué pelear si los de Madrid no nos quieren?», titula M.A. Castro (1997b) uno de sus artículos en las obras comentadas aquí].

La ambigüedad del 98 puertorriqueño se debe a la combinación de varios factores coadyuvantes de naturaleza contradictoria y explica en sí misma por qué casi todos los estudios abordan el tema desde una perspectiva global articulada en torno al análisis político. Por un lado, los lazos mercantiles con España estaban asegurados por la exportación allí o a Cuba del principal producto local, el café; por otro, a finales del siglo XIX se redujo el precio de dicho artículo provocando una merma de los beneficios de los cafeicultores que coincidió, por esa y otras razones, con una caída del poder adquisitivo de las clases medias y populares y con un crecimiento de la industria azucarera, cuyo mercado estaba en los EE.UU. Además, y lo mismo que en la Gran Antilla, cuestiones raciales desalentaron la causa independentista que, aunque existente y bien

R. $I ., 1999, \mathrm{n}^{\circ} 215$ 
estudiada, no logró una movilización social suficiente para poner en peligro el régimen colonial, a pesar de que casi todos los autores están de acuerdo en que su reforma, también como en el caso cubano, no bastó para resolver los referidos problemas socioeconómicos que padecía la isla. Según M.D. Luque (1997a), todos esos motivos explican, por ejemplo, que el ejército norteamericano fuese recibido con júbilo por un pueblo que poco antes había hecho lo propio con una infanta española. Dicha ambigüedad, finalmente, no se redujo, sino que aumentó después de 1898 debido a la referida indefinición del status del país dentro de los EE.UU. que además, como mostraba F. Picó (1997a), reforzó el carácter elitista y excluyente del sistema político. En el mismo sentido, un artículo de F.A. Scarano (1998) argumenta que la transición imperial se realizó mediante un pacto liberal destinado a mantener la jerarquía.

Específicamente, el asunto político que más atención ha recibido de la historiografía sobre el 98 en Puerto Rico es el tema de la autonomía (aunque como en casos anteriores, también se articula desde su óptica el estudio de aspectos socio-económicos), íntimamente relacionado con el de la reforma del Estado colonial, pues el autogobierno hubiese podido amortiguar algunos de sus problemas - al menos así lo creyeron sus defensores - como la conflictividad criollo-peninsular o las dificultades de acceso de los productos locales al mercado norteamericano, pero cuando finalmente se estableció fue demasiado tarde para ofrecer resultados. Muchos trabajos analizan el tema, aunque con enfoques distintos y resultados muy diferentes, y buena parte de ellos están reunidos en la compilación de J.E. Hernández, ed. (1998), bien desde una perspectiva general, como los de A. Cubano (1997-98), M.T. Cortés (1999), o el propio J.E. Hernández (1998b); bien atendiendo a asuntos más concretos, como los factores precipitantes de la Carta Autonómica; su génesis y práxis, los debates y conflictos entre los autonomistas [H.R. Feliciano (1998), E.M. Burgos (1997) y A. Cubano (1997c y 1998a)], su gestión al frente del gobierno [R.A. Torrech (1997 y 1998-99) y J.E. Hernández (1998a)] o el efecto de este último en lugares como la ciudad de San Germán [L. Torres (1998)].

En algunos de los estudios citados, como el de E.M. Burgos (1997), el autonomismo puertorriqueño es presentado como la forma de gobierno más idónea alcanzada bajo el dominio colonial español; fórmula que se legitima todavía más al contraponerse con la situación creada bajo el gobierno interventor norteamericano, tema que también ha estudiado recientemente en un artículo P.A. Cabán (1998).

Para el caso del autonomismo en Cuba, aunque allí tuvo más peso el movimiento independentista, autores como M. de la Torre (1997c y 1998a y b), M. Bizcarrondo (1998), L.M. García Mora (1998a y 1998-99) o P. Estrade (1999) han estudiado distintos aspectos del problema, aunque desde ángulos muy distintos. En el caso de las investigaciones realizadas en Cuba, el tema se ha analizado sin tener en cuenta las últimas aportaciones historiográficas, entendiéndolo como un freno al independentismo, carente de otras propuestas. L.M. García Mora, de quien además esperamos una tesis doctoral acerca del asunto, por contra, aplica a su análisis los avances más recientes de la teoría política y se preocupa por aspectos como la razón de sus presupuestos programáticos o de su desempeño práctico en el contexto de la sociedad insular, o como la procedencia y capacidad económica de sus miembros, intentando, en definitiva, conocer su representatividad. Tanto él como M. de la Torre, empero, coinciden en un asunto básico: la necesidad de saber más sobre un fenómeno que representó una alternativa hacia la independencia, más o menos sólida, pero sin duda menos cruenta que la guerra, y cuyos estudios clásicos son muy antiguos [ver R. Cabrera (1923) o R. Montoro (1930)]. Por ejemplo, todos los que han examinado el tema están de acuerdo 
en que un factor desencadenante de ésta fue el hecho de que el Partido Liberal Autonomista decidiese no presentarse a las elecciones de $1891^{47}$.

Los estudios sobre el autonomismo, algunas de las obras ya comentadas de historia socio-política y de las que comentaremos cuando hablemos de la economía debaten en torno al problema de la reforma del Estado colonial tras la primera guerra de independencia cubana (1868-1898). Trabajos recientes, pero anteriores a los examinados en este apartado, como los de J. Casanovas (1995a) o P. Estrade (1995a), dedicados al análisis del asociacionismo burgués y proletario y del denominado Movimiento Económico, así como los más actuales de M.C. Barcia (1998e), J.A. Piqueras (1997) sostienen en su mayoría que la amplitud de aquélla fue mucho mayor de la que hasta ahora había señalado buena parte de la historiografía [ver, por ejemplo, el libro de A.M. Fernández (1988)], aunque sobre todo en lo concerniente a la sociedad civil, lo que, paradójicamente, potenció un desarrollo de ésta superior al del sistema político que, a la postre, fue uno de los elementos que explican la independencia. En ese sentido, P. Estrade muestra cómo las crisis económica de las décadas de 1880 y 1890 provocaron una integración de intereses de la oligarquía al margen del referido sistema político debido a la insuficiencia de éste para resolverlas, no obstante se disolvió sin haber logrado muchos de sus objetivos debido a que estuvo a punto de romper dicho sistema ${ }^{48}$.

Además del autonomismo, los otros movimientos políticos coloniales han seguido atrayendo el interés de los autores, en un sentido general, como en los trabajos de M.C. Barcia y M. Hernández (1996) y P.P. Rodríguez y R. de Armas (1996) sobre Cuba, o específico, concentrado especialmente en el análisis del anexionismo y el independentismo en esta última [J. Opatrný (1998-99) y L.A. Pérez (1997)] y en Puerto Rico [G.L. García (1997a) y J.R. Navarro (1998)]. La historia político-institucional postcolonial parece haber despertado menos interés, en parte debido a la ausencia de investigadores foráneos, sobre todo españoles, cuya preocupación por las antiguas dependencias de su país prácticamente desaparece cuando dejaron de serlo, salvo excepciones entre las que, modestamente, nos incluimos los firmantes de este artículo. Sin duda tal carencia es una de las que convendría resolver en el futuro y seguramente era a ella a la que se refería E. Hernández Sandoica (1998b) cuando señalaba que insistir en los factores de continuidad en la relación entre españoles y cubanos y puertorriqueños impedía indagar en los de ruptura. Esperamos que el inicio del nuevo siglo, la conmemoración de la imposición de la Enmienda Platt y del nacimiento de la República de Cuba deparen en breve nuevos trabajos al respecto y terminen con tal despreocupación.

La escasez de investigadores españoles interesados en el período postcolonial provoca, entre otras cosas, una descompensación en el debate, carente en este caso de aportaciones que sí gozan otros temas. Hecha esa salvedad, que por supuesto no es un problema actual, sino secular, debemos decir que la más reciente historiografía política aplicada a los primeros años de dicho período ha seguido profundizando en algunos asuntos señalados en el apartado anterior, como la revolución confiscada o no consumada, la incierta victoria cubana o la transición de colonia a neocolonia en la Mayor de las Antillas, objetos de análisis de R. Serge (1998), O. Loyola (1998), L. Navarro

47 Además de los trabajos sobre el autonomismo, ver un estudio de A. Sánchez Andrés (1997a) acerca de la alternativa federal a la crisis colonial.

48 No insistimos más sobre este aspecto, pues lo desarrollamos ampliamente en otro trabajo, A. Santamaría y C. Naranjo (1999). Acerca de las reformas, aunque concentrando fundamentalmente en la política internacional, ver también el artículo de M.D. Elizalde (1998), y en relación con el asociacionismo del que habla J. Casanovas (1995b), y que fue pieza esencial en el referido proceso de reformas sociales y en el citado desarrollo de la sociedad civil, los estudios mencionados al hablar de la inmigración, la población cubana de color y el movimiento obrero fundamentalmente. 
(1998a), H. Pérez Concepción (1997) o A. García Álvarez (1998a y b) para el caso de Cuba, o en la creación del Consejo Ejecutivo y la norteamericanización de Puerto Rico, tema examinado por P.A. Cabán (1998), pero también ha explorado otros asuntos menos conocidos como la cultura política, los partidos o las elecciones ${ }^{49}$.

En general, se puede decir que el problema de la construcción de nuevos espacios políticos en Puerto Rico y Cuba en la coyuntura finisecular, además de análisis institucionales, ha generado reflexiones de diversa índole que intentan explicar la especial relación que tanto los EE.UU. como la ex-metrópoli mantuvieron a partir de 1898 con ambas islas y su evolución en el tiempo, tema normalmente vinculado a la dialéctica atraso-modernidad [ver O. Zanetti (1998a y e)], que se superpone a la controversia dependencia-independencia. Así, C. Almodóvar (1993) explicaba que la percepción historiográfica de la participación norteamericana en la lucha cubana por la emancipación había variado a lo largo de los años, transitando de posiciones relativamente aquiescentes a posturas que la concibieron como un obstáculo, representadas en la obra de E. Roig (1961) y alentadas por la causa revolucionaria a partir de 1959. Lo mismo cabe decir del papel jugado por España en la historia insular, cuya valoración se ha modificado, tanto gracias a las aportaciones científicas de los estudiosos del tema, como a los muchos acontecimientos que desde mediados de la década de 1980 han propiciado un acercamiento entre ambos países, y que en lo referente a la historiografía tuvo sus primeras materializaciones en las compilaciones de F. Solano y A. Gimerá, coords. (1990) y de Estudios de Historia Social (1988). El caso de Puerto Rico es más complejo si cabe. Trabajos como el de R. Barreto (1997) son una muestra de los muchos interrogantes que plantea. El autor se pregunta por qué los EE.UU. le negaron el autogobierno y, al igual que tantos otros que han examinado el asunto, en sus explicaciones no halla respuesta. Dice que las conclusiones obtenidas al analizar la cuestión están polarizadas entre los que tratan de exculpar a ese país de responsabilidad aludiendo a la falta de preparación de la isla para la independencia, y los que creen que fue una acción deliberada y cuidadosamente decidida como alternativa más conveniente para los intereses norteamericanos. En las obras comentadas aquí, artículos como los de A. Sagardia (1998) o M.R. Urrutia (1998), que examinan las leyes (Actas Foraker y Jones), que dieron origen al especial status político puertorriqueño, o el mencionado de P.A. Cabán (1998), abundan en tales controversias.

\section{Otros temas. La historia económica de siempre y el lento avance hacia una perspectiva más integradora}

Son muchos los asuntos que por falta de espacio han quedado sin tratar, bien por la dificultad de integrarlos en la estructura con que hemos ordenado en el texto, bien por tratarse de aspectos en que todavía ha abundado poco la historiografía. Algunas cosas, no obstante, si nos parece necesario decir sobre ambos. Por ejemplo, merece la pena destacar que a pesar de la concentración temática de las investigaciones dedicadas al Puerto Rico finisecular de la que hablamos anteriormente, autores como R.N. Velasco (1998) o C. Orozco (1998) nos han regalado análisis acerca de problemas mucho más

49 En este mismo sentido continuista de las tendencias precedentes, ver el trabajo de I. Hidalgo (1997) sobre la disolución del Partido Revolucionario Cubano. Para la cultura política y los partidos y las elecciones, ver los de M. de la Torre (1997b y 1998c), M.C. Barcia (1997c), A. Ferrer (1998), R.J. Scott (1998) y M. Zeuske (1997), los dos últimos referidos fundamentalmente a la población de color en el área de Cienfuegos. Ambos temas tienen antecedentes recientes en los trabajos del propio $\mathrm{M}$. Zeuske (1996) [un ensayo excepcional acerca de la cultura política] y de R. de Armas et al. (1985). 
específicos, pero igualmente interesantes, como la construcción legal de la familia y la beneficencia municipal en Guayama. También hay que mencionar una tendencia creciente en los últimos años a realizar estudios regionales y locales y de historia comparativa, costumbre antigua y que se ha mantenido entre los historiadores económicos, ${ }^{50}$ pero que recientemente se ha extendido a los de la sociedad y la política. Ejemplos de esto son la compilación de S. Álvarez Curbelo et al., eds. (1998) para Puerto Rico o los trabajos de M. Zeuske (1998b y en prensa) para Cuba. Sin duda, como ha ocurrido en otros países, examinar las cosas desde esas dimensiones aportará en el futuro nuevas respuestas a ciertos problemas y perspectivas hasta ahora desconocidas.

Igual que en el apartado anterior, acabamos nuestro análisis hablando de la economía que ha sido, junto con la política, la que más interés ha despertado en las obras comentadas aquí, y eso que casi todos los trabajos se refieren al caso cubano, exceptuando alguno que abarca también el puertorriqueño, como la bibliografía azucarera de F. Moscoso (1998) o nuestro estudio del ferrocarril, A. Santamaría (1998d y e). Aparte de éstos, unos pocos artículos específicos abundan en tesis desarrolladas años atrás, como el de J.A. Giusti (1998) acerca del grupo español en la banca y la industria azucarera, o inician la explotación de nuevos problemas, como el de B. Rivera (1998) sobre el puerto de San Juan; el de R.L. Cintrón (1998) en relación con los comerciantes a escala local, concretamente en la ciudad de Guayama; el de M. García Pedraza (1998), que examina los fraudes en las aduanas, y los de M.D. Luque (1998-99 y 1999), que indagan en las inversiones extranjeras y en el 98 en el imaginario empresarial criollo. Precisamente, la temática de este último, que aborda la economía en relación con otros asuntos, lo mismo que la del texto de A. Cubano (1997a) dedicado a la interacción comercio-moneda-política, explican la escasez reciente de trabajos de historia económica de Puerto Rico, pues como ya dijimos, se ha producido una concentración de los intereses de muchos autores en torno a la historia política como articuladora del debate sobre la coyuntura finisecular en esa isla, a partir de la cual analizan más o menos marginalmente otras cuestiones referentes a la sociedad o a la economía.

Lo primero que hay que mencionar respecto a Cuba es que recientemente su historia económica ha empezado a ocupar el lugar que por su importancia le corresponde dentro de los principales estudios conjuntos sobre el tema en América Latina, espacio del que habitualmente había estado ausente. No es éste lugar para explicar todas las razones de dicha ausencia, pero sí, brevemente, las que tienen que ver con el 98 en ese sentido amplio con que se entiende en este trabajo. Debido a su especialización en la elaboración de azúcar, resultado de la forma en que aprovechó su ventaja comparativa y de su especial vinculación con el mercado norteamericano, la economía insular se caracterizó por un crecimiento y un desarrollo similar al de los países más avanzados de la región (nivel de PIB per capita, tasas de mortalidad o urbanización) asentados sobre características estructurales parecidas a las de los más atrasados (dependencia de un sólo producto y de la importación de alimentos, o concentración geográfica de su comercio), paradoja que se intenta aclarar en uno de esos estudios. No comentaremos aquí, sin embargo, la calidad de tales aportaciones, pues su autoría corresponde a uno de nosotros ${ }^{51}$.

so Sobre la historia económica regional ver, por ejemplo, O. Zanetti y A. García Álvarez (1976), R. Hoernel (1976), L.W. Bergad (1990), H. Venegas (1980 y 1995), R.J. Scott (1996 y 1998) o E. Torres-Cuevas (1999) para Cuba y F. Picó (1981) o J.A. Giusti (1994) para Puerto Rico. Acerca de la historia comparativa, R.J. Scott (1995) o A. Santamaría (1998d y 1999).

51 Las principales obras conjuntas sobre la historia económica latinoamericana publicadas recientemente son las compilaciones de E. Cárdenas et al., eds. (1999) y J. Sanz, coord. et al. (1998a y b). Ambos incluyen trabajos de uno de nosotros acerca de la economía de Cuba en general y del ferro-

\author{
R. I., $1999, \mathrm{n}^{\circ} 215$
}


Aunque lentamente, los estudios recientes de historia económica de Cuba son probablemente los que más han avanzado en la resolución de las carencias que presentaba el conocimiento del tema tan sólo unos años atrás. Decíamos que era preciso un esfuerzo de reconstrucción y estimación de grandes agregados que nos permitiesen hablar con mayor precisión de hechos como las causas y efectos económicos de la independencia, prestar más atención a las actividades menos vinculadas con el sector externo, incluso a la evolución de este último en las décadas finales del siglo XIX. En todos esos aspectos se ha producido algún avance, aunque todavía no ha dado tiempo para que los trabajos de síntesis se hagan eco de tales esfuerzos, algunos de los cuales todavía están en prensa o en fase de realización. Dichas síntesis recientes, lo que han incorporado de momento son las novedades de la investigación en fechas precedentes. Aparte de la escrita por uno de nosotros y citada anteriormente, A. Santamaría (1999), y del análisis historiográfico, A. Santamaría (1998a), en el que desarrollamos con más detalle los problemas esbozados en este artículo, en las compilaciones comentadas aquí hay investigaciones de este tipo de F. Iglesias (1996) para las últimas décadas del siglo XIX, de M.C. García Bernal (1998) sobre el momento específico de la guerra y de A. García Álvarez (1997b) acerca del inicio del período neocolonial, tema que también examina en un capítulo del tomo tercero del IHC (1994-), que debe publicarse próximamente.

Aunque, como decimos, muchos de los recientes esfuerzos de reconstrucción y estimación de las series, indicadores y datos imprescindibles para hacer una historia económica más precisa aún no se han publicado, sí han aparecido varios estudios que anticipan su contenido y es posible informar al lector de lo que se espera próximamente. La ausencia de una estadística comercial desagregada por productos y mercados para el siglo XIX todavía no se ha resuelto, pero un libro y varios artículos recientes de O. Zanetti (1997, 1998a, b, c, f y g), una investigación que proyectan A.D. Dye y R. Sicotte, y algunos datos recopilados últimamente por uno de nosotros - A. Santamaría- sobre ese asunto y que quizás sinteticemos en el futuro en un trabajo, mejoran bastante lo que sabemos del tema en breve. De momento, las conclusiones de $\mathrm{O}$. Zanetti, que son las únicas publicadas, precisan la importancia del comercio como factor explicativo de la crisis colonial. En contribuciones más específicas, por su parte, J.A. Piqueras (1998c) y P. Fraile y A. Escudero (1998) revisan las tesis tradicionales respecto a la importancia que el mercado de Cuba tenía para la economía española.

Otra estimación que verá la luz próximamente es nuestra reconstrucción de un índice general de precios para el período 1872-1901, A. Santamaría (inédito-b) que prolonga la serie de O. Zanetti y A. García Álvarez (1976: 441-2) y cuyo análisis muestra, por ejemplo, que factores como la evolución del sistema económico internacional son más importantes que la política comercial española para entender la independencia de la isla. Dichas conclusiones coinciden con las de otros estudios mencionados anteriormente y que insistían en que una de las razones de la emancipación fue el fracaso de las reformas para adaptar la administración colonial a los cambios en la coyuntura mundial de fin de siglo. En ese sentido, una tesis complementaria de J.A. Piqueras (1998e) intenta probar que si bien en tal coyuntura arreció el alejamiento de las economías cubana y española medido en términos de la vinculación de aquélla con el mercado de los EE.UU., ello no permite hablar de una pérdida progresiva de la colonia, como han señalado algunos autores, pues justo en esos años fue cuando la metrópoli extrajo más renta de ella.

carril y la economía puertorriqueña y cubana, A. Santamaría (1998c, d y e y 1999). En fechas relativamente cercanas, y antes que nosotros, M. Moreno (1991) y P. Fraile et al. (1993) escribieron los capítulos dedicados al Caribe español en el período de entresiglos y a la Gran Antilla en el siglo XIX en las compilaciones sobre la economía y la sociedad y economía de América Latina de L. Prados y S. Amaral, eds. (1993) y L. Bethell, ed. (1985-). 
Aparte de los aranceles e impuestos, otro mecanismo de extracción de renta colonial fue el inherente a la presencia de españoles (y también de británicos y norteamericanos) en las principales actividades productivas de la isla. Un trabajo de A. Quiroz (1998a y b) prueba que uno de los efectos de la Guerra de los Diez Años (1868-1878) fue el reforzamiento de esa presencia en detrimento de la de los criollos, abundando en las tesis que ya habían sostenido autores como A. García Álvarez (1990) o A. Bahamonde y J.G. Cayuela (1992), que recientemente han seguido indagando en el trasvase de capitales [A. Bahamonde (1998a y b) y A. Bahamonde y J.G. Cayuela (1997)], al igual que J.A. Piqueras (1998a, d, e y 1998-99), quien sostiene algunas ideas enfrentadas con las de A. Bahamonde acerca de la importancia económica que la isla tuvo para España. Finalmente, sobre las consecuencias de la Guerra de 1895-1898 contamos con un nuevo estudio de J. Maluquer (1997), que se promete como primera entrega de una investigación mayor, y en breve publicará la compilación de P. Tedde, ed. (en prensa) con varios artículos sobre estos y otros problemas como la deuda o el comercio colonial.

Nadie duda de la relación entre el crecimiento y transformación de la industria azucarera o la concentración de las exportaciones de dulce en el mercado norteamericano y la emancipación y la configuración del sistema económico cubano postindependencia, pero los estudios referidos antes prueban que las cosas no fueron tan sencillas como en principio esa relación podría llevar a pensar. Además, ya decíamos también que faltaban investigaciones sobre dicha industria en el último tercio del siglo XIX, que no estaban cerrados debates como el de la abolición de la esclavitud y que aún eran muchos los aspectos que quedan por conocer de la modernización que experimentó el sector en esos años y de sus efectos socio-económicos. Abundan en tales problemas los estudios de uno de nosotros, A. Santamaría (inédito-a), A. Santamaría y L.M. García Mora (1998a y b) y L.M. García Mora y A. Santamaría (1999 e inédito) acerca del fin de la esclavitud, del establecimiento del sistema de colonato o de los costes de elaboración del azúcar; un libro de F. Iglesias (en prensa) sobre el proceso de centralización de la producción, donde responde a algunos de los interrogantes citados (por ejemplo, afirma que la Guerra de 1895-1898 favoreció la concentración horizontal de la oferta y la modernización técnica de los ingenios); la magnífica tesis doctoral de A.D. Dye (1998), que acaba de editarse como libro y donde se aplican métodos econométricos para explicar la elección de las técnicas y de los criterios organizativos con que operaron los centrales desde principios del siglo XIX, y un interesante artículo de J.A. Piqueras (1998a) que analiza los rendimientos del dulce e intenta probar que su escasa mejora en las décadas de 1880 y 1890 expulsó hacia otras actividades más rentables capital que podría haber sido reinvertido en el sector ${ }^{5}$.

Decíamos también que además de la industria azucarera últimamente se están realizando algunos estudios para otros sectores, algunos ligados a ella y objeto de investigaciones anteriores, como los de uno de uno nosotros sobre el ferrocarril [A. Santamaría (1998c, d y e)] que, además, cuenta también con una nueva edición corregida y en

52 La industria azucarera, la colonización y, en relación con ello, la diversificación y modernización de la agricultura cubana, que deparó infinidad de proyectos y fue vista por infinidad de historiadores como una solución ideal para muchos de los problemas de la isla (atracción de inmigración blanca, reducción de la dependencia de las exportaciones de azúcar y del mercado norteamericano) preocupa a historiadores como R. Misas (1998), I. Balboa (1998c) y L. Fernández Prieto (1999 y en prensa). De las dos últimas esperamos en el futuro, además, sendas tesis doctorales. Otros trabajos referidos al azúcar son los de J. Gilard (1999), de carácter general y que estudia tanto Cuba como Puerto Rico, el referido de E. Torres-Cuevas (1999) acerca de la influencia que éste tuvo en la formación de los complejos socioeconómicos regionales, o el de M. Guicharnaud-Tollis (1999a), que indaga en la difusión del sistema Deroesne en los ingenios.

R. I., $1999, \mathrm{n}^{\circ} 215$ 
inglés de la obra clásica de O. Zanetti y A. García Álvarez (1998), o los de F. Iglesias (1998), I. Roldán (1997a y b), A. García Álvarez (1998c), M. Rodrigo (1998a), C. Saiz Pastor (1998) y E. Collazo, sobre las finanzas y los bancos. I. Roldán examina el tema en términos generales y en la coyuntura específica de la Guerra de 1895-1898, a lo que también se dedica F. Iglesias. Esta explica cómo la ausencia de un sistema crediticio destinado a resolver otras necesidades que las de la producción exportable perjudicó a los pequeños y medianos productores agrarios tras la finalización del conflicto, cuya falta de recursos y endeudamiento les hizo muy vulnerables frente a la penetración del capital estadounidense. I. Roldán se preocupa también por el modo en que se financió la contienda (hasta 1896 con fondos del Tesoro cubano y, cuando éstos se agotaron, mediante un empréstito interno de la Hacienda metropolitana) y por las razones que condujeron al gobierno español a asumir luego la deuda generada por la misma a pesar de que no estaba obligado a ello según las estipulaciones del Tratado de París. A. García Álvarez, por su parte, analiza el caso concreto del Banco Español de la Isla de Cuba entre 1881-1921, completando otra investigación de I. Roldán (1995) sobre su antecesor (el Banco Español de La Habana, 1856-1881). Ambos coinciden en el papel esencial que éste jugó dentro de la maquinaria político-institucional de la administración colonial, y el segundo detalla cómo se adaptó después a la estructura económica neocolonial, y no sólo representando los intereses españoles en la isla, pues su inserción dentro de ella fue tal que no resistió a la primera gran crisis de la misma en 1920-1921. Finalmente, frente a los anteriores y a M. Rodrigo, quien se ocupa del Banco Hispano-Colonial, los trabajos de E. Collazo, entre los que se encuentra una tesis de licenciatura, un libro y algún artículo todavía no publicados y una tesis doctoral en proceso de elaboración, se dedican más a la banca privada y, en especial, a la creada por inmigrantes asturianos en la Gran Antilla.

Sin menospreciar las aportaciones anteriores, para finalizar, hay que resaltar por su novedad en el actual panorama historiográfico los estudios sobre sectores no vinculados con las principales artículos de exportación de la isla, esencialmente los trabajos de M.A. Marqués (1996b y 1998a y b) acerca de las industrias menores (actividades manufactureras no azucareras ni tabacaleras), de A. García Álvarez (1997a) respecto a una de esas industrias, la del henequén, y de E.L. Moyano y S. Fernández (1998) en relación con la minería. Finalmente, esperamos también en fechas próximas un libro del propio A. García Álvarez y M. Martí (en preparación) dedicado al banano y una tesis doctoral de $\mathrm{R}$. Funes sobre la deforestación. Todas esas obras coinciden en señalar el escaso interés que han despertado sus respectivos objetos de análisis debido a la preeminencia del azúcar (económica e historiográfica), aunque su conocimiento es interesante desde infinidad de puntos de vista. Por ejemplo, M.A. Marqués destaca la expansión a finales del siglo XIX de una serie de industrias menores con un carácter complementario respecto a la producción de dulce, ofreciendo una imagen más completa del sistema económico cubano del que hasta ahora teníamos. Sus tesis, por otro lado, concuerdan con las conclusiones de las investigaciones sobre otros países latinoamericanos, con lo que señalaban trabajos como nuestro estudio de precios [A. Santamaría (inédito-b)] o el artículo de J.A. Piqueras (1998a), que explicaba la necesidad que tuvieron muchos sacarócratas de invertir sus beneficios en actividades distintas del azúcar en las últimas décadas del siglo XIX, aunque, frente a este último, aquélla autora ofrece una explicación diferente para ese hecho relacionada con la diversificación de riesgos más que con problemas de rendimientos en los ingenios ${ }^{53}$.

53 Algunos de los estudios mencionados cuentan con antecedentes clásicos y recientes, como los de A. Calvache (1944), L.D. Soto (1981) y J.A. Uribe (1995) para la minería. Las que M.A. Marqués 
Para finalizar, junto a las obras anteriores debemos señalar también algunas otras más difíciles de agrupar o que abundan en temas estudiados en páginas precedentes, pero desde el punto de vista de la economía. Entre estas últimas hay que destacar las de J.A. Piqueras (1998d) o M. Rodrigo (1998b) sobre los negocios y la política metropolitana en Ultramar o la de A. de la Fuente (1997), que relaciona los problemas del mercado de trabajo con el racismo y la inmigración en la mayor de las Antillas; entre las primeras debemos señalar, por otra parte, una investigación de A. Sánchez Andrés (1997b) acerca de los presupuestos coloniales, y varios artículos que, centrados en la economía española, como algunos de los mencionados antes de A. Bahamonde o J.A. Piqueras, examinan también la cubana, así sucede, por ejemplo, con un breve pero claro ensayo de G. Tortella (1997-98) y con el análisis econométrico realizado por P. Fraile y A. Escudero (1998).

\section{IDEAS PARA TERMINAR}

Un análisis historiográfico es en sí mismo un trabajo de conclusiones, por lo que no vamos a terminar aquí con un corolario al uso en el que se detallen las principales cuestiones expuestas en páginas precedentes. Sí creemos necesario, sin embargo, resaltar unas cuantas ideas para acabar. La primera es que en muy pocas ocasiones la historiografía de algún tema, sobre todo tan amplio, con tantas posibilidades e implicaciones ha gozado de la colaboración de un número tal de esfuerzos personales e institucionales en varios países y continuado a lo largo de varios años como el 98 (las últimas décadas del siglo $\mathrm{XX}$ y primeras del $\mathrm{XX}$ ) en América, gracias, entre otras cosas, a la concatenación de varias conmemoraciones y a la renovación y actualización de los estudios históricos por distintas razones en España, Cuba y Puerto Rico.

Pensamos que los resultados han justificado los esfuerzos y en varios sentidos. Primero, por la cantidad y calidad de los trabajos que han visto la luz últimamente; segundo, por el buen entendimiento y la colaboración que ha presidido los debates $y$, tercero, por la disposición y el oficio que han mostrados muchos de los profesionales a la hora de decidir qué asuntos del pasado son menos conocidos y más interesa investigar y de qué manera debe hacerse, formulando preguntas y aplicando herramientas teórico-metodológicas relevantes a nivel internacional que, por supuesto, ni son las únicas posibles ni tampoco las mejores, pero sí las que hoy por hoy caracterizan el avance de nuestra disciplina.

A pesar de lo dicho, todavía es mucha la labor que queda por hacer, aunque esto no es, desde luego, una conclusión negativa, sino una invitación a continuar los referidos esfuerzos y a validarlos más allá de las celebraciones, incluso a inventar otras si es preciso para seguir avanzando. En 1902, por ejemplo, se estableció formalmente la República de Cuba y entró en vigencia la Enmienda Platt. Con o sin esas ocasiones, es necesario que en un futuro próximo seamos capaces de sintetizar todos los esfuerzos recientes en obras más globales y comprensivas, tanto destinadas a los profesionales, como a los alumnos universitarios y de instituto, como al lector meramente interesado en la historia. También urge que las completemos en varios sentidos, sobre todo, insistiendo más en el estudio de la sociedad finisecular, de los grandes agregados macroeconómicos, interesando a los autores españoles en el examen de la realidad cubana y

llama industrias menores apenas han sido trabajadas. Entre las pocas excepciones destacables está el libro de J.A. Chía (1977) sobre el monopolio del jabón y del perfume.

R. I., $1999, \mathrm{n}^{\circ} 215$ 
puertorriqueña postcolonial o especializando más los análisis sobre Puerto Rico, excesivamente concentrados o articulados en torno a los problemas políticos.

En Puerto Rico, la ocasión de estudiar y discutir sobre la coyuntura finisecular y, en concreto, sobre el 98 , ha sido en gran medida un acicate para enfocar su historia desde el presente, de forma que a veces parece que no han transcurrido cien años, fundamentalmente en lo que respecta al debate sobre su identidad nacional. La reivindicación continua de esta última desde el momento en que la isla cambió de soberanía ha concentrado la labor historiográfica, generando trabajos, algunos de ellos todavía en proceso, acerca de la hispanofilia o la modernidad de su sociedad. En esos trabajos se examina el referido problema de la identidad y la construcción del imaginario puertorriqueño, tanto a partir de los programas y de la acción política real, como del proceso de legitimación y de apropiación de las diferentes herencias culturales que coexistieron y coexisten en la isla en un contexto en el cual una de ellas tuvo (la española) y tiene (la estadounidense) un status dominante frente a las demás. Así, aunque la tarea reciente de ciertos autores, especialmente de los que se han ocupado de la cultura y de las mentalidades, destaca por su excelencia y hasta permite evidenciar nuevos e interesantes rumbos en la investigación, la vigencia de estas cuestiones ha provocado que, en muchas ocasiones, el análisis científico se traslade a un segundo plano frente a las argumentaciones políticas. Esto se entiende mejor si tenemos en cuenta, por ejemplo, que Puerto Rico se enfrentará en breve a un nuevo plebiscito en el que se decidirá su destino como Estado.

Aunque la importancia de la coyuntura finisecular y del 98 en la historia posterior de Cuba no ha sido menor que en la de Puerto Rico, se ha definido menos en aspectos específicos como la identidad nacional, especialmente en lo escrito después de la Revolución de 1959. Eso y el hecho de que los sucesos recientes (desaparición de la URSS) han provocado una necesidad de revisión historiográfica, han permitido una producción más variada y preocupada por múltiples aspectos que, desde nuestro punto de vista, los autores han sabido casi siempre articular bien con el tema central del centenario del final del dominio colonial español, asunto que ha presidido las reuniones y publicaciones de los últimos años acerca de la isla. Sólo hay que lamentar, en términos generales, la escasa incorporación a sus estudios de las investigaciones realizadas fuera del país, que no pueden ser invisibles durante más tiempo para esta historiografía.

"The "98 in America» is an exhasutive study about the recent historiographic production about last Spanish colonies in West Indies in the late Nineteenth and early Twentieth Centuries. In the first part of the paper it is analized the clasical books and articles about the thema, the one allows us explain in the second part the most important contributions of this recent historiographic production to the knowledge and its deficiencies, which must be resolved in the future. The study finishes with a bibliographic relation which contain all the works written in the last years $y$ the aforemencioned clasical books and articles about the thema. 


\section{REFERENCIAS BIBLIOGRÁFICAS}

1898: desastre nacional o impulso modernizador (1998) monográfico de Revista de Occidente, 202-203. El 98 (1998), monográfico de Temas, 12-13.

El 98 Iberoamericano (1998), Madrid, Pablo Iglesias.

El 98 visto desde América (1998), monográfico de Cuadernos Hispanoamericanos (1998), 577-578.

ABAD, D. (1995), «El PRC en la Guerra de Independencia. Observaciones preliminares», en $\mathrm{O}$. Loyola, coord. (1995): 69-86.

- (1996), Cuba. La Revolución del 95, La Habana, Ciencias Sociales.

ABAD, L.V de (1945), Azúcar y caña de azúcar. Ensayo de orientación cubana, La Habana, Mercantil.

- (1949), Los ferrocarriles de Cuba, La Habana.

ABELLAN, J.L. (1972), La idea de América. Madrid, Istmo.

- (1996), «La realidad puertorriqueña a la luz del último referéndum sobre su status político», en Puerto Rico... (1996): 13-22.

- (1998), «Modernismo: Ariel como símbolo», en El 98... (1998): 149-60.

ABREU, J. (1993), «La respuesta española a la insurrección de Oriente, 1868-1869», en ACI (1993): 36-44.

ACI [Aula de Cultura Iberoamericana] (1993), Nuestra común historia. Cuba y España. Poblamiento y nacionalidad, La Habana, Ciencias Sociales.

- (1995), Nuestra común historia. Cuba y Espa-

ña. Cultura y sociedad, La Habana, Ciencias Sociales.

ACOSTA, E. (1997), «El 98: un siglo de dudas, silencios y profecías», en Contracorriente (1997): 6-11.

ACOSTA, I. (1998), «Poderes y resistencias en la vida cotidiana de la ciudad de Caguas, 1897-1900», en S. Álvarez Curbelo et al., eds. (1998): 142-57.

AGosto, N. (1998), «Género y discurso religioso en el movimiento carismático en Puerto Rico: la Madre Elenita de la Santa Montaña», en S. Álvarez Curbelo et al., eds. (1998): 193-207.

AGRAIT, L. (1996), «Puerto Rico en el vórtice del 98: 'a prisa, a toda prisa, formemos patria'«, en C. Naranjo et al., eds. (1996): 97-108.

- (1997), «95+3: balance de un encuentro», en L.E. González Vales, ed. (1997): 435-46.

- (1998a), «El 98 en Puerto Rico», en El 98.. (1998): 15-34

- (1998b), «Puerto Rico del 98 al 98», en A. Gutiérrez y M.L. Laviana, eds. (1998)

- (1998-99), «Usos del pasado, usos del futuro en el Puerto Rico de 1898 \%, en M.T. Cortés et al., eds. (1998-99).

- (1999), «Puerto Rico del 98 al 98: frontera de culturas/culturas de frontera», en C. Naranjo y C. Serrano, eds. (1999)

- y A. Cubano, coords. (1997), Puerto Rico 1898, monográfico de Revista de Indias, 211.

AGURRE, S. (1965), Antecedentes históricos del movimiento obrero cubano, monográfico de Cuader nos de Historia, 2.

- (1968), Las clases sociales en el siglo XIX. Corrientes políticas e ideológicas, La Habana, UPEC.
A.LGRIA, R., ed. (en preparación), Obras clásicas pare la historia de Puerto Rico (CD-Rom), Colec. Clásicos Tavera, Serie I, Madrid, Fund. Histórica Tavera. «Algunas reflexiones sobre la guerra en Cuba en el período 1898-1898m, en Cuadernos... (1998): 3-10.

ALfA, F. (1998), «Recursos y registros de información bibliográfica: América continental y el Caribe», en J.G. Cayuela, coord. (1998): 41-60.

ALIENES, J. (1950), Características fundamentales de la economía cubana, La Habana, Banco Nacional.

ALMODÓVAR, C. (1987 y 1989), Antología crítica de la historiografia cubana (2 vols.), La Habana, Pueblo y Educación.

- (1989), «Historiografia realizada en Cuba (19591984)», Revista de Indias, 185: 173-91.

- (1993), «La temática independentista en la historiografía cubana», en ACI (1993): 62-71.

- (1995), «Martí en la mirada de Trujillo, José 1. Rodríguez y Collazo», en O. Loyola, coord. (1995): 115-34.

- (1996), «La escuela primaria cubana en el período de 'ocupación'«, en C. Naranjo et al., eds. (1996): 467-78.

- (1997a), «El 98 en Cuba abre las puertas al Kindergarten», en C. Almodovar, comp. (1997): 31-9.

- (1997b), «Balance sobre la historiografia cubana referida a los procesos de 1895 a 1898 », en M.R. Rodríguez, coord. (1997): 55-65.

- (1997c), «Cómo analizan los historiadores cubanos de la República las relaciones surgidas en el 98 entre Cuba y los EUA?, en La sociedad... (1997): 157 . 65.

-, comp. (1997), Nuestra común historia. Cuba y España. En torno al $98, \mathrm{La}$ Habana, Ciencias Sociales. -, ed. (1998), Máximo Gómez. Diario de Campaña (1868-1899), Oviedo, Univ. de Oviedo.

Alonso, C. (1993), "Consideraciones sobre la inmigración española: siglo XIX», en ACI (1993): 106-15.

- (1996), «Caracterización socio-demográfica dos combatientes espanois no exercito cubano (18951898), en Estudios Migratorios... (1998): 211-28.

ÁlVAREZ, E. (1988), Vida, mansión y muerte de la burguesía cubana, La Habana, Ciencias Sociales.

ÁLVAREZ, L. (1988), La diplomacia bismarkiana ante la cuestión cubana, 1868-1874, Madrid, CSIC.

- (1994), «Un proyecto de colonización alemana para la isia de Cuba en $1871 \%$, en C. Naranjo y $T$. Mallo, eds. (1994): 109-20.

- (1996), «El contexto internacional del noventa y ocho», en C. Naranjo et al., eds. (1996): 713-28.

- (1997), "Historiografia española sobre el 98», en M.R. Rodríguez, coord. (1997): $41-54$.

- (1998), "Tánger en la Guerra HispanoNorteamericana de $1898 \%$, Boletín de la Real Academia de la Historia, 1: 81-132.

- (1998-99), «El concierto de las naciones y la quiebra colonial española en el siglo XIX», en M.T. Cortés et al., eds. (1998-99).

ÁlVAREZ, R. (1986), La emigración cubana a los Estados Unidos, La Habana, Ciencias Sociales.

R. I., $1999, \mathrm{n}^{\circ} 215$ 
- (1988), Azúcar e inmigración, 1900-1940, La Habana, Ciencias Sociales.

ÁlVAREZ ÁlVAREZ, L. (1998), «98 y poesía cubana», en El 98 (1998): 116-34.

Álvarez Curbelo, S. (1997), «Despedidas», en L. Agrait y A. Cubano, coords. (1997): 783-99.

- (1998), «Las fiestas públicas de Ponce: politicas de la memoria y cultura cívica», en S. Álvarez Curbelo et al., eds. (1998): 208-31.

- (1999), «El pais de Luis Muñoz Rivera: cuerpo femenino y discurso viril», en C. Naranjo y C. Serrano, eds. (1999).

- et al., eds. (1998), Los arcos de la memoria. El ' 98 de los pueblos puertorriqueños, San Juan, Univ. de Puerto Rico.

AMORES, J.B. (1998), Cuba y España, 1868-1898. El final de un sueño, Pamplona, Enusa.

ANDERLE, A. (1998), «Cien años de guerra por Martí, en En torno al 98 (1998): 73-80.

ANDREO, J. (1999), «La Cuba real y la Cuba imaginaria a través del grabado del siglo XIX», en C. Naranjo y C. Serrano, eds. (1999).

ANES, P. (1993), La emigración de asturianos a América, Gijón, Júcar.

APARICIO, R. (1996), Homenaje a Antonio Maceo.

La Habana, Ciencias Sociales.

AQuino, E. (1998-99), «La crisis del 98 y la cuestión nacional en América Latina», en M.T. Cortés et al., eds. (1998-99).

ARANGUREN, D., ed. (en prensa), España y el 98, Madrid, Pablo Iglesias.

ARMAS, R. de (1975), La revolución pospuesta, La Habana, Ciencias Sociales.

- (1994), «José Martí: su República de mayoría populars, en C. Naranjo y T. Mallo, eds. (1994): $261-78$. - et al. (1984), Historia de la Universidad de La Habana (2 vols.), La Habana, Ciencias Sociales. - et al. (1985), Los partidos políticos burgueses en Cuba neocolonial, La Habana, Ciencias Sociales.

- y P.P. RoDRfGUEz (1996), «El pensamiento de Martí y la creación del Partido Revolucionario Cubano», en IHC (1996): 380-429. vitas.

ARREBOL.A, G. (1943), Historia de Nuevitas, Nue-

ARRIAGA, M.D. y A. DELGADO (1995), «Contribución al estudio de la vivienda pobre en La Habana del siglo XIX: ciudadelas y accesorías», Revista de Indias, 204: 453-84.

AYALA, C.J. (1990), Industrial Oligopoly and Vertical Integration: the Origins of the American Sugar Kingdom in the Caribbean, Ph. D., Univ. of New York.

- (1994), «La nueva plantación antillana», $O p$. Cii., 8: 123-65.

-(1995), «Social and Economic Aspects of Sugar Production in Cuba, 1880-1930\%, Latin American Resarch Review, 30/1: 95-124.

AZCÁRATE, P. (1968), La guerra del 98, Madrid, Alianza.

BALLESTEROS, M. (1996), «La población indígen de Boriquén», en Puerto Rico... (1996): 23-38.
BAHAMONDE, A. (1998a), «Cuba, corazón de Ultramar. Política y economía en las relaciones de las elites hispano-antillanas con España (1830-1868)», en J.G. Cayuela, coord. (1998): 225-44.

- (1998b), «Cuba, ¿perla económicas de las Antillas para España?, en $E / 98$... (1998): 47-60.

- coord. (1997), Cuba y el 98, monográfico de Studia Historica. Historia Contemporánea, 15.

- y J.G. Cayuela (1992), Hacer las Américas. Elites coloniales españolas en el siglo XIX, Madrid. Alianza.

$-y-(1997)$, «Traficantes, armadores y hacen dados: elite colonial hispano-cubana y trasvase de capitales en el siglo XIX», en A. Bahamonde, coord. (1997): 9-20.

Balboa, I. (1998a), «Más allá del final del imperio. Cuba y España en el Diario de la Marina», en Estudios de Historia Social... (1998).

- (1998b), «Bandidos y bandidos», en J.A. Piqueras, ed. (1998): 115-50.

- (1998c), «Colonización y poblamiento militar versus independencia. Cuba 1868-1895", en Rábida (1998): 121-38.

- (1998d), «Protesta nural e independencia nacional», en M.C. Barcia ef al. (1998): 200-71.

- (1998e), Reconstrucción, colonización e inmigración. Cuba, 1828-1895, tesis de licenciatura. Castellón, Univ. Jaume 1

BALTAR, E. (1997), «El contexto internacional del 98. Imperialismo y reparto colonial», en La sociedad... (1997): 7-20.

BANSART, A. (1999), «La amargura del azúcar: un mismo gusto en todas las literaturas caribeñas», en $\mathrm{M}$. Guicharnaud-Tollis, ed. (1999): 263-8.

BANTJES, A.A. (1998), «The Spanish-CubanAmerican War: a Cuban Perspective», en C. Mellizo y L. Núñez, coords. (1998): 103-32.

BARALT, G. (1993), Tradición de futuro: el primer Banco Popular de Puerto Rico, 1893-1993, San Juan, Banco Popular.

Barbosa, P. (1996), Un lustro crucial (18931895), San Juan, Univ. de Puerto Rico.

BARCHINO, M. (1998), «La literatura hispanoamericana de fin de siglo en publicaciones y revistas literarias españolas», en J.G. Cayuela, coord. (1998): 655-68.

BARCIA, M.C. (1987), Burguesía esclavista y abolición, La Habana, Ciencias Sociales.

- (1993), «La política de los grupos de presión de Cuba en España (1868-1870)», Santiago, 76: 116-38.

- (1994), «La esclavitud en la moderna historiografía americana, 1974-1994», Historia Social, 19: 89-98.

- (1996a), «Los deportados de la guerra. Cuba, 1895-1898», en C. Naranjo et al., eds. (1996): 635-46.

- (1996b), «La sociedad cubana en el ocaso colonial. Vida y cultura», en IHC (1996): 270-317.

- (1997a), «La experiencia del destierro: los deportados de las guerras de Cuba, 1869-1898», en Historia y Sociedad (1997): 29-50.

- (1997b), «Historia social ¿camino o encrucijada?», en En busca... (1997): 94-8. 
- (1997c), «Los primeros partidos políticos bur. gueses de Cuba», en C. Almodóvar, comp. (1997): 83-96.

- (1998a), «El 98 en La Habana: sociedad y vida cotidiana», en A. García Álvarez y C. Naranjo, coords. (1998): 85-100.

- (1998b), Elites y grupos de presión en Cuba, 1868-1899, La Habana, Ciencias Sociales.

- (1998c), «La esclavitud en Cuba. Caracteristicas de su desarrollo», en S. Palazón y C. Saiz Pastor, eds. (1998): 25-48.

- (1998d), «Los grupos de presión de la burguesía insular», en M.C. Barcia et al. (1998): 4-70.

- (1998e), «La historia profunda: la sociedad civil del $98 \%$, en $E l 98$ (1998): 27-33.

- (1998f), «Mujeres en torno a Minerva», en Rábida (1998): 99-106.

- et al. (1998), La turbulencia del reposo: Cuba, 1878-1895, La Habana, Ciencias Sociales.

- y M. HERNÁNDEZ (1996), «El reagrupamiento social y político. Sus proyecciones (1878-1895)», en IHC (1996): 209-69.

- y E. TORRES-CuEVAS (1994), «El debilitamiento de las relaciones sociales esclavistas», en IHC (1994): 401-63.

BarCIA PAZ, M. (1998), «La resistencia esclava en la plantación, 1790-1870", en Rábida (1998): 121-38.

BARNACH-CaLvo, E. (1996), «Lengua y educación en Puerto Ricom, en Puerto Rico... (1996): 39-46. BARNET, M. (1966), Biografía de un cimarrón, La Habana, Acad. de Ciencias.

- (1997), «Cuba y el 98 », en La sociedad... (1997): 114-5.

BARRERA. T. (1998a), «Luis Pales Matos y el antillanismo", en A. Gutiérrez y M.L. Laviana, eds. (1998).

- (1998b), «Nicolás Guillén y su concepción de la poesía mulata a través de la prosa», en A. Gutiérrez y M.L. Laviana, coords. (1998): $177-90$.

BARRETO, C.M. (1997a), «Un modelo de estrategia identitaria: los hermanamientos canarios-cubanos», en J.A. Galbán, ed. (1997): 1 I -8.

- (1997b), «Procesos sociales y rituales festivos en Cuba: 'lo nuestro' y 'lo de ellos'», en J.A. Galbán, ed. (1997): 111-24.

BARRETO, R. (1997), «Appurtenant and Belonging... But not Apart of: ¿por qué el gobierno de los Estados Unidos le negó a los puertorriqueños el derecho al gobierno propio?», en L.E. González Vales, ed. (1997): 447-63.

BATISTA, V. (1997-98), «Negociar o perder», S. Juliá, dir. (1997-98): 143-5.

BEJARANO, M. (1996), La comunidad hebrea de Cuba y la memoria histórica, Jerusalem. IAHJC, Univ. Hebrea de Jerusalem.

BELROSE, M. (1998), «Latinidad vs. imperialismo yanqui en El Cojo llustrado, 1898-1903», en Casa de las... (1998): 72-7.

Belnap, J. y R. Fernández, eds. (1998), José Marti's "Our American», Durham. Duke Univ. Press.

BENíteZ, A. (1997), «La cuestión del negro en tres momentos del nacionalismo literario cubanos, en A. Díaz Quiñones, ed. (1997): 275-88.
Benjamin, J.R. (1977). The United States and Cuba: Hegemony, Dependence and Development, 1880-1933, Pittsburgh, Pittsburgh Univ. Press.

BERGAD, L.W. (1983), Caffe and the Growth of Agrarian Capitalismo in Nineteenth Century in Porto Rico, Princenton, Princenton Univ. Press

- (1990), Cuban Rural Society in Nineteenth Century. The Social on Economic History of Monoculture in Matanzas, Princenton, Princenton Univ. Press.

- et al. (1995), The Cuban Slave Market, 17901880, Nueva York, Cambridge Univ. Press. BERNECKER, W.L. (1998a), «La inclusión de un Estado caribeño en la doctrina de la western hemisphere: el caso de Haití», en W.L. Bemecker, ed. (1998): 246-68. - (1998b), «Introducción», en W.L. Bernecker, ed. $(1998): 7-16$.

- ed. (1998), I898: su significado para Centro américa y el Caribe, monográfico de LateinamerikaStudien, 39.

BETHELl, L. ed. (1985-), Historia de América Latina (varios vols.), Barcelona, Crítica.

-, ed. (1993), Cuba. A Short Story, Cambridge, Cambridge Univ. Press.

BIANCHI, H. (1998), «Las ideas-fuerza», en $E l 98$ visto... (1998): 7-22

BINDER, W. (1998), «Miles \& More. 1898 and 'caballeros líricos'. Luis Muñoz Rivera and José de Diegos, en W.L. Bernecker, ed. (1998): 193-212.

BIZCARRONDO, M. (1998), «Entre Cuba y España: el dilema del autonomismo», en El 98 visto... (1998): 171-200.

-, ed. (1998), Rafael M. de Labra y otros, El problema colonial contemporáneo, Oviedo, Univ. de Oviedo.

BlanCO, J.A. (1996), «La actitud de Martí ante los españoles y la presencia de éstos en el Ejército Libertador Cubano», en J.P. Fusi y A. Niño, eds. (1996): 211-24.

- y C. Alonso (1996), Presencia castellana en el ejército libertador cubano, Salamanca, Junta de Castilla y León y UNED.

Bolfvar, N. (1989), Los Orishas en Cuba, La Habana, Letras Cubanas.

BothWell, R., comp. (1979), Puerto Rico. Cien años de lucha política (4 vols.), Río Piedras, Universitaria.

BRETOS, M.A. (1996), «Imaging Cuba under the American Flag: Charles Edward Doty in Havana, 1899-1902», en Cuba Theme... (1996): 82-103.

BUENO, S. (1997), «Las letras cubanas en 1898», en La sociedad... (1997): 116-7.

Burgos, E.M. (1997), Génesis y prásix de la carta autonómica de 1897 en Puerto Rico, San Juan, Centro de Estudios Avanzados de Puerto Rico y el Caribe, Inst. de Estudios Puertorriqueños y Fund. Luis Muñoz Marín.

- (1999), «El vernáculo como elemento aglutinante de la nacionalidad puertorriqueña: un nuevo discurso y un nuevo retor, en C. Naranjo y C. Serrano, eds. (1999).

En busca de la cubanidad (1997), monográfico de Debates Americanos, 3.

Bustamante, A.S. (1923), Discursos, La Habana. 
BUZNEGo, E. et al. (1986), Mayor General Máximo Gómez Báez. Sus campañas militares, La Habana, Ciencias Sociales.

- et al. (1996a), «La Revolución del 68. Ascenso militar y contradicciones políticas", en IHC (1996): 56-98.

- et al. (1996b), «La Revolución del 68. Cumbre y ocaso», en IHC (1996): 99-155.

- et al. (1997), «Las guerras del 95 e hispanocubana-norteamericana. Análisis militar», en M.R. Rodríguez, coord. (1997): 191

Caballero, M. (1996), «Puertorriqueños en la calle: El entierro de Cortijo de E. Rodríguez Juliá», en Puerto Rico... (1996): 47-64.

- (1998a), «El arpa y la sombra: penúltimos viajes del Almirante Colón", en A. Gutiêrrez y M.L. Laviana, coords. (1998): 141-60.

- (1998b), «Llegaron los americanos», en $E l 98$ visto... (1998): 293-8.

- (1998c), «Repercusiones del 98 en la actual narativa puertorriqueña», en A. Gutiérrez y M.L. Laviana, eds. (1998).

CABÁN, P.A. (1998), «El Consejo Ejecutivo y la 'norteamericanización' de Puerto Ricos, en El 98 (1998): 82-95.

CABrales, G. (1996), Epistolario de héroes. Cartas y documentos históricos, La Habana, Ciencia Sociales.

CABrera, J.G. (1997), Canarios en Cuba, Las Palmas, Cabildo Insujar de Gran Canaria.

CABRERA, L (1970), La sociedad secreta Abakúa narrada por viejos adeptos, Miami, CR.

- (1992), Cuentos negros de Cuba, Madrid, Icaria.

- (1993), El monte, Letras Cubanas.

CABRERA, O. (1985), Los que viven de sus manos, La Habana, Ciencias Sociales.

- (1993), «Los españoles en el movimiento obre ro cubano», en ACI (1993): 97-105.

- (1999), «Imágenes de la literatura y de la experiencia; españoles y cubanos en las fábricas de tabaco (siglo XIX)», en C. Naranjo y C. Serrano, eds. (1999).

CABRERA, R. (1923), La campaña autonomista. Artículos y discursos pronunciados en la Unión de Güines, 1878-1995, La Habana, Cervantes.

CABRERA, R.L. (1998), «Del auge vulnerable a la supervivencia: los peninsulares en suelo corozaleño los efectos del ' $98 \%$, en S. Álvarez Curbelo et al, eds. (1998): 232-48

CAIRO, A. (1997a), «Emilia Casanova y la dignidad de la mujer cubana», en Contracorriente (1997): 12-21.

- (1997b), «Los intelectuales del siglo XIX y la humillación permanente», en La sociedad... (1998): 143-50.

- (1998), «Contra el panhispanismo: de José Martí a Fernando Ortiz», en El 98 (1998): 96-106.

Calavera, A. (1994), «El sistema crediticio español en el siglo XIX y su reflejo en Cuba: los comerciantes banqueros», en C. Naranjo y T. Mallo, eds. (1994): $335-46$
- (1996), «Del 68 al 98. Oligarquia habanera y conciencia independentista», en C. Naranjo et al., eds. (1996): 109-22.

CALvaChe, A. (1944), Historia y desarrollo de la mineria en Cuba, La Habana.

CALvo, P. (1997), «La articulación de los intereses económicos castellanos antes del desastre», en J.P. Fusi y A. Niño, eds. (1996): 1-8.

CALvo, T. (1996), «Hispanos en U.S.A. La lengua como sangre común», en Puerto Rico... (1996): 65-82.

CAMACHO, E. (1998-99), «El cambio político cubano en la historiografía española», en M.T. Cortés $e$ al., eds. (1998-99).

CAMPOS, J.R. (1993-94), «La emigración gallega a América, 1880-1930. Integración y retorno», Minius. 2-3: 133-45.

CANCEL, M.R. (1998a), «La historiografia del ' 97 hasta la generación del ' 30 : de la historia a la ideología o viceversam, en J.E. Hernández, ed. (1998): 43-58.

- (1998b), «Mayagüez 1898: la ciudad y los manejos del poder», en S. Álvarez Curbelo et al, eds. (1998): 39-55.

CANTón, J. (1998), «José Martí, el 98 y la República Independiente», en Cuadernos... (1998): 143-55.

- et al. (1997), «Nacionalismo, patriotismo y emancipación», en Contracorriente (1997): 118-41.

CARANDELL, L. (1997-98a), «Quién mató a Maceo?», en S. Juliá, dir. (1997-98): 180.

- (1997-98b), «Remember the Maine», en S. Juliá, dir. (1997-98): 116

- (1997-98c), «Un soldado del 98», en S. Juliá, dir. (1997-98): 68 .

- (1997-98d), «El testimonio de Cajal», en S. Juliá, dir. (1997-98): 52

CÁRDENAS, E. et al., eds. (1999), The Export Age: the Latin American Economies in the Late Nineteenth and Early Twentieth Centuries, Londres, Macmillan y México, FCE (versión en español).

CARdona, G. y J.C. Losada (1997), Nuestro hombre en La Habana, Barcelona, Planeta.

CARPENTIER, A. (1989), Ecue yamba o, Madrid, Alianza.

«Carta Autonómica de 1897» (1998), en J.E. Hernández, ed. (1998): 91-106.

Casa de las Américas (1998), 211. (monográficao sobre 1898)

CASANOVAS, J. (1995a), «El asociacionismo burgués y proletario en Cuba de los años 1870 a inicio de los 1880», en J. Opatmý, ed. (1995): 97-116.

- (1995b), Labor and Colonialism in Cuba in the Second Half of the Nineteenth Century. Ph. D. Ann Arbor, Michigan, UMI

- (1995c), «Movimiento obrero y lucha anticolonial en Cuba después de la abolición de la esclavitud", Boletín Americanista, 1995: 157-79.

- (1996), «El movimiento obrero y la política colonial española en la Cuba de finales del siglo XIX», en C. Naranjo et al., eds. (1996): 363-76.

- (1997), «El movimiento obrero cubano: del reformismo al anarquismo», en Historia y Sociedad (1997): $77-110$. 
- (1998a), Bread, or Bullets! Urban Labor and Spanish Colonialism in Cuba. 1850-1898, Pittsburgh, Pittsburgh Univ. Press.

- (1998b), «El movimiento obrero cubano durante la Guerra de los Diez Años (1868-1878)», en En torno al 98 (1998): 243-66.

- (1998c), «Los trabajadores urbanos y la política colonial española en Cuba desde la Paz de Zanjón hasta la Guerra de Independencia (1879-1898)», en W.L. Bernecker, ed. (1998): 131-52.

- coord. (1997), 1898. La fi d'un imperi, monográfico de L'Avenç. Revista de Historia, 217.

CASSÁ, R. (1998), «Perfiles históricos e ideológicos del antillanismo», en A. Gutiérrez y M.L. Laviana, eds. (1998).

CASTAÑEDA, D. (1998), «El Caribe colonial en 1898: ruptura y continuidad», en El 98 (1998): 69-81.

CASTILlo, Y. et al. (1998), La crisis del 98, monográfico de BIHES, 8 (Madrid, CINDOC).

CASTRO, M.A. (1997a), «El '98 incesante: persistencia y evolución en la memoria puertorriqueña», en L.E. González Vales, ed. (1997): 17-42.

- (1997b), «¿A qué pelear si los de Madrid no nos quieren? Una revisión criolla de la guerra del 98 en Puerto Ricos, en L. Agrait y A. Cubano, coords. (1997): 657-94.

- (1998-99), «El 98 en dos tiempos: de los sepultureros de España a la crónica de la guerra», en M.T. Cortés et al., eds. (1998-99).

CAYuela, J.G. (1993), Bahía de Ultramar. España y Cuba en el siglo XIX. El control de las relaciones coloniales, Madrid, Siglo XXI.

- (1994), «El nexo colonial de una transición: elite antillana y capitanes generales en Cuba», en C. Naranjo y T. Mallo, eds. (1994): 239-48.

- (1996), «1898: el final de un Estado a ambos lados del Atlántico», en C. Naranjo et al., eds. (1996): $391-404$.

- (1997), «Relación colonial y elite hispanocubana en la España del siglo XIX», en A. Bahamonde, coord. (1997): 21-34.

- (1998a), «Formación histótica y quiebra de un Estado a ambos lados del Atlántico. Del descubrimiento a los acontecimientos del desastre (14921898)», en J.G. Cayuela, coord. (1998): 131-222.

- (1998b), «Introducción y método: el crisol», en J.G. Cayuela, coord. (1998): 23-38

- coord. (1998), Un siglo de España: centenario, 1898-1998, Cuenca, Univ. de Castilla-La Mancha.

CEPEDA, R. (1997), «En la entraña del 98: un fenómeno histórico", en La sociedad... (1997): 112-3.

CEPERO, R. (1947), Azúcar y abolición. Apuntes para una historia crítica del abolicionismo, La Habana, Cénit.

Cervera, J. (1998), El Almirante Cervera. Un marino ante la historia, Madrid.

CÉsPEDES, C.M de (1997), «Valoración personal —brevemente expresada- del significado de 1898 y de la conmemoración centenarias, en La sociedad... (1997): 106-11.

CÉSPEDES, O. (1995), «La historia social frente a la historia de las personalidades: Carlos Manuel de Céspedes», en ACl (1995): 40-7.

R. I., $1999, \mathrm{n}^{\circ} 215$
Chang, F. (1975), «Los militares y el ejército en la República Neocolonial. Las tres primeras décadas», en La República Neocolonial I, (1975): 187-207. Chanan, M. (1998), «De regreso al principio: 1898 y el cine en Cuba», en El 98 (1998): 143-51. ChapMan, Ch. E. (1926), A History of Cuban Republic, Nueva York, McMillan.

Chía, J.A. (1977), El monopolio del jabón y del perfume en Cuba, La Habana, Ciencias Sociales.

Ciencia en Cuba (1991), monográfico de Asclepio, 43/2.

CINTRÓN, R.L. (1998), «Los comerciantes de Guayana: intercambios y control en el 98», en $S$. Álvarez Curbelo et al., eds. (1998): 249-59.

COCHRAM, T. (1959), The Puerto Rico Businessman, Philadelphia, Univ. of Pennsyvania Press.

COLL Y TOSTE, C. (1985), La invasión americana

de Puerto Rico, Santo Domingo, Corropio.

COLLAZO, E. (1989), «Crédito y proyectos bancarios en Cuba durante el siglo XIX», Boletín del Archivo Nacional, 3: 67-102.

- (1996), «Las formas de crédito bancario. Tránsito y ruptura en la Cuba de entresiglos», en C. Naranjo et al., eds. (1996): 283-93.

COMPANYS, J. (1996), wLa reina regente y los intentos de paz antes del $98 \%$, en J.P. Fusi y A. Niño, eds. (1996): 389-96.

- (1998), La prensa amarilla norteamericana en 1998, Madrid, Sílex.

CONDE, A. (1997), «Historia y nación en Emilio Roig de Leuchsenring», en En busca... (1997): 29-38. CONTE, R. y J.M. CaPMANY (1912), Guerra de razas, La Habana, Imp. Militar Pérez.

Contracorriente (1997), 9.

CORBEa, J. (1996), «La Virgen de la Caridad del Cobre: construcción simbólica y cultura popular», en Cuba/España (1996): 4-11.

CORDovi, Y. (1998), «Campaña de la Reforma: el arte de la defensa activa», en Cuademos... (1998): 85-94. CORTÉs, M.T. (1995), «Análisis historiográfico de Cuba contemporánea», en J. Opatrný, ed. (1995): 47-58. - (1997), «La memoria nacional puertorriqueña en Salvador Brau», en L. Agrait y A. Cubano, coords. (1997): 761-82.

- (1998-99), «Ciencia y nación en Román Baldorioty de Castro", en M.T. Cortés et al., eds. (1998).

- (1999), El Partido Autonomista puertorriqueño y el trasfondo social y cultural de la formación nacional, Ph. D., Madrid, Univ. Complutense.

- et al. eds. (1998-99), El Caribe y América Latina: el 98 en la coyuntura imperial, Morelia, Univ. Michoacana San Nicolás de Hidalgo, Univ. de Puerto Rico y CSIC.

- y M.R. RodRfGUez (1997), «América Latina y los Estados Unidos. La expansión en el Caribe y Centroamérica en el concierto de 1898", en M.R. Rodríguez, coord. (1997): 188.

CRIADO. M. (1996), «Panorámica de nuestra lengua para mayores de edad», en Puerto Rico... (1996): 95-106.

CRISTóbal A. (1997), «La nación cubara y la Revolución de 1959», en Contracorriente (1997): 32-9. 
CRUZ, J.L. (1997), «Proceso migratorio de Villa de Mazo e inserción en la cultura del trabajo tabacalero cubano», en J.A. Galbán, ed. (1997): 47-62.

Cuadernos Cubanos de Historia (1998), 1 (monográfico sobre 1898) 25 .

Cuba/España (1996), monográfico de Del Caribe,

Cuba Theme Issue (1996), monográfico de The Journal of Decorative and propaganda Arts (1996), 22. Cubano, A. (1990), El hilo en el laberinto. Cla ves de la lucha política en Puerto Rico, Río Piedras. Huracán.

- (1993), Un puente entre Mallorca y Puerto Rico: la emigración de Sóller (1830-1930), Gijón, Júcar.

- (1996), «El autonomismo en Puerto Rico, 1887 1898: notas para la definición de un modelo de política radical», en C. Naranjo et al., eds. (1996): 405-16.

- (1997a), «Comercio, moneda y politica en Puerto Rico a finales del siglo XIX: una perspectiva socio-económica», en L.E. González Vales, ed. (1997): 209-20.

- (1997b), «Criollos ante el 98: la cambiante imagen del dominio español durante la crisis y caída en Puerto Rico, I898- 1898", en L. Agrait y A. Cubano, coords. (1997): 637-56.

- (1997c), «Politica colonial y autonomismo en Puerto Rico, 1887-1897: renovación y conflicto en el Partido Autonomista Puertorriqueño», en J.P. Fusi y A Niño, eds. (1997): 151-62.

- (1997-98), «Los autonomistas de Puerto Rico», en S. Juliá, dir. (1997-98): 155-7.

- (1998a), «Los debates del autonomismo y la Carta Autonómica en Puerto Rico a finales del siglo XIX», en J.E. Hernández, ed. (1998): 17-28.

- (1998b), «Political Culture and Male MassParty Formation in Late-Nineteenth-Century Puerto Rico», en Hispanic... (1998).

- (1998c), «Reflexiones en torno al 98 en Puerto Rico y la crisis del colonialismo español», en 1898 . desastre... (1998): 213-22.

- (1998d), «Sociedad e identidad nacional en Cuba y Puerto Rico: un acercamiento comparativo (1868 1898)», en Op. Cit. (1998): 7-24.

Damiani, J. (1998), «El hato cangrejero que se transformó en suburbio: Santurce al filo del 98», en S Álvarez Curbelo et al., eds. (1998): 11-18.

DASH, M. (1997), «Juicio a la Créolité: perspectivas sobre la identidad del Caribe francés en el fin de siglo», en A. Díaz Quiñones, ed. (1997): 165-75.

DÁvilA, A. (1997), «El Vaticano y la crisis del '98», en L.E. González Vales, ed. (1997): 371-80.

Debates Americanos (1998), 5. (monográfico sobre 1898).

DEERE, C.D. (1998), «Here Come the Yankees! The Rise and Decline of United States Colonies in Cuba, 1898-1939», en Hispanic... (1998)

DEERR, N. (1950), The History of Sugar (2 vols.), Londres, Chapman \& Hall.

La demografia Cubana ante el $V$ Centenario (1992), La Habana, Ciencias Sociales.
Deschamps, P (1979), El negro en la economía habanera del siglo XIX, La Habana, UNEAC.

DíaZ, J. (1997-98a), «Pascual Cervera», en S. Juliá, dir. (1997-98): 147.

- (1997-98b), «La rendición de Santiagom, en S Juliá, dir. (1997-98): 133-7.

- (1997-98c), «Theodore Roosevelt», en S. Juliá, dir. (1997-98): 146.

DiAZ, Y. (1994), «Dos ejércitos en lucha, tácticas y estructuras militares en la Guerra de Cuba, 1895 1898", Revista Complutense de Historia de América 20: $257-76$.

- (1996a), «Algunas consideraciones sobre el ejército español de operaciones de Cuba, 1895-1898", en J.P. Fusi y A. Niño, eds. (1996): 151-60.

- (1996b), «Un episodio español poco conocido. La evacuación militar de Cuba en 1898 ", en J.P. Fusi y A. Niño, eds. (1996): 143-50.

- (1998a), «Calixto García, artífice de la campaña de Oriente», en Cuadernos... (1998): 95-106.

- (1998b), «España abandona Cuba. La evacuación militar de 1898", en J.A. Piqueras, ed. (1998): 179-200.

- (1998c), «La sanidad militar del ejército espanol en la Guerra de 1895 en Cuba», Asclepio, 50/1: 159-73.

- (1998-99), «Sobre la vida del soldado español en la guerra de Cuba: mito y realidad», en M.T. Cortés et al., eds. (1998-99)

DIAZ QUIÑNONE, A. (1997), «Martí: la guerra desde las nubes», en A. Díaz Quiñones, ed. (1997): 201-26.

- (1997-98), «Entre dos 'noventa y ochos'», en S. Juliá, dir. (1997-98): 158-9.

- (1998a), «1889», en Hispanic.. (1998)

- (1998b), «1898: hispanismo y guerra», W.L. en Bernecker, ed. (1998): 17-36.

-, ed. (1997), El Caribe entre imperios (Coloquio de Princenton), monográfico de Op. Cit., 9.

DIETL, R. (1998), «American Expansion: from Jeffersonianism to Wilsonianism. The United States and its Southern Neighbours at the Turn of the Centurym, en W.L. Bernecker, ed. (1998): 47-60.

DIETZ, J. (1986), Economic History of Porto Rico, Princenton, Princenton Univ. Press.

DIEZ, A.R. et al. (1995), De la ciencia ilustrada a la ciencia romántica, Aranjuez, Doce Calles.

«Documentos-monumentos» (1997), en La Sociedad... (1997): 195-207.

DOMINGo, M.D. (1991), «Bibliografía», en Cuba (1991), monográfico de Síntesis, 15: 441-62.

- (1992), «Las expediciones a Cuba: apoyo a la insurrección cepedista, 1868-1878", Revista Complutense de Historia de América, 18: 241-56.

- (1994), «La participación de los españoles en el movimiento liberador cubanos, en C. Naranjo y $T$. Mallo, eds. (1994): 167-82.

- (1996), «Los españoles en Cuba y su participación en la Guerra de Independencia», en C. Naranjo et al., eds. (1996): 647-62.

- (1997), «Los Cuerpos de Voluntarios en la Guerra de los Diez Años en Cuba, 1868-1878\%, en Historia y Sociedad (1997): 51-76. 
- (1998), «Rafael María de Labra ante la cuestión de Cuba, 1898», en En torno al 98 (1998): 153-64.

DOMínGUEZ, M. (1998), «Modelos linguííticos en contienda: hacia un nuevo 98", en El 98 (1998): 135-42.

DORRIES, R.R. (1998), «1898: a New American Begining or Historial Continuity?», en W.L. Bernecker, ed. (1998): 37-46.

DUHARTE, R.A. (1998), «La situación del negro cubano dentro de la coyuntura de fin de siglo», en Estudios de Historia Social... (1998).

DumoulíN, J. (1965), «Monocultivo y proletarización: dos ejemplos en Las Villas», Ciencias Sociales Contemporáneas, 56: 31-56.

- (1974), «El primer desarrollo del movimiento obrero y la formación del proletariado en el sector azucarero. Cruces, 1886-1902», Islas, 48: 97-121.

DURNERIN, J. (1999), «Le sucre dans El siglo de las luces, d'Alejo Carpentier», en M. GuicharnaudTollis, ed. (1999): 287-96.

DYE, A.D. (1991), Tropical Technology and Mass Production: the Expansion of Cuban Sugarmills, 18991930, Ph. D., Urbana-Champaign, Univ. of Illinois at Urbana-Champaign.

- (1993), «Producción en masa del azúcar cubano, 1899-1929. Economías de escala y elección de técnicas», Revista de Historia Económica, XV/1: 563-94.

- (1994a), «Avoiding Holdup: Asset Specifity and Technical Change in the Cuban Sugar Industry, 1899-1929», The Journal of Economic History, 54/2: $628-53$.

- (1994b), «Cane Contracting and Renegotiation: A Fixed Effects Analysis of the Adoption of New Technologies in the Cuban Sugar Industry, 1899. 1929», Explorations in Economic History, 31: 141-75.

- (1998), Cuban Sugar in the Age of Mass Production: Technology and Economics of Cuban Sugar Central, 1899-1929, Nueva York, Stanford Univ. Press.

ELIZALDE, M.D. (1997-98), «España en el reparto del mundom, en S. Juliá, dir. (1997-98): 170-73.

- (1998), «Política exterior y política colonial de Antonio Cánovas. Dos aspectos de una misma cuestión", en J. Tusell y F. Portero, eds. (1998): 233-88.

Elorza, A. (1996), «El sueño de Cuba en José Martí», en C. Naranjo et al., eds. (1996): 65-78.

- y E. HERnÁNDEZ SANDOICA (1998), La guerra de Cuba (1895-1898). Historia política de una derrota colonial. Madrid, Alianza.

ELY, R.T. (1963), Cuando reinaba su majestad el azúcar, Buenos Aires, Sudamérica.

ERICE, V. (1996), «Los asturianos en Cuba y sus vínculos con Asturias: rasgos y desarrollo de una colectividad regional en la etapa final del colonialismo español», en P. Gómez, coord. (1996): 71-152.

ESCRIBANO, T. (1998), «La industria de la caña, la esclavitud y la música colonial en Cuba», en Rábida (1998): 99-106.

ESPADAS, M. (1996), «Lecturas históricas del 98», en Naranjo et al., eds. (1996): 697-712.

- (1997), «El Ejército y la Marina antes del 98», en J.P. Fusi y A. Niño, eds. (1997): 75-84.
- (1998), «El 98 en perspectiva internacional», en J.G. Cayuela, coord. (1998): 359-78.

España 1898: Ocaso colonial (1998), dossier de La Aventura de la Historia, 2.

ESTEBAN, A. y A. MORENO (1998), "Martí y la raza indígena», en lbero Americana Pragensia (1998): 65-75. ESTRADE, P. (1987), José Martí (I853-95) ou des fondements de la démocratie en Amérique Latine, (3 vols), Paris, Caribeennes.

- (1993), Les écrits de Betances dans la Republique Cubaine, Saint Denis, Historie des Antilles Hispaniques, 1993.

-(1994), «Los colonos yucatecos como sustitutos de los esclavos negros», en C. Naranjo y T. Mallo, eds. (1994): 93-108.

- (1995a), «A dónde se encaminaba el llamado Movimiento Económico (1890-1993)?», en J. Opatrný, ed. (1995): 117-42.

- (1995b), «José Martí, ¿Una biografía imposible?», Revista de Indias, 205: 573-96.

- (1996), (La nación antillana: suelo y afán de 'EI Antillano' (Betances)», en C. Naranjo et al., eds. (1996): 25-36

- (1998a), José Martí Los fundamentos de la democracia en América Latina, Aranjuez, Doce Calles.

- (1998b), «La última guerra de independencia desde la perspectiva antillana», en En torno al 98 (1998): 23-37.

- (1998-99), «El acercamiento filipino-cubano en la guerra contra España», en M.T. Contés et al., eds. (1998-99).

- (1999), «El autonomismo criollo y la nación cubana (antes y después del 98)», en C. Naranjo y C. Serrano, eds. (1999).

Estudios de Historia Social (1988), 44-47, (monográfico sobre Cuba).

Estudios de Historia Social y Económica de América (1998), 17, (monográfico sobre 1898).

Estudios Migratorios (1996), 2.

ETTE, O. Y T. HEYDENREINCH, eds. (1994), José Marti 1895/1995. Literatura-politica-filosofía-estética, monográfico de Lateinamerika Studien, 34.

FELICIANO, H.R. (1998), «Factores precipitantes de la Carta Autonómica de 1897», en J.E. Hernández, ed. (1998): 1-16.

FELL, C. (1999), «Representación simbólica de España, Puerto Rico y Cuba en La peregrinación de Bayoán de Eugenio María de Hostos", en C. Naranjo y C. Serrano, eds. (1999).

FERmoselle, R. (1998), Política y color en Cuba. La guerrita de 1912, Madrid, Colibrí.

FERNÁNDEZ, A.M. (1988), España-Cuba, 18681898. Revolución burguesa y relaciones coloniales, La Habana, Ciencias Sociales.

- (1996), «La presencia española en Cuba después de 1898. Su reflejo en el Diario de la Marina'», en C. Naranjo et al., eds. (1996): 509-18.

- (1997a), «Asturias y Cuba en trono a 1898», en C. Almodóvar, comp. (1997): 62-71.

- (1997b), «España y la crisis del 98», en La sociedad... (1997): 33-49.

R. $1 ., 1999, \mathrm{n}^{\circ} 215$ 
- (1997c), «En torno al 98: época de transición», en M.R. Rodríguez, coord. (1997): 185.

- (1998a), «Desastre, realidad, regeneracionismo. España y el 98», en El 98 (1998): 62-8.

- (1998b), «La diplomacia del 98 desde el ámbito cubanom, en J.G. Cayuela, coord. (1998): 345-58.

- (1998c), «España y Cuba: ruptura y continuidad en el 98», en Casa de las... (1998): 78-83.

- (1998d), «España y Cuba: ruptura y continuidad en las sociedades cubana y española en el tránsito de siglo», en J.G. Cayuela, coord. (1998): 427-36.

-, ed. (1998), Cuba y el 98, CD-Ron, La Habana. FERNÁNDEZ, I. (1997), «El '98 en Puerto Rico: enfoques y perspectivas», en L.E. González Vales, ed. (1997): 405-34.

FernándeZ, S. (1987), Banking, Credit and Colonial Finances in Cuba, 1878-1895, Ph. D., Michigan, Ann Arbor, UMI.

FERNÁNDEZ, T. (1990), El negro en Cuba, 1900 1958, La Habana, Ciencias Sociales.

FERNÁNDEZ-MARTÍNEZ, L. (1995), «Life in a 'Male City'. Native and Foreign Elite Woman in Niniteenth Century", Cuban Studies, 25: 27-49.

- (1998a) «Don't Die Here. The Death and Burial of Protestant in the Hispanic Caribbean, 1840-1885\%, The Americas, 64/1: 23-48.

- (1998b), Fighting Slavery in the Caribbean. The Life of a British Family in Nineteenth-Century Havana, Nueva York, Sharpe

FERNÁNDEZ DE PINEDO, E. (1993), La emigración vasca a América (siglos $X I X$ y $X X$ ), Colombres, Archivo de Indianos.

FERNÁNDEZ Prieto, L. (1998), «Cuba y el Parlamento español (1878-1890), en J.A. Piqueras, ed (1998): $151-78$

- (1999), «La agricultura cubana a finales del siglo XIX: ciencia y economía», Actas del V Congreso de Latinoamericanistas Españoles, La Palmas de Gran Canaria (en prensa)

- (en prensa), «Competencia o rentabilidad?: la diplomacia del azúcar, 1878-1895». Se publicará en una monografía que prepara C. Parcero (título sin determinar).

- y R. FunEs (1998-99), «Prensa legal y revolución en Cuba: 1895", en M.T. Cortés et al., eds. (1998-99).

FERNÁNDEZ SOSA, M. (1996), "Construyendo la nación: proyectos e ideología en Cuba, 1899-1909'«, en C. Naranjo et al. eds. (1996): 123-30.

FERRAO, L.A. (1996), «Puerto Rico y Cuba 1898: ¿transición hacia la modernidad?», en C. Naranjo et al., eds. (1996): 567-74.

FERRER, A. (1995a), «Esclavos, ciudadanía y los límites de la nacionalidad cubana: la Guerra de los Diez Años, 1868-1878\%, Historia Social, 22: 117-39.

- (1995b), To Make a Free Nation: Race and the Struggle for Independence in Cuba, 1868-1989, Ph. D. Michigan, Univ. of Michigan.

- (1998), «Rustic Men, Civilized Nation: Race, Culture and Contention on the Eve of Cuban Independence», en Hispanic... (1998).

FERRES, J. (1990), Antillanismo y anticolonialis mo en Betances, Hostos y Máximo Gomez, Río Piedras, Univ. de Puerto Rico, 1990.
FIEBIG-Von HASE, R. (1998), «The German Challenge to American Hegemony in the Caribbean: the Venezuela Crisis of 1902/1903\%, en W.L. Bernecker, ed. (1998): $77-112$

Figarola, J.J. (1996), «Apuntes sobre la crisis de posesión en Cuba», en Cuba/España (1996): 12-5.

Figuero, J. y C. Garcia Santa Cecilia (1997), La España del desastre, Barcelona, Plaza \& Janés.

- (1998), 1898, suplemento diario de El Mundo (Madrid).

FigueroA, A. (1998), «1898 y Panamá: ¡cesura, cambio o continuidad?», en W.L. Bernecker, ed. (1998): 237-46.

FIGUEROA, J. (1997), «Cuba, el reformismo y la Universidad del Aire (1949-1950)», en Historia y Sociedad (1997): 129-44

FIGUEROA, R. (1998a), «El Correo Español: la prensa españolista mexicana y el 98 », en El 98 visto... (1998): 87-98

- (1998b), «Dos neutralidades comparadas. España ante la invasión norteamericana a México (1846 1848); México ante la guerra hispano-cubanaamericana», en $E l 98 \ldots$ (1998): 107-48.

FISCHER, T. (1998), «Fin de siglo en Colombia: la Guerra de los Mil Días en el contexto internacional», en W.L. Bernecker, ed. (1998): 213-26.

FLORES, M. (1998), «La lucha por definir la nación: el debate en torno a la creación del Instituto de Cultura Puertorriqueña, 1955», en Op. Cit. (1998): 175-200.

FONER, P.S. (1973), Historia de Cuba y sus relaciones con los Estados Unidos (2 vols.), La Habana, Ciencias Sociales.

- (1978), La guerra hispano-cubana-norteamericana y el surgimiento del imperialismo yanqui, La Habana, Ciencias Sociales.

FRADERA, J.M. (1997), «Quiebra imperial y reorganización política en las Antillas españolas, 18101868», en A. Díaz Quiñones, ed. (1997): 189-216.

- (1999), Gobernar colonias, Barcelona, Península. Fralle, P. (1997-98), «iFue realmente un desastre», en S. Juliấ, dir. (1997-1998): 203-5.

- et al. (1993), «El caso cubano», en L. Prados y S. Amaral, eds. (1993): 31-52.

- y A. EsCRIBANo (1998), "The Spanish 1898 Disaster: the Drift Towards National-Proteccionism», en P.K. O'Brien y L. Prados, eds. (1998): 291-322.

FRANCÉs, M. (1998), «Guayama: resentimientos soterrados y ajustes de cuentas», en S. Álvarez Curbelo et al, eds. (1998): 128-41.

FRANCO, J.L. (1967-68), La batalla por el dominio del Caribe y el Golfo de México (3 vols.), La Habana.

- (1975), Antonio Maceo. Apuntes para una historia de su vida (3 vols.), La Habana, Ciencias Sociales.

FrIEDLAENDER, H. (1944), Historia económica de Cuba (2 vols.), La Habana, J. Montero.

FREYRo, B. (1996), «La situación del soldado en Cuba vista desde el Parlamento», en J.P. Fusi y A. Niño, eds. (1996): 161-72.

FUENTE, A. de la (1995), «Race and Inequality in Cuba, 1899-1981", Journal of Contemporary History, 30: $131-68$. 
- (1996), «Negros y electores: desigualdad y políticas raciales en Cuba, 1900-1930", en C. Naranjo et al., eds. (1996): 163-78.

- (1997), «Two Dangers, One Solution: Inmigration, Race and Labor in Cuba, 1900-1939», International Labor Working Class History, 51: 7-29.

Fundación dE LOS FERROCARRILES EsPañoles (1989), El Camino de Hierro La Habana-Güines, Madrid.

FUSI, J.P. y A. Niño, eds. (1996), Antes del desastre. Orígenes y antecedentes de la crisis del '98. Madrid, Univ. Complutense.

- y -, eds. (1997), Vísperas del 98. Origenes y antecedentes de la crisis del 98 , Madrid, Biblioteca Nueva.

GALBÁN, J.A. (1997a), «De Cánarias a Cuba (1875-1930): causas de la emigración, el viaje y los asentamientos», en J.A. Galbán, ed. (1997): 21-34.

- (1997b), «isleño, come gofio!: identidad y adaptación sociocultural en Cuba», en J.A. Galbán, ed. (1997): 69-80

- (1997c), «Tipos de emigración, procesos de trabajo e inserción laboral de los canarios en Cuba», en J.A. Galbán, ed. (1997): 35-46.

-, ed. (1997), Canarios en Cuba. Una mirada desde la antropologia, Santa Cruz de Tenerife, Cabildo insular de Tenerife.

GARCíA, F.A. (1998-99), «El conservadurismo chileno a finales del siglo XIX», en M.T. Cortés $e t$ al., eds. (1998-99).

GARClA, G.L. (1997a), «Los anexionismos crioIlos en la coyuntura del 98», en M.R. Rodríguez, coord. (1997): 190

- (1997b), «El otro es uno: Puerto Rico en la mirada norteamericana de 1898 », en L. Agrait y A Cubano, coords. (1997): 729-60.

$-(1997 \mathrm{c})$, «Strangers in paradise? Puerto Rico en la correspondencia de los cónsules nonteamericanos (1868-1900)», en A. Díaz Quiñones, ed. (1997): 27-55.

- (1998-99), «Puerto Rico propio y ajeno: prospecto para centenaristas del $98 \%$, en M.T. Cortés et al., eds. (1998-99).

GARCía, I. (1998), «Voluntarios españoles del Rió de la Plata en la Guerra de Cubas, en El 98 visto.. (1998): 113-28.

GaRCía, J.S. (1998), «El entorno agrario. Cambios y marcos productivos desde las dos riberas del Atlántico», en J.G. Cayuela, coord. (1998): 833-42.

GARCíA, V. (1996), «Nuestra lengua en Puerto Ricom, en Puerto Rico... (1996): 107-14.

García Álvarez, A. (1990), La gran burguesía comercial en Cuba, La Habana, Ciencias Sociales.

- (1991), Algunos aspectos de la realidad sociocultural cubana en las tres primeras décadas del siglo $X X, \mathrm{La}$ Habana, Ciencias Sociales.

- (1993a), "Testimonio: literatura e historia oral", en $\mathrm{ACl}$ (1993): $71-9$.

- (1993b), «Los traficantes del golfo», Historia Social, 17: 33-46.

- (1994), «Una saga azucarera en torno a dos siglos», en J. Uría, ed. (1994): 43-56.

R. $1 ., 1999, \mathrm{n}^{\circ} 215$
- (1995a), «Antecedentes de la dominación neocolonial de Cuba por el imperialismo norteamericano», en A. García Álvarez y C. Planos (1995): 4-44.

- (1995b), «Esquema para una historia general de Matanzas», La Formación del Historiador, 14: 37-57.

- (1996), «Estructuras de una economía colonial en transición», en C. Naranjo et al., eds. (1996): 195-210.

- (1997a), «Cuba: una etapa en la trayectoria caribeña del henequén», en Historia y Sociedad (1997): 7.28 .

- (1997b), «Después de la guerra: una república azucarera en auge», en A. Bahamonde, coord. (1997): 115-34.

- (1998a), «El 98, un puente para el desarrollo del neocolonialismo en Cuba», en S. Palazón y C. Saiz Pastor, eds. (1998): 119-39.

- (1998b), «Cuba y los Estados Unidos después del 98", en J.G. Cayuela, coord. (1998): 419-24.

- (1998c), «Metamorfosis de una institución financiera: el Banco Español de la Isla de Cuba», en J.A. Piqueras, coord. (1998): 117-36.

- (1998-99), «La trama colonial-neocolonial ante el 98», en M.T. Cortés et al., eds. (1998-99).

- et al. (1972), La categorización de los ingenios azucareros, monográfico de Cuadernos de Humanidades, 2.

- y L.M. GaRCía MORA, eds. (1998), Obras clásicas para la historia de Cuba (CD-Rom), Colec. Clásicos Tavera, Serie I, Madrid, Fund. Histórica Tavera.

- y M. MARTf (en preparación), Historia del banano en Cuba, La Habana (título provisional).

- y C. NARANJo (1998), «Cubanos y españoles después del 98: de la confrontación a la convivencia pacífica», en A. García Álvarez y C. Naranjo, coords. (1998): 101-30.

- y - coords. (1998), Cuba 1898, monográfico de Revista de Indias, 212.

- y C. Planos (1995), Historia de Cuba HI, en Historia de Cuba (1989-).

GARCIA BERNAL, M.C. (1998), «La economía cubana en la disyuntiva del 98 ", en A. Gutiérrez y M.L. Laviana, coords. (1998): 73-82.

GARCfa BlaNCO, R. (1996), «La ciencia en Cuba a finales del siglo XIX», en C. Naranjo et al., eds. (1996): 455-66.

- (1997), «Francisco de Albear, un héroe de la ciencia», en La sociedad... (1997): 141-7.

Garcla Carranza, A. (1995), «La bibliografía cubana: inventario de nuestra culturam, en ACI (1995): 143-66.

Garcla GonzAlezZ, A. (1994), «En torno a la antropología y el racismo en Cuba en el siglo XIX», en C. Naranjo y T. Mallo, eds. (1994): 45-64.

- (1995), «Racismo, ciencia y autonomismo en Cuba", en A.R. Díez et al. (1995): 169-82.

- (1996), «Ciencia y racismo en la enseñanza de la biología en Cuba», en C. Naranjo et al., eds. (1996): 479-96.

- (1998a), «Etnografía y racismo en la enseñanza de la geografía en Cuba a finales del siglo XIXm, en Estudios de Historia Social... (1998). 
- (1998b), «Eugenesia, inmigración y 'mejoramiento racial' en Cuba, 1900-1940», en Rábida (1998): $51-66$.

- (1999), «Empatías y conflictos en las relaciones científicas hispano-cubanas a finales del siglo XIX», en C. Naranjo y C. Serrano, eds. (1999).

- y R. ÁlvaRez (1999), En busca de la raza perfecta. Eugenesia e higiene en Cuba, I898-1958, Madrid, CSIC

- y C. NARANJo (1998), "Antropología, raza y población en Cuba en el último cuarto del siglo XIX», en En torno al 98 (1998): 267-89.

GARCÍA LÓPEZ, J.R. (1992), Las remesas de los emigrantes españoles a América, siglos XIX y XX, Gijón, Júcar.

- (1994), «Las repercusiones del 98 sobre las remesas de emigrantes $y$ las transferencias de capital», en J. Uría, ed. (1994): 75-84.

- (1996), «Los comerciantes-banqueros en el sistema bancario cubano, 1880-1910\%, en C. Naranjo et al., eds. (1996): 267-82.

GARCiA MORA, L.M. (1993a), «Labra, el Partido Autonomista Cubano y la reforma colonial», Tebeto, 5/1: 397-415.

- (1993b), «Relaciones España-Cuba, 1890-1895: las causas del fracaso colonial español a la luz de la publicística de la época», en ACI (1993): 45-61.

- (1994a), El Partido Liberal Autonomista Cubano (1978-1895): estado de la cuestión (economía y sociedad en Cuba en la segunda mitad del siglo XIX, tesis de licenciatura, Madrid, Univ. Complutense.

- (1994b) «Tras la revolución las reformas: el Partido Liberal Cubano y los proyectos reformistas tras la paz de Zanjón", en C. Naranjo y T. Mallo, eds. (1994): 197-212.

- (1995), «Del Zanjón a Baire: a propósito de un balance historiográfico sobre el autonomismo cubanow, en J. Opatrný, ed. (1995): 29-46.

- (1996a), «El Ateneo de Madrid y la reforma colonial en vísperas de la Guerra de Independencia Cubana», Revista de Indias, 207: 429-50.

- (1996b), «La autonomía cubana en el discurso colonial de la prensa de la Restauración, 1878-1895», en C. Naranjo et al., eds. (1996): 347-62.

- (1998a), «Algunas aclaraciones necesarias sobre el autonomismo cubano», Estudios de Historia Social... (1998).

- (1998b), «Clases y castas: Desequilibrios regionales y conflictos coloniales: hacia una sociedad de clases en Cuba», en Ibero Americana Pragensia (1998): 129-42.

-(1998-99), «Quiénes eran y a qué se dedicaban los autonomistas cubanos?», en M.T. Cortés $e t$ al., eds. (1998-99).

- y C. NARANJo (1997), «Intelectualidad criolla y nación en Cuba, 1878-1898», en A. Bahamonde, coord. (1997): 115-34.

- y A. Santamarla, (1999), «A propósito de la industria azucarera en Cuba (1860-1877): mano de obra y tecnología», en M. Guicharnaud-Tollis, ed. (1999): 71-94.

$-y-$ (inédito), «Centrales por ingenios y colonos por esclavos. Cambio tecnológico y mano de obra en la industria azucarera cubana (1860-1877). Un estudio cuantitativo», Madrid.

GARCIA PEDRAZA, M. (1998), «Los fraudes cometidos en las aduanas españolas de Puerto Rico», en Estudios de Historia Social... (1998).

GARCIA DEL PINO, C. (1988), La acción naval de Santiago de Cuba, La Habana, Ciencias Sociales.

- (1993), «España y las guerras de Cuba: el Grito de Yara, el de Lares y la Gloriosa», en ACI (1993): 23-35.

- (1996), Expediciones de la Guerra de Independencia. 1895-1898, La Habana, Ciencias Sociales.

García Rodríguez, G. (1995), «La economía colonial: fuentes cuantitativas y reconstrucción históricas, en ACI (1995): 111-24.

- (1996), La esclavitud desde la esclavitud. La visión de los siervos, México, CIC lng. J.L. Tamayo.

- (1998a), «La sociedad cubana a fines de siglo», en Cuadernos... (1998): 27-38.

- (1998b), «Trabajadores urbanos: comportamiento político y conciencia de clase», en M.C. Barcia et al. (1998): 143-99.

- et al. (1987), Fuentes estadisticas para la historia económica y social de Cuba (1760-1900) (2 vols.), La Habana, Academia.

- et al. (1997), «Clases y grupos sociales en la transición al capitalismo (la sociedad cubana en el último cuarto del siglo XIX)»., en M.R. Rodríguez, coord. (1997): 187

- y O. GárCiga (1994), «El inicio de la crisis de la economía esclavista», en IHC (1994): 360-400.

García RondA, D. (1998), «Reacción intelectual cubana ante la crisis del 98\%, en Temas (1998): 107-15.

Garcia Sanz, F. (1996), «La Guerra de Cuba, las alianzas de España y el equilibrio mediterráneo», en C. Naranjo et al., eds. (1996): 755-66.

- (1997-98), «El escenario europeo», en S. Juliá, dir. (1997-98): 27-29.

GAYER, A. et al. (1938), The Sugar Economy of Porto Rico, Nueva York, Columbia Univ. Press.

GazTambide, A. (1997), «La invención del Caribe a partir de 1898: las definiciones e identidades caribeñas como herencia de transiciones imperialesm, en L.E. González Vales, ed. (1997): 263-92.

- y S. Álvarez Curbelo, eds. (1996), Historias vivas: historiografía puertorriqueña contemporánea, San Juan, Posdata.

GELABERT-NAVIA, J.A. (1996), «American Architects in Cuba, 1900-1930», en Cuba Theme... (1996): 132-59.

GÉNOVA, C. (1958), Apuntes sobre la fundación de la escuela cubana, La Habana.

GiLA, A. (1998), «La poesía popular en lengua vasca ante la guerra de Cuba», en A. Gutiérrez y M.L. Laviana, eds. (1998).

GILARD, J. (1999), «Le sucre des Antilles dans le cordel espagnol du XIX ${ }^{c}$ siècle», en $\mathrm{M}$. GuicharnaudTollis, ed. (1999): 213-29.

GiUsTI, J.A. (1994), Labor, Ecology and History in a Caribbean Sugar Plantation Zone: Piñones (Loiza), Puerto Rico, 1770-1950, Ph. D., Nueva York, of the Univ. State of New York-Binghamton. 
- (1996), «En busca de la nación concreta: 'el grupo español' en la industria azucarera de Puerto Rico», en C. Naranjo et al., eds. (1996): 211-24.

- (1998), «Hacia otro 98: el grupo español en Puerto Rico, 1890-1930 (azúcar, banca y política)», en Op. Cit. (1998): 75-24.

GolzueTa-Mimo, F. (1974), Azúcar cubano. Monocultivo y dependencia económica, Oviedo, Gráfica Summa.

GÓMEz, P. (1994), «Emigrantes asturianos a Cuba en el siglo XIX. Efectivo migratorio e integración del emigrante, matrimonio y endogamia grupal», en J. Uría, ed. (1994): 15-42

-, coord. (1996), De Asturias a América. Cuba (1850-1930). La comunidad asturiana en Cuba, Gijón, Archivo de Indianos.

GONZÁLEZ, A.M. Y J.J. FERNÁNDEZ (1998), «Identidad lingüística en Cuba», en J.G. Cayuela, coord. (1998): 737-44.

GONZÁLEZ, D. (1992), «La manufactura tabacalera cubana en la segunda mitad del siglo XIX», Revista de Indias, 194: 192-226.

- (1994), «Empresarios asturianos del tabaco. Siglo XIX», en J. Uría, ed. (1994): 57-74.

- (1996), «La guerra económica y su efecto en el tabaco", en C. Naranjo et al., eds. (1996): 305-16.

GoNZÁLEZ, E. (1997), «El Estado y la nación en América Latina (1826-1940)», en Contracorriente (1997): 22-31.

GONZÁLEZ, F. (1998), «El desarrollo de la población en Cuba durante los siglos XIX y XX», en J.G. Cayuela, coord. (1998): 807-12.

GONZÁLEZ, J. (1998), «Cultura y violencia en José Martí», en Estudios de Historia Social... (1998).

GONZÁLEZ, J.C. (1998), «Historia de la mujer en Cuba: del feminismo liberal a la acción política femenina», en J.A. Piqueras, ed. (1998): 271-85.

GONZÁLEZ, J.F. (1995), «La pedagogía ¿contra el poder, desde el poder? El caso del Colegio de Empresa de los Hermanos Guiteras», en ACI (1995): 125-42.

GONZÁLEZ, L.M. (1996), «Progreso y modernidad: las ferias de fin de siglo y los hombres de letras en Puerto Rico», en C. Naranjo et al., eds. (1996): 539-46.

- (1998), «La ilusión del paraíso: fotografias y relatos de viajeros de Puerto Ricon, en S. Álvarez Curbelo et al., eds. (1998): 173-204.

- (1999), «Entre el tiempo y la memoria: los intelectuales y la construcción del imaginario nacional en Puerto Rico, 1867-1898», en C. Naranjo y C. Serrano, eds. (1999).

GONZÁLEZ, P.C. (1997), «Las derechas españolas ante la crisis del 98», en A. Bahamonde, coord. (1997): 193-219.

GONZÁlez PÉREZ, C. (1996), «A sociedade de instrucción 'Santa María de Urdilbe y sus contomos' da Habana», Estudios Migratorios... (1996): 177-210.

GONZÁLEZ-RIPOLL, M.D. (1996), «Independencia y antillanismo en la obra de Hostos», en C. Naranjo et al., eds. (1996): 37-48.

- (1997), Eugenio María de Hostos: utopía y fundación, Morelia, Univ. Michoacana San Nicolás de Hidalgo.

R. I., $1999, \mathrm{n} .^{\circ} 215$
- (1997-98), «Eugenio María de Hostos», en S. Juliá, dir. (1997-98): 160

- (1998a), «Cuba, México y España (1895-1898): un triángulo de cuatro lados», en Ibero Americana Pragensia (1998): 143-51.

- (1998b), «La emigración cubana a Cayo Hueso (1855-1896): independencia, tabaco y revolución", en A. García Álvarez y C. Naranjo, coords. (1998): 237-54.

- (1998c), (Las trampas de la utopía: Hostos y el 98 cubano y puertorriqueñom, en En tomo al 98 (1998): 39-60

- (1999), «El imaginario nacional puertorriqueño en la obra de Eugenio $\mathbf{M}^{\mathrm{a}}$ de Hostos», en C. Naranjo y C. Serrano, eds. (1999).

- y L.M. García MORA (1997), El Caribe en la época de la independencia y de las nacionalidades. Morelia, Univ. Michoacana San Nicolás de Hidalgo.

GONZÁLEZ SUÁREZ, D. (1988), «La política inmigratoria en los inicios de la pseudorepública», Economía y Desarrollo, 56-77.

GONZÁLEZ VALES, L.E., ed. (1997), 1898: enfoques y perspectivas, San Juan, First Book.

GROSFOGUEL, R. (1998), «La geopolítica de la migración caribeña: de la guerra fría a la postguerra fría», en Op. Cit. (1998): 125-52.

GuadarRama, P. (1998), «Algunas visiones de la intelectualidad cubana sobre el $98 \%$, en El 98 visto... (1998): 159-70.

GUANCHE, J. (1997a), «Aspectos etnodemográficos de la nación cubana: problemas y fuentes de estudio», en En busca... (1997): 11-22.

- (1997b), (La presencia de los chinos en Cuba», en Contracorriente (1997): 148-9.

Guerra, R. (1925), Historia de Cuba, La Habana, Siglo $X X$.

- (1946), La industria azucarera en Cuba, La Habana, La Cultural.

- (1948), Mudos testigos. Crónica del ex-cafetal Jesús Nazareno, La Habana.

- (1970), Azúcar y población en las Antillas, La Habana, Ciencias Sociales.

- (1972), La Guerra de los Diez Años (2 vols.), La Habana, Ciencias Sociales.

- (1974), En el camino de la independencia: estudio sobre la rivalidad de los Estados Unidos y la Gran Bretaña en sus relaciones con la independencia de Cuba, La Habana, Ciencias Sociales.

-, comp. (1952), Historia de la nación cubana (10 vols.), La Habana, 1952, Historia de la Nación Cubana.

GUERRERO, I. (1998), «J. Martí y la mujer de fin de siglo: una lectura de sus crónicas», en Ibero Americana Pragensia (1998): 77-83.

GuichaRnaUD-TOllis, M. (1996), Regards sur Cuba au XIX siècle. Temoignages européens, París, L'Harmattan.

- (1999a), «L'équipage Derosne en Guadalupe et à Cuba: Stratégie commerciale française et réticences au XIX ${ }^{e}$ siècle», en M. Guicharnaud-Tollis, ed. (1999): 125-39.

- (1999b), «Nación y cultura hispano-cubana en la ensayística crítica de José María Chacón y Calvo», en C. Naranjo y C. Serrano, eds. (1999). 
-, ed. (1999), Le Sucre dans l'espace Caraïbe hispanophone aux $X I X^{c}$ et $X X^{c}$ siècles, Paris, L'Harmattan.

Gullón, A.J. (1996), «Un acercamiento a la prostitución cubana a finales del siglo XIX", en C. Naranjo et al., eds. (1996): 497-508.

GuTHunZ, U. (1998), «The Year 1898 in Porto

Rico: Caesura, Change, Continuation?», en W.L. Bernecker, ed. (1998): 171-92.

GUTIÉRREZ, A. (1998-99), «Nicaragua en la óptica finisecular», en M.T. Cortés et al., eds. (1998-99).

GutiéRrez, A. y M.L. LAVIANA, coords. (1998), Cuba entre dos revoluciones. Un siglo de historia cultura cubana, Sevilla, Diputación de Sevilla.

- y -, eds. (1998), Las Antillas, España y el 98, Sevilla (título provisional).

HAGelBerG, G.B. (1996), «Açúcar e História: um panorama global», en A. Vieira, coord. (1996): 9-26.

HARPER, P. (1996), «Cuba Conections: Key WestTampa-Miami, 1870 to 1945 ", en Cuba Theme.. (1996): 278-91.

HeLG, A. (1995), Our Righful Share. The Afro Cuban Struggle for Equality, 1880-1912, Chapel Hill, North Carolina Univ. Press.

- (1998), «Sentido e impacto de la participación negra en la guerra de la independencia de Cuba», en A García Álvarez y C. Naranjo, coords. (1998): 47-64

HERNÁNDEZ, H. (1997), «Evolución histórica de la Universidad hacia finales del siglo XIX», en La sociedad... (1997): 166-78.

HERNÁNDEZ, J.E. (1997), «La invasión del '98 a Puerto Rico: esbozo bibliográfico», en L.E. González Vales, ed. (1997): 81-96.

- (1998a), «Los gabinetes autonómicos de Puerto Rico, 1897 y 1898», en J.E. Hernández, ed. (1998): 37-42.

- (1998b), «En torno a un centenario olvidado», en J.E. Hernández, ed. (1998): i-ii.

-, ed. (1998), Centenario de la Carta Autonómica de Puerto Rico (1897-1997), San Juan, Univ. Interamericana.

HERNÁNDEZ, J.M. (3992), Cuba and the United States: Intervention and Militarism, 1868-1933, States: Intervention and
Austin, Univ. of Texas Press.

HERNÁNDEZ, M. (1997), «La emigración canaria a Cuba en la primera mitad del siglo XIX», en A Bahamonde, coord. (1997): 71-83.

- (1998), «La emigración canaria ante el 98: de la deserción a Venezuela a la eclosión en la Cuba republicana», en Estudios de Historia Social... (1998).

HeRnÁndez SandotCA, E. (1982), Pensamiento burgués y problemas coloniales en la España de la Restauración, 1875-1887 (2 vols.), Madrid, Univ. Complutense.

- (1988), «Ciencia, educación y política en Cuba, siglo XIX (posibilidades y limitaciones del sistema educativo superior), en J.L. Peset, coord. (1989): 423-41.

- (1989) «La Compañía Transatlántica Española: una dimensión ultramarina del capitalismo español», Historia Contemporánea, 2: 73-96.
- (1994a), «A propósito del imperio colonial español en el siglo XIX : los negocios cubanos del Marqués de Comillas», en C. Naranjo y T. Mallo (1994): 183-96.

- (1994b), «Rafael Maria de Labra y Cadrana (1841-1919): una biografía política», Revista de Indias, 172: 597-658.

- (1996), «Emigrantes, indianos y capitalistas (siglo XIX): una bibliografía aproximada», en $\mathrm{Cu}$ ba/España (1996): 81-8.

- (1997a), «La historiografia reciente acerca de los españoles en Cuba (siglo XIX): comercio, emigración, negocios y finanzas», en Historia y Sociedad (1997): 149-70.

- (1997b), «La política colonial española y el despertar de los nacionalismos ultramarinos», en J.P. Fusi y A. Niño, eds. (1997): 115-32.

- (1997-98), «Barcos para el desastre», en S. Juliá, dir. (1997-98): 60-1.

- (1998a), «Conocer y revisar el 98. Reseña del libro de Consuelo Naranjo, Miguel A. Puig-Samper y Luis M. García Mora, eds., La nación soñada: Cuba, Puerto Rico y Filipinas ante el 98», Tiempos de América, 2: 142-5.

- (1998b), «Cuba en el período intersecular: continuidad y cambio», en W.L. Bernecker, ed. (1998) 153-70.

- (1998c), «Escenarios ultramarinos del 98: Cuba antes de la autonomía», en 1898: desastre... (1998): 203-12.

- (1998d), «El factor colonial en la España de la Restauración», en J. Paniagua y J.A. Piqueras, eds. (1998): 113-161.

- (1998e), «Hacia 1898: panorama brevísimo del imperio insular», en Rábida (1998): 91-8.

- (1998f), «La historia de Cuba vista desde España: estudios sobre política, raza y sociedad», en A. García Álvarez y C. Naranjo, coords. (1998): 7-24.

- coord. (1998), 1898: España fin de siglo, dossier de Cuadernos de Historia Contemporánea, 20.

HERRERA, M.S. (1998), «Hacia 1898: conspiraciones separatistas cubanas en México», Historia Mexicana (1998), 47/4: 807-836.

HERRERo, J. (1998), «Dandismo y modernidad literaria en la obra del poeta cubano Julián del Casar (1863-1893): un estudio de literatura comparada en el ámbito del simbolismo y del modernismo», en J.G. Cayuela, coord. (1998): 717-30.

Hevia, O. (1996), El Directorio Central de las Sociedades Negras de Cuba (1886-1994), La Habana, Ciencias Sociales.

- (1997), «Otra contribución a la historia de los negros sin historia», en La sociedad... (1997): 77-90.

Hidalgo, I. (1992), El Partido Revolucionario de la Isla, La Habana, Ciencias Sociales.

- (1997), «Proceso de cambio y disolución de Partido Revolucionario Cubano», en M.R. Rodríguez, coord. (1997): 189.

HiLTon, S. (1998a), «"Americana en letra y espiritu": la Doctrina Monroe y el Presidente McKinley en 1898\%, en E. Hernández Sandoica, coord. (1998): 205-19.

R. $1 ., 1999, \mathrm{n}^{\circ} 215$ 
- (1998b), «Los federalistas españoles y el mito americano durante la crisis colonial de 1895-1898", en Ibero Americana Pragensia (1998): 11-29.

- (1998c), «La nueva Doctrina Monroe de 1895 y sus aplicaciones para el Caribe español: algunas interpretaciones coetáneas españolas», en En torno al 98 (1998): 125-52.

HiNSBRUNER, J. (1996), Not of Pure Blood. The Free People of Color and Racial Prejudice in Nineteenth Century Puerto Rico, Durham, Duke Univ. Press.

Hispania (1997), 196. (monográfico sobre 1898).

Hispanic American Historical Review (1998), $78 / 4$ (monográfico sobre 1898).

Historia de Cuba (1989-) [5 vols.], La Habana. Univ. de La Habana.

Historia general de la emigración española a lberoamérica (1992) [2 vols.], Madrid, Historia 16CEDEAL.

Historia y Sociedad (1997), IX.

HOBSON, J.A. (1902), Imperialismo, Londres \& Nueva York, J. Pott \& Co.

HOERNEL, R.B. (1976), «Sugar and Social Change in Oriente, Cuba, 1898-1946», Journal of Latin American Studies, 8: 215-49.

HOFFMAN, L.F. (1997), «Anténor Firmin y los Estados Unidos: puls ça change, plus cést la même chose», en A. Díaz Quiñones, ed. (1997): 63-70.

HowARD, P.A. (1998), Afro-Cuban Cabildos and Societies of Color in the Ninetheenth Centurys, Louisiana State Univ. Press.

HowaRD, W. (1998), «A Splendid Little War? United States Perspectives on the War with Spain», en C. Mellizo y L. Núñez, coords. (1998): 13-36.

HUERTAS, R y R CAMPOS (1998-99), «Medicina y regeneracionismo en la España del cambio de siglo», en M.T. Cortés et al., eds. (1998-99).

Hulme, P. (1997), «El encuentro con Anacaona: F. Albión Ober y el Caribe autóctonom, en A. Díaz Quiñones, ed. (1997): 75-104.

IBARRA, J. (1972), Ideología mambisa, La Habana, Inst. Cubano del Libro.

- (1980), José Marti, dirigente político e ideólogo revolucionario, La Habana, Letras Cubanas.

- (1981), Nación y cultura nacional, La Habana, Letras Cubanas.

- (1984), «Los mecanismos económicos del capital financiero obstaculizan la formación de la burguesía doméstica en Cuba», Islas, 79: 111-34.

- (1985a), Un análisis psicosocial del cubano, La Habana, Ciencias Sociales.

- (1985b), Historia de Cuba, La Habana, Ciencias Sociales.

- (1992), Cuba: 1898-1921, partidos políticos y clases sociales, La Habana, Ciencias Sociales.

- (1995a), Cuba: 1898-1958, estructura y procesos sociales, La Habana, Ciencias Sociales.

- (1995b), «Herencia española, influencia estadounidense (1898-1925)», en ACI (1995): 16-39. 1: 5-17.

- (1995c), «Historiografía y revolución», Temas,

R. I., $1999, \mathrm{n}^{\circ} 215$
- (1996), "Cultura e identidad nacional en el caribe hispano: el caso puertorriqueño y el cubanos, en C. Naranjo et al., eds. (1996): 85-96.

- (1997), "Los nacionalismos hispano-antillanos del siglo XIX», en J.P. Fusi y A. Niño, eds. (1997): 133-50.

Ibero Americana Pragensia (1998), 34, (monográfico sobre 1898).

IGLESIAS, F. (1980), «Azúcar y crédito durante la segunda mitad del siglo XIX», Santiago, 40: 119-44.

- (1982), «Población y clases sociales en la segunda mitad del siglo XIX", Revista de la Biblioteca Nacional José Martí, 26: 101-32.

- (1986), «Azúcar, esclavitud y tecnología (segunda mitad del siglo XIX)», Santiago, 16:113-32.

- (1988a), «Características de la emigración española a Cuba, 1904-1930», en N. Sánchez-Albornoz, comp. (1988): 270-95.

- (1988b), «Changes in Cane Cultivation in Cuba, 1860-1900m, Social and Economics Studies, 37: 341-63.

- (1995), «Fuentes cuantitativas para la historia económica y social de Cuba», en ACI (1995): 101-10.

- (1996), «El desarrollo del capitalismo en Cuba en los albores de la época imperialista», en IHC (1996): 156-208

- (1997), «El coste demográfico de la Guerra de Independencia», en La sociedad... (1997): 67-76.

- (1998), «Las finanzas de Cuba en el ocaso colonial», en A. García Álvarez y C. Naranjo, coords. (1998): 215-36.

- (en prensa), Del ingenio al central, San Juan, Univ. de Puerto Rico.

IGLESIAS, M. (1998), «José Martí: mito, legitimación y símbolo. La génesis del mito martiano y la emergencia del nacionalismo republicano en Cuba (1895-1920)», en J.A. Piqueras, ed. (1998): 201-26.

IHC [Instituto de Historia de Cuba] (1987), Historia del movimiento obrero cubano, 1865-1958 (2 vols.), La Habana, Política.

- (1994-), Historia de Cuba (5 vols.), La Habana,

Política.

- (1994), La colonia, en IHC (1994-).

- (1996), Las luchas, en IHC (1994-)

IRIZARRY, L.R. (1996), «La contribución sobre caudales relictos y donaciones, de los Estados Unidos y su posible efecto en Puerto Rico», en Puerto Rico... (1996): 115-22.

IRUROZQUI, M. (1998), «La guerra de razas de 1899: crisis y reajuste de la identidad nacional boliviana», en Estudios de Historia Social... (1998).

- (1998-99), «De Juan de la Rosa a la Guerra Federal. Ciudadanía política en Bolivia de fin de siglo», en M.T. Cortés et al., eds. (1998-99).

JAMES, J. (1995), «Urgencias y exigencias historiográficas», Temas, 1 (1995): 129-32

JARAMILLO, I. (1998), «Alfred Thayer Mahan y el paisaje de fin de siglo», en El 98 (1998): 152-62.

JENKS, L.H. (1928), Our Cuban Colony, Nueva York, Vanguard Press.

JiMÉNEZ, J. (1963), Los chinos en la lucha por la liberación cubana, 1847-1930, La Habana. 
- (1983), Los chinos en la historia de Cuba, 1847-1930, La Habana, Política.

III Jornadas de Historia Militar. La presencia militar española en Cuba (1868-1895) (1995), Madrid, Minist. de Defensa.

JOVER, J.M. (1979), 1898. Teoría y práctica de la redistribución colonial, Madrid, Fund. Universitaria Española.

- (1997), «Aspectos de la civilización española en la crisis de fin de siglo», en J.P. Fusi y A. Niño, eds. (1997): 15-46

JULIÁ, S., coord. (1998), Debates en torno al 98. Estado, sociedad y política, Madrid.

-, dir. (1997-98), Memoria del 98. De la Guerra de Cuba a la Semana Trágica, monográfico de El Pat́s (Madrid).

KNIGHT, F.W. (1978), The Caribbean: Genesis of a Fragmentary Nationalism, Nueva York.

- (1996), «Escravatura e Açúcar em Cuba, 17921886: o conflito entre a política e a economiam, en $\mathrm{A}$. Vieira, coord. (1996): 229-48.

- (1998), «Cuba, Puerto Rico y la guerra de 1898», en A. Gutierrez y M.L. Laviana, eds. (1998).

KUETHE, A.J. (1998), «La fidelidad cubana durante la edad de las revoluciones», en En torno al 98 (1998): 209-20.

LABRADOR, S. (1997), «El miedo al negro: el debate de lo racial en el discurso revolucionario cubano", en Historia y Sociedad: (1997): 111-28.

LAGUNA, F. (1991), Las ideas hispanoamericanas de Rafael María de Labra, Madrid, Univ. Complutense.

LAPIQUE, Z. (1997), «Ignacio Cervantes: Cuba en sus danzas", en La sociedad... (1997): 147-52.

- (1999), «Los sucesos de la historia de España y Cuba en las etiquetas de los cigarrillos y habanos cubanos», en C. Naranjo y C. Serrano, eds. (1999).

Laviana, M.L. (1988), José Martí, la liberfad de Cuba, Madrid, Anaya.

-, ed. (1988), José Marti (1853-1895). Antologia del pensamiento politico, social y económico latinoamericano, Madrid, Cultura Hispánica

LE RIVEREND, J. (1944), «Sobre Ia industria azucarera cubana en el siglo XIX», El Trimestre Económico, 9/1: 163-86.

- (1973), La República. Dependencia y revolución, La Habana, Ciencias Sociales.

- (1981), La Habana (biografía de una provincia), La Habana, Ciencias Sociales.

- (1985), Historia económica de Cuba, La Habana, Pueblo y Educación.

- (1997), «1898: una crisis diferente en dos fases semejantes», en C. Almodóvar, comp. (1997): 1-8.

-, ed. (1986), Temas acerca de la esclavitud, La Habana, Ciencias Sociales.

LEAL, E. (1997), «Meditación ante el 98», en La sociedad... (1997): 91-4.

LEGUINECHE, M. (1998), Yo pondré la guerra, Madrid, El País/Aguilar.
LENIN, V.I. (1939), The Imperialism: the Highest Stage of Capitalism: a Popular Outline, Nueva York, International.

LEWIS, A.W. ed. (1970), Tropical Development, 1880-1914. Studies in Economic Process, Londres.

LIDA, C.E. (1998), «Un desastre anunciado, 18681898, voces anticolonialistas en España", en El 98... (1998): 1-14.

LINARES, M.T. (1997), «La música cubana en 1898», en La sociedad... (1997): 118-22.

LIZARDI, J.L. (1998), «La guerra y sus imágenes.

México y la representación gráfica de la guerra hispano-cubana-americanas, en $\mathrm{El}$ 98.. (1998): 69-86.

LOBO, M.L. y Z. LAPIQUE (1996), «The Years of Social», en Cuba Theme... (1996): 104-31

LÓPEZ, M. (1998), «La reconcentración: Weyler por Weyler», en Cuadernos... (1998): 71-84.

LOPEZ, S. y M.C. MARIAL (1997), "José Martí:

l'origen del símbol fundacional del nacionalismo Cubá», en J. Casanovas, coord. (1997): 38-42.

López-BARALT, L. y M. (1998), E. López Giménez. Crónica del 98. El testimonio de un médico puertorriqueño, Madrid, 1998

López Cantós, A. (1991), Eugenio María de Hostos, Madrid, Cultura Hispánica.

LOPEZ CIVEIRA, F. (1995), José Martí, 1853.

1895: la dignidad humana, Morelia, Univ. Michoacana San Nicolás de Hidalgo.

- (1997), «Mirada a Estados Unidos desde la independencia de Cuba», en La sociedad... (1997): 123-33.

LÓPEZ ISLA, M. (1997), «La vida social del isleño en Cabaiguán (Cuba)», en J.A. Galbán, ed. (1997): 63-8.

LOPEZ MESA, E. (1999), «Historiografía y nación en Cuba», en C. Naranjo y C. Serrano, eds. (1999).

LOPEZ SÁNCHEZ, J. (1987), Finlay. El hombre y la verdad cientifica, La Habana, Ciencias Sociales.

LóPEZ SEGRERA, F. (1980), Raices históricas de la Revolución cubana, La Habana, UNEAC.

- (1989a), Cuba, cultura y sociedad, La Habana, Letras Cubanas.

- (1989b), Sociología de la colonia y neocolonia cubana, 1510-1959, La Habana, Ciencias Sociales.

LOSADA, A.F. (1994), Cambio demográfico y crecimiento económico en Cuba (1898-1958). Las primeras fases de la transición demográfica, $\mathrm{Ph}$. D., Univ. de Santiago de Compostela.

- (1995), «The Cuban Labor Market and Inmigration from Spain, 1900-1930m, Cuban Studies, 25: 147-64.

- (1996), «Nuevos agentes en el crecimiento económico cubano (1898-1968)», en J. Pujol et al., eds. (1996): 211-33.

LOYOLA, O. (1997), «Cuba: para entender una revolución finiseculars, en M.R. Rodríguez, coord. (1997): 103-12.

- (1998), «La altemativa histórica de un 98 no consumadom, en $E l 98$ (1998): 19-26.

- coord. (1995), Cuba: la Revolución de 1895 y el fin del imperio colonial español, Morelia, Univ. Michoacana San Nicolás de Hidalgo.

LUCENA, M. (1996), «El Reglamento de Esclavos en Cuba», en Cuba/España (1996): 89-99. 
LuCiA, D.O. (1998), «Buenos Aires, 1898: el momento iberoamericano en claves positivistas», en $E l$ 98 visto... (1998): 99-112.

LUQue, M.D. (1997a), «Los conflictos de la modernidad: la elite criolla en Puerto Rico, 1898-1904», en L. Agrait y A. Cubano, coords. (1997): 695-728.

- (1997b), «Fondos documentales para el estudio de 1898 que se encuentran en Puerto Rico», en M.R. Rodríguez, coord. (1997): 92-102.

- (1998-99), «Las alianzas del capital: inversiones extranjeras en Puerto Rico, 1898-1914», en M.T. Cortés et al., eds. (1998-99).

- (1999), «E1 98 en el imaginario de los profesionales puertorriqueños», en C. Naranjo y C. Serrano, eds. (1999).

LuZón, J.L. (1989), Economía, población y territorio en Cuba, Madrid, Cultura Hispánica.

LLopts, A., ed. (1998), Imágenes y ensayos del 98, Valencia.

LLORDÉN, M. (1992), «Asociaciones españolas de emigrantes», en M.C. Morales y M. Llordén. eds. (1992): 9-59.

- (1996), "O asociacionismo dos emigrantes espanois. Unha explicación histórica», en Estudios Migratorios... (1996): 39-84

MACíAs, A. (1992), La migración canaria, 15001980, Gijón, Júcar.

MAESTRE, J. (1998a), «Las dos Españas. Una reflexión ante los dos 98», en A. Gutiérrez y M.L. Laviana, eds. (1998).

- (1998b), "Vectores jurídicos y políticos de la dinámica cubana», en A. Gutiérrez y M.L. Laviana, coords. (1998): 83-106.

MAINER, J.C. (1997), «Galdós a escena: una campaña teatral (1892-1896)», en J.P. Fusi y A. Niño, eds. (1997): 257-68.

Malamud, C.D. (1998), «América, Cánovas y la pérdida de las últimas colonias", en J. Tusell y F. Portero, eds. (1998): 393-414.

Maldonado-Dents, M. (1980), Puerto Rico: hacia una interpretación histórico-social, México, Siglo XXI.

- (1992), Eugenio María de Hostos y el pensamiento social iberoamericano, México, FCE.

MALEFAKIS, E. (1997), «Los Estados Unidos a finales del siglo XIX», en J.P. Fusi y A. Niño, eds. (1997): 269-78.

- (1997-98), «El imperialismo de los Estados Unidos», en S. Juliá, dir. (1997-98): 114-5.

MaLlo, T. (1996), «El Ateneo de Madrid ante el 98", en C. Naranjo et al., eds. (1996): 529-38.

MALUQUER, J. (1974), «El mercado colonial antillano en el siglo XIX», en J. Nadal y G. Tortella, eds. (1974): 322-57.

- (1988), «La formación del mercado interior en condiciones coloniales: la inmigración y el comercio catalán en las Antillas españolas durante el siglo XIX», Santiago, 69: 89-112.

- (1992), Nación en inmigración: españoles a Cuba (siglos XIX y XX), Gijón, Júcar.
- (1994), «La inmigración española a Cuba. Elementos de un debate historiográficom, en C. Naranjo y T. Mallo, eds. (1994): 137-48.

- (1996), «La financiación de la Guerra de Cuba y sus consecuencias sobre la economía española. La deuda pública», en C. Naranjo et al., eds. (1996): 317-30.

- (1997), «Las consecuencias económicas de la guerra de independencia. Un primer acercamientos, en M.R. Rodríguez, coord. (1997): 164-84.

ManSILlA, I. (1996), «Los concursos de redacción de CAPRE y su importancia en el intercambio cultural entre España y Puerto Rico», en Puerto Rico... (1996): 123-30.

MARCHENA, A. (1998), «La población en Cuba en 1899: el precio de la guerra», en A. Gutiérrez y M.L. Laviana, eds. (1998).

MARFIL, B.E. (1998), «Las enfermedades infecciosas en el ejército español durante la última guerra de Cuba: datos para un debate historiográfico», en Estudios de Historia Social... (1998).

MARIN, F. (1998), «La estrategia militar en la Guerra de Cuba», en C. Mellizo y L. Núñez, coords. (1998): 37-76

MARíNEZ, P.A. (1998), «Cuando reinaba su majestad el azúcar, entrevista con Roland T. Ely», en $O p$. Cit. (1998): 61-74

MARQUÉS, M.A. (1982), La burguesía no azucarera ante la crisis del sistema neocolonial en Cuba, tesis de licenciatura, La Habana, Univ. de La Habana.

- (1996a), «El empresariado español en la industria no azucarera insular (1880-1920)", en C. Naranjo et al., eds. (1996): 251-66.

- (1996b), «Las industrias menores en la Cuba finisecular: problemas de mercado compartido», Estudios de Historia Social y Económica de América, 13: 449-57.

- (1998a), «La Cámara Española de Comercio de La Habana: entre la diferencia y el marco de la integración nacional (1914-1920)», en J.G. Cayuela, coord. (1998): 299-310.

- (1998b), Empresas y empresarios en las entidades industriales menores de Cuba (1870-1929), $\mathrm{Ph}$. D., Madrid, Univ. Autónoma.

MÁrqueZ, M. (1941), Proceso histórico de la Enmienda Platt, La Habana, Siglo XX.

- (1975), La diplomacia en nuestra historia, La Habana, Ciencias Sociales.

MARRERO, L. (1973-92), Cuba: economía y sociedad (13 vols.), Madrid, Playor.

MARRERo, V.M. (1993), «La relación entre región histórica y región político-administrativa: el caso de las Tunas», en ACI (1993): 87-96.

MARSISKE, R. (1998), «La universidad latinoamericana fin de siglo: el caso de México», en Estudios de Historia Social... (1998).

MarTí, J. (1891), «Nuestra América», en L. Zea (1979): 70-82.

Martín, C. (1998), «Perú y el 98», en Estudios de Historia Social... (1998).

MARTÍN, F. (1998), «Una mirada impresionista sobre el arte cubano contemporáneo», en A. Gutiérrez y M.L. Laviana, coords. (1998): 205-24.

R. I., $1999, \mathrm{n}^{\circ} 215$ 
MARTíNEZ, L. (1997), «El '98 antes del '98: el expansionismo norteamericano en el Caribe hispano durante la segunda mitad del siglo XIX», en L.E González Vales, ed. (1997): 381-404.

MARTíneZ, R. (1929), Cuba. Los primeros años de independencia, París, Liber Livre.

Martínez Díaz, N. (1986), José Martí, Madrid, Historia 16.

MARTinez-Vergne, T. (1992), Capitalism in Colo nial Porto Rico, Gainesville, Univ, of Florida Press.

MATEO, M.C. (1997), «Creencias rituales: la medicina popular canaria en Cubas, en J.A. Galbán, ed. (1997): 89-110

MatTo, D., coord. (1994), Teoría y política de la construcción de identidades y diferencias en el Caribe. París, UNESCO.

MAZA, M.P. (1997), Entre la ideología y la compasión. Guerra y paz en Cuba, 1895-1903: testimonio de los Archivos Vaticanos, Santo Domingo, Inst. P.F. Bono.

MeEs, L. (1997), «De la Marcha de Cádiz al Árbol de Guernica. El País Vasco ante la guerra y la crisis del 98", en A. Bahamonde, coord. (1997): 239-64.

MÈGevand, S. (1999), «Le sucre dans l'iconogoraphie cubaine du XIX" siecle», en M. GuicharnaudTollis, ed. (1999): 249-61.

MELlizo, C. y L. NúÑEZ, coords. (1998), España, Estados Unidos y la crisis de 1898, Madrid, FPAES, Papeles de la Fundación, 43.

MEna, M. y S. Hernández (1994), Fuentes do cumentales de la administración española en el Archivo Nacional de Cuba. La administración autonómica española de Cuba en 1898, Salamanca.

MENoCal, N.G. (1996), «An Overriding Passionthe Quest for a National Identity in Painting», en Cuba Theme... (1996): 186-219.

MESA, R. (1967), El colonialismo en las crisis del siglo XIX español, Madrid, Ciencia Nueva.

- (1998), «España y la política internacional a finales del siglo XIX», en El 98... (1998): 87-106.

MESA-LAGO, C. (1972), The Labor Force, Employement, Umemployement and Underemployement in Cuba, 1899-1970, Beverly Hills, Sage.

MEZA, J. (1995), «Enrique José Varona: la educación en Cuba», en ACI (1995): 87-100.

Migraciones canarias y adaptación socio-cultural en Cuba (1995), monográfico de Guize (1995), 2.

MiLLIs, W. (1931), The Martial Sprint. A Study of Our War with Spain, Nueva York.

MINTZ, S.W. (1974a), «The History of a Porto Rican Plantation», en S.W. Mintz, ed. (1974): 56-77.

- (1974b), Worker in the Cane: a Porto Rican Life of History, Nueva York, Norton \& Co.

-, ed. (1974), Caribbean Transformation, Chicago, Aldine Pub.

MIRANDA, A. (1931), Historia documentada de la masoneria en Cuba, La Habana.

MIRó, J. (1970), Crónicas de la guerra, La Habana, Ciencias Sociales.

MisAS, R. (1998), «La ciencia en el programa de desarrollo agropecuario del Conde de Pozos Dulces (1857-1858)», en J.A. Piqueras, ed. (1998): 91-114.
MOLINARY, R.D. (1996a), «Discurso de ingreso a la Real Academia de Córdoba: Puerto Rico, frontera cultural de América: conciencia e identidad hispanas», en Puerto Rico... (1996): 257-70.

- (1996b), «Puerto Rico y Galicia: encuentros y paralelismos», en Puerto Rico... (1996): 131-48.

MONCADA, A. y J. Olvis (1996), «Puertortiqueños en los Estados Unidos (están mal, pero pueden estar peor)», en Puerto Rico... (1996): 149-62.

MONET-DESCOMBEY, S. (1999), «L'image du $\mathrm{ci}$ marrón dans la poésie caribéenne contemporaine», en M. Guicharnaud-Tollis, ed. (1999): 269-85

MONTERO, F. (1997), «El catolicismo español finisecular y la crisis del $98 \%$, en A. Bahamonde, coord (1997): 193-219.

MONTORO, R. (1930), Obras completas ( 3 vols.), La Habana, Lex.

MORA, C. de (1998), «Virgilio Piñera o la estética del disparate», en A. Gutiérrez y M.L. Laviana, coords. (1998): 161-76.

MORALES, M.C. y M. LLORDÉn, eds. (1992), Arte, cultura y sociedad en la emigración española a América, Oviedo, Univ. de Oviedo.

MORALES, S.E. (1998a), Espacios en disputa. Mé xico y la independencia de Cuba, México, CIC Ing. J.L. Tamayo y SEC.

- (1998b), "Visión mexicana del 98", en El 98 visto... (1998): 23-44.

- y A. SANCHEZ ANDRÉs (1998), Cuba y Españo en el horizonte latinoamericano del 98 . Diplomacias en conflicto, México, CIC Ing. J.L. Tamayo.

MORENo, J.J. (1997-98), «La Gloriosa en las Antillas», en S. Juliá, dir. (1997-98): 14-5.

MOREJÓN, B. (1981), Migraciones en Cuba, La Habana, CEDEM.

MORENo, M. (1978), El ingenio. Complejo económico social cubano del azúcar ( 3 vols.), La Habana, Ciencias Sociales.

- (1983), La historia como arma y otros ensayos sobre ingenios, esclavos y plantaciones, Barcelona, Crítica.

- (1991), «Economia de plantación y sociedades en el Caribe español, 1860-1930», en L. Bethell, ed. (1991), VII: 163-201.

- (1995), Cuba/España, España/Cuba. Historia común, Barcelona, Crítica.

- (1997-98a), «La Guerra de los Diez Años», en S. Juliá, dir. (1997-98): 5-10.

$-(1997-98 b)$, «Guerra en la paz», en S. Juliá, dir. (1997-98): 37-42. 46.

- (1998), «E1 98 en Cuba», en El 98... (1998): 35

- el al. (1983), «El nivel y estructura de los precios de los esclavos de las plantaciones cubanas a mediados del siglo XIX: algunas perspectivas comparadas», Revista de Historia Económica, 1/1: 97-120.

- et al., eds. (1985), Between Slavery and Free Labor: The Spanish-Speakings Caribbean in the Nineteenth Century, Baltimore, John Hopinks Univ. Press.

- y J.J. MORENO (1993), Guerra, emigración y muerte (el ejército español en Cuba como via migrato ria), Oviedo, Júcar. 
Moscoso, F. (1998), «Ingenios, producción y comercio del azúcar: Andalucía, el Atlántico, el Caribe y Brasil, Bibliografia generai», en Op. Cit. (1998): 237-68.

Mota, A.M. (1998), «La pérdida de Cuba y Filipinas en el Diario de Tarragonas, en Estudios de Historia Social... (1998).

MoUlin-CiviL, F. (1999), «El discurso regeneracionista en Fernando Ortiz», en C. Naranjo y C. Serrano, eds. (1999).

MoURelle, M. (1996), «Puerto Rico y Hostos visto desde España heterodoxamente», en Puerto Rico... (1996): 163-82.

MOYANO, E.L. (1991), La nueva frontera del azúcar: el ferrocarril y la economía cubana en el siglo $X I X$, Madrid, CSIC.

- (1994), «El ferrocarril cubano, una expresión de crecimiento económico», en C. Naranjo y T. Mallo, eds. (1994): 325-34.

- y S. FERNÁNDEZ (1998), «La minería en Cuba en las últimas décadas del siglo XIX», en En torno al 98 (1998): $221-42$

MuNoz, P. (1997-98), «Camilo García de Polavieja», en S. Juliá, dir. (1997-98): 193.

MUÑoz, T. (1996), «La proyección de la filosofía en la construcción nacional cubana», en C. Naranjo et $a l$. , eds. (1996): 445-54.

- (1998), «La forja de la cubanidad: antecedentes y presencia del pensamiento español en Cuba (18981930)», en J.G. Cayuela, coord. (1998): 629-36.

NADAL, J. y G. TORTELla, eds. (1974), Agricultura, comercio colonial y crecimiento económico en la España contemporánea, Barcelona, Ariel.

NARANJo, C. (1987), Cuba vista por el inmigrante español (1900-1959), Madrid, Anexos de la Revista de Indias, CSIC.

- (1988), Del campo a la bodega: recuerdos de gallegos en Cuba, La Coruña, Do Castro.

- (1993), «La emigración española a Iberoamérica desde 1880 a 1930: análisis cuantitativo", en $\mathrm{ACl}$ (1993): 116-55.

- (1994), «La población española en Cuba, 18801953», en C. Naranjo y T. Mallo, eds. (1994): 121-36.

- (1995), «La historia social de Cuba en el siglo XIX, una disciplina por estudiar», en J. Opatrný, ed. (1995): 19-28.

- (1996a), «En busca de lo nacional: migraciones y racismo en Cuba, 1880-1910», en C. Naranjo et al. eds. (1996): 149-62.

-(1996b), «Hacia una sociedad moderna: inmigración y blanqueamienton, en Cuba/España (1996): 54-62.

- (1997-98), «Ramón Emeterio Betances», en S Juliá, dir. (1997-98): 161

- (1998a), «Cuba, 1898: reflexiones en torno a los imaginarios nacionales y a la continuidad», en $\mathrm{E}$ Hernández Sandoica, coord. (1998): 221-34.

- (I998b), «Hispanización y defensa de la integridad nacional en Cuba, 1868-1898», en J.A. Piqueras, coord. (1998): 71-92.

- (1998c), «Inmigration, Race and Nation in $\mathrm{Cu}$ ba in the Second Half of the Ninetheenth Century», en Race, Society... (1998): 303-26.
- (1998d), «Visiones de España en Cuba en el tránsito de siglo (1880-1910)», en A, Gutiérrez y M.L. Laviana, eds. (1998).

- (1998-99), «Evolución y revolución en el pensamiento científico de Enrique José Varona», en M.T. Cortés et al., eds. (1998-99).

-, coord. (1990), Hacer la América: un sueño continuado, monográfico de Arbor, 536-37.

-, coord. (1998), Filipinas 1898, monográfico de Revista de Indias, 213.

- et al. (1998), «Bibliografía citada», en C. Naranjo et al., eds. (1998): 819-90.

- et al., eds. (1996), La nación soñada: Cuba, Puerto Rico y Filipinas ante el 98, Aranjuez, Doce Calles.

- y A. García Álvarez (1998), «La tradición española en Cuba después del 98», en Rábida (1998): 67-80.

- y A. García GonzÁlez (1996a), Medicina y racismo en Cuba, Santa Cruz de Tenerife, Taller de Historia.

- y - (1996b), Racismo e Inmigración en Cuba en el siglo XIX, Aranjuez, FMI y Doce Calles.

$-y-(1998)$, «Inmigraciones e higiene racial en Cuba (1900-1940)", en J.G. Cayuela, coord. (1998): 437-50.

- y L.M. García MORa (1996), aCuban Documentary and Periodical Collections for the Study of ' 98 Housed in Spanish Archives, 1878-1898m, Cuban Studies, 26: 225-46

- y T. Mallo, eds. (1994), Cuba. La Perla de las Antillas, Aranjuez, Doce Calles y CSIC.

- y C. SERRANo (1999), Imágenes e imaginarios nacionales en el Ultramar español, Madrid, CSIC y Casa de Velázquez.

NAVAJAS, C. (1996), «El presupuesto de guerra. El gasto militar en la Restauración (1876-1898)», en J.P. Fusi y A. Niño, eds. (1996): 161-72.

NAVARRO, J.R. (1998), «El independentismo puertorriqueño tras el 98", en Estudios de Historia Social... (1998).

NAVARRO, L. (1998a), «1898, la incierta victoria de Cuba», en En tomo al 98 (1998): 165-87.

- (1998b), «Cuba y España en el siglo XIX: las razones de un desencuentro», en A. Gutiérrez y M.L. Laviana, coords. (1998): 19-30. drid.

- (1998c), Las guerras de España en Cuba, Ma-

NAVAS, A. (1998): «Precedentes diplomáticos de la cesión de Cuba y Puerto Ricon, en Estudios de Historia Social... (1998).

NEARING, S. y J. FREEMAN (1973), La diplomacia del dólar, La Habana, Ciencias Sociales.

NúÑEZ, L. (1998), «La prensa española en la crisis del 98", en C. Mellizo y L. Núñez, coords. (1998): 245-84.

NÚÑEZ, R. (1996a), «Los otros españoles que fueron a Cuba: el drama de los repatriados», en C. Naranjo et al., eds. (1996): 597-620.

- (1996b), «Las raices de la Ley de Jurisdicciones: los conflictos de competencia entre tribunales civiles y militares en los años 90», en J.P. Fusi y A. Niño, eds. (1996): 185-98.

R. I., $1999, \mathrm{n}^{\circ} 215$ 
- (1998), El ejército español en el desastre de 1898, Madrid.

NúN̄EZ, S. (1996), «La prensa y la opinión pública española en torno al desastre», en J.P. Fusi y A. Niño, eds. (1996): 453-64.

O, M. de la y A. LOPEZ (1997), sosé A. Cortina: muerte civil, prensa y patriodramam, en La sociedad... (1997): 147-52.

O'BRIAN, P.K. y L. PRADOS, eds. (1998), The Costs and Beneficts of European Imperialism from the Conquest of Ceuta, 1415, to the Treaty of Lusaka, 1974, monográfico de Revista de Historia Económica (1998), XVL/1.

O'DONELL, H. (1997), «La Armada: proyectos y realidades de una política naval», en J.P. Fusi y A. Niño, eds. (1997): 85-100.

OFFNER, J.L. (1997), «La política norteamericana y la guerra hispano-cubana», en J.P. Fusi y A. Niño, eds. (1997): 195-204.

OJEDA, G., ed. (1998), Nuestra guerra de Cuba. Una campaña de prensa, Llanes, El Oriente de Asturias.

OJEDA, J. de (1997-98a), «El efecto de la prensa amarillam. en S. Juliá, dir. (1997-98): 108-110.

- (1997-98b), «William McKinley», en S. Juliá, dir. (1997-98): 108 .

OLIVEROS, A. (1996), «Marco político, cultural y educativo en la trayectoria vital de Hostos», en Puerto Rico... (1996): 183-98.

Op. Cit. (1998), 10, (monográfico sobre 1898)

OPATRNÝ, J. (1986), Antecedentes históricos de la formación de la nación cubana, Supplementum de Ibero Americana Pragensia, 3.

- (1994), «Algunos aspectos del estudio de la formación de la nación cubana», en C. Naranjo y $T$. Mallo, eds. (1994): 249-60.

- (1995), «Algunos apuntes sobre los estudios de historia de Cuba en los años 90 \%, en J. Opatrný, ed. (1995): 5-18.

- (1996), «El fin de la época europea en América: Cuba, 1878-1898», en C. Naranjo et al., eds. (1996): 785-96.

- (1998a), «La crítica martiana del concepto de panamericanismo de J.G. Blaine», en W.L. Bernecker, ed. (1998): 113-30.

- (1998b), «La guerra hispano-norteamericana en la prensa checa de fines del siglo XIX», en En torno al 98 (1998): 103-24.

- (1998-99), «1898 ¿La realización del programa anexionista en Cuba?», en M.T. Cortés et al., eds. (1998-99).

- ed (1995), Cuba. Algunos problemas de su historia, Supplementum de lbero Americana Pragensia, 7.

ORIA, A. (1997), "Perspectiva de la guerra final de emancipación y de la Hispano-Americana a través de la literatura cubana», en L.E. González Vaies, ed. (1997): 245-62.

OROzCo, C. (1998), «El Ayuntamiento de Guayama y el socorro a los pobres, 1896-1901», en S. Álvarez Curbelo et al., eds. (1998): 178-92.

OROZCO, R. y N. BOLÍVAR (1998), Cubasanta, Madrid, El País-Aguilar.
ORTELLI, S. (1998), «La colonia española de México frente al conflicto", en El 98 visto... (1998): 73-86.

ORTK, F. (1916), Hampa afrocubana: los negros esclavos. Estudio sociológico y de derecho público, La Habana.

- (1973), Contrapunteo cubano del tabaco y del azúcar, La Habana, Ciencias Sociales.

- (1974), Música afrocubana, Madrid, Júcar.

- (1975), El engaño de las razas, La Habana, Ciencias Sociales.

- (1987a), Entre cubanos, La Habana, Ciencias Sociales.

- (1987b), Los negros esclavos, La Habana, Ciencias Sociales.

OTERO, C. (1998), «La Habana: tránsito de siglo, tránsito de imagen», en J.G. Cayuela, coord. (1998): 779-84.

OTERo, H. (1997), «El Maine, una víctima de anonimato cómplice», en La sociedad... (1997): 50-60.

- (1998), «Un desconocido para la historia de Cuba: Miguel Ángel de la Campa», en J.A. Piqueras, ed. (1998): 247-70.

PABÓN, C.E. (1996), «El 98 en el imaginario nacional: Seva o 'Ja nación soñada'», en C. Naranjo et al. (1996): 547-58.

PABÓN, J. (1963), «El 98 acontecimiento internacional», en Dias de ayer. Historias e historiadores contemporáneos, Barcelona, Alpha.

PAGDEN, A. (1990), Spanish Imperialism and the Political Imagination, New Haven, Yale Univ. Press.

PALACIOS, M. (1998), «El nacionalismo económico latinoamericano en los primeros años de este siglo», en $E / 98$... (1998): 61-8.

PALAZÓN, S. (1998), «La inmigración española a Cuba durante el siglo XIX», en S. Palazón y C. Saiz Pastor, eds. (1998): 49-75.

- y C. SAIZ PASTor, eds. (1998), La ilusión de un imperio. Las relaciones económicas hispanocubanas en el siglo XIX, Murcia, Univ. de Alicante.

PALMiE, S. (1998), «Fernando Ortiz and the Cooking of Historym, en Race, Society... (1998): 353-74.

PAN-MONTOJO, J. (1997-98), «La repatriación», en S. Juliá, dir. (1997-98): 190-1.

-, coord. (1998), Más se perdió en Cuba. España. 1898 y la crisis de fin de siglo, Madrid, Alianza.

PanAdero, M. (1998), «Diferenciación regional y proceso de urbanización en América Latina en el siglo XX», en J.G. Cayuela, coord. (1998): 821-33.

PANDO J. (1996) «Las conversaciones Prim Sickles: España-Cuba-Estados Unidos en 1868-1870m, en J.P. Fusi y A. Niño, eds. (1996): 359-78.

Paniagua, J. y J.A. Piqueras, eds. (1998), Poder económico y poder político, Valencia, Biblioteca Historia Social, UNED.

PARAmIO, L. (1998), «España y América, un siglo después», en El 98... (1998): 187-97.

PASCUAL, P. (1996), «El Parlamento español ante la guerra de Cuba», en J.P. Fusi y A. Niño, eds. (1996): $111+8$.

- (1998a), «Los indianos y la repatriación de capitales», en Estudios de Historia Social... (1998).

- (1998b), «La prensa cubana independentista en el exilio", en Estudios de Historia Social... (1998). 
PATERSON, T.G. (1997), «Intervención norteamericana en Cuba, 1898: historiografia sobre la guerra hispano-americano-cubano-fillipina», en M.R. Rodríguez, coord. (1997): 13-40.

PAUTÉ, J.P. (1999), «Le theme du sucre dans l'univers afro-antillais d'Alejo Carpetier», en M. Guicharnaud-Tollis, ed. (1999): 297-304.

PAZ, M. de (1994), «Algunas reflexiones sobre el bandolerismo en Cuba», en C. Naranjo y T. Mallo, eds. (1994): 163-66.

- (1996a), «Julio Sanguily y Garrite (1846-1906) y los alzamientos de febrero de 1895 en el occidente de Cuba», Revista de Indias, 207: 387-428.

- (1996b), «En torno a los alzamientos de febrero de 1895 en el Occidente de Cuba», en C. Naranjo et al., eds. (1996): 663-74.

- (1997), «La imagen de sí mismos. Los isleños en la revista Islas Canarias de La Habana», en A. Bahamonde, coord. (1997): 85-92.

- et al. (1993-94), El bandolerismo en Cuba (1800-1933). Presencia canaria y protesta rural (2 vols.), Santa Cruz de Tenerife, Taller de Historia.

- y F. Guerra (1998), Cuba y Canarias. Imágenes de una ausencia, Islas Canarias, Gobierno Canario.

- y M. HERNÁNDEZ (1992), La esclavitud blanca, Santa Cruz de Tenerife, Taller de Historia.

Pedraza, T. (1997-98a), «Carlos Manuel de Céspedes», en S. Juliá, dir. (1997-98): 17.

-(1997-98b), «Esclavitud y racismo», en S. Juliá, dir. (1997-98): 11-3.

Pelayo, F. (1998-99), «Las ciencias de la tierra en España en el tránsito del siglo XIX al XX», en M.T. Cortếs et al., eds. (1998-99).

PENABAD, A. (1997), «La educación en Cuba al finalizar el período colonial», en C. Almodóvar, comp. (1997): 17-30.

PERALTA, V. (1998-99), «El regeneracionismo en Perú (1880-1900)», en M.T. Cortés et al., eds. (1998-99).

PÉREZ, C. (1998), «Notas sobre la educación en Cuba», en A. Gutiérrez y M.L. Laviana, coords. (1998): 107-14.

PÉREZ, L. (1998a), «Imágenes del 98: visiones de una realidad histórica y su manipulación en el cine», en A. Gutiérrez y M.L. Laviana, eds. (1998).

- (1998b), «La sociedad cubana vista a través del cine», en A. Gutiérrez y M.L. Laviana, coords. (1998): 191-204.

- (1999), «Azúcar y esclavitud en el cine cubanom, en M. Guicharnaud-Tollis, ed. (1999): 369-83.

PÉREZ, L.A. (1986), Cuba Under the Platt Amendment, Pittsburgh, Pittsburgh Univ. Press.

- (1988a), Cuba Between Reform and Revolution, Nueva York, Oxford Univ. Press.

- (1988b), "Twenty-Five Years of Cuban Historiography. View of Abroad», Cuban Studies, 18: 36-58.

- (1989), Lords of Mountains. Social Banditry and Peasant Protest in Cuba, 1878-1918, Pittsburgh, Pittsburgh Univ. Press

- (1990), Cuba and United States. Ties of a Singular Intimacy, Athens, Univ. of Georgia Press.

- (1991), Intervention, Revolution and Politics in Cuba, Pittsburgh, Pittsburgh Univ. Press.
- (1995a), Essays on Cuban History: His toriography and Research. Gainesville, Florida Univ. Press.

- (1995b), «Historia, historiografia y estudios cubanos», Temas, 2: 22-35.

- (1997), «Identidad y nacionalidad: las raices del separatismo cubano, 1868-98\%, en A. Díaz Quiñones. ed. (1997): 185-94.

- (1998), The War of 1898. The United States and Cuba in History and Historiography, Chapel Hill, North Carolina Univ. Press.

PÉrez, M.E. (1998), «El 98 español visto desde Uruguay», en El 98 visto... (1998): 129-40.

PÉrez, N. (1998), «En el espacio urbano: ayer y hoy de la ciudad de La Habana. Potencialidades para la gestión comunitaria», en J.G. Cayuela, coord. (1998): 813-20.

Pérez Concepción, H. (1997), «Cuba: de colonia española a neo-colonia americana, 1898-1902», en L.E. González Vales, ed. (1997): 323-36.

Pérez GuZmán, F. (1985), «La historiografía de las guerras de independencia en veinticinco años de revolución», Revista de la Biblioteca Nacional José Martí, 21/1: 69-89

- (1996), "La Revolución del 95. Desde la conclusión de la campaña de invasión hasta el fín de la dominación española», en IHC (1996): 481-546.

- (1997a), La Habana, clave de un imperio, La Habana, Ciencias Sociales.

- (1997b), «Una herida profunda», en La sociedad... (1997): 61-7.

- (1998a), «Los efectos de la reconcentración (1896-98) en la sociedad cubana. Un estudio de caso: Güira de Melena», en A. García Álvarez y C. Naranjo, coords. (1998): 277-93.

- (1998b), Una Herida profunda, La Habana, Ciencias Sociales.

- (1998c), «La guerra de Weyles», en Cuadernos... (1998): 57-70.

- (1998-99), «Cómo favoreció la reconstrucción a la intervención norteamericana en la guerra de independencia de Cuba», en M.T. Cortés et al., eds. (199899)

- e I. Hidalgo (1996), «La Revolución del 95. De los alzamientos a la campaña de invasión», en IHC (1996): 430-80.

Pérez Herrero, P. (1996), «Los proyectos de integración de los mercados caribeños: retos actuales y experiencias históricas», en Cuba/España (1996): 7480.

PÉrez LlorCA. J.P. (1998), 1898. La estrategia del desastre, Madrid.

PÉREZ DE LA RIVA, F. (1944), El café: historia de su cultivo y explotación en Cuba, La Habana. Montero.

- (1973), La habitación rural en Cuba, La Habana, Siglo XX.

PÉREZ DE LA RIVA, J. (1970), «La contradicción fundamental de la sociedad cubana: trabajo esclavo contra trabajo libre», Economia y Desarrollo, 2: 144-54.

- (1975), «Los recursos humanos de Cuba al comenzar el siglo», en La República Neocolonial I (1975): 9-44

R. I., $1999, \mathrm{n}^{\circ} 215$ 
- (1979), «Cuba y la emigración antillana, 19001930», en La República Neocolonial II (1979): 9-50.

- (1985), Para la historia de las gentes sin historia, Barcelona, Ariel.

- (1987), El barracón, Barcelona, Grijalbo.

Pérez Rivera, J.M. (1998), «El antiguo Casino Español de San Juan tras la crisis del $1898 \%$, en S. Álvarez Curbelo et al., eds. (1998): 260-72.

PESET, J.L., coord. (1989), Ciencia, vida y espacio en Iberoamérica (2 vols.), Madrid, CSIC.

PICó, F. (1981), Amargo café. Los pequeños y medianos cafeicultores de Utuado en la segunda mitad del siglo XIX, Río Piedras, Huracán, 1981.

- (1987), 1898, la guerra después de la guerra, San Juan, Huracán.

- (1988), Historia General de Puerto Rico, Río Piedras, Huracán.

- (1997a), «Las construcciones de lo español entre los militares norteamericanos en Puerto Rico, 1898 1899", en L. Agrait y A. Cubano, coords. (1997): 625 36.

- (1997b), «Transgresiones populares de los espacios públicos urbanos en el 1898 puertorriqueño", en L.E. González Vales, ed. (1997): 337-352 y M.R. Rodriguez, coord. (1997): 113-23.

- (1998), «Del himno de Massot y Quevedo a las pedradas de Cuba: una visita al '98 utuadeño», en S. Álvarez Curbelo et al., eds. (1998): 119-27.

- (1998-99), «EI país en el ojo invasor», en M.T. Cortés et al., eds. (1998-99).

- (1999), «Representaciones del «otro» en el 98 puertorriqueño: las cartas de Charles Hartzell y Mrs. Blythe», en C. Naranjo y C. Serrano, eds. (1999).

PINo, O. (1984), Cuba, historia y economía, La Habana, Ciencias Sociales.

$-(1998)$, «El de acá y otros 98 ; un enfoque global», en $E l 98$ (1998): 14-22

PINo, R.F. (1998), Martí. Una estrella alta y luminosa, Madrid.

PIÑEIRO, J.R. (1996), «En Madrid, a principios de los sesenta», en Puerto Rico... (1996): 199-210.

PIQUERAS, J.A. (1992), La revolución democrática (1868-1874), cuestión social, colonialismo y grupos de presion, Madrid, Mterio. de Trabajo.

- (1996), «Grupos económicos y política colonial. La determinación de las relaciones hispanocubanas después del Zanjón», en C. Naranjo et al., eds. (1996): 333-46.

- (1997), «Sociedad civil, política y dominio colonial en Cuba, 1878-1898», en A. Bahamonde, coord. (1997): 93-114.

- (1998a), «Capitales en el Azúcar. Los hacendados cubanos ante la rentabilidad económica y la oportunidad de inversión (1878-1895)», en A. García Álvarez y C. Naranjo, coords. (1998): 163-94.

- (1998b), «Ensayo de contextualización de la última historiografía cubana», en J.A. Piqueras, ed. (1998): $9-40$.

- (1998c), «Mercados protegidos y consumo desigual: Cuba y el capitalismo español entre 1868 y 1898", Revista de Historia Económica, 3: 747-782.
- (1998d), «Negocios y política en el siglo XIX español», en J. Paniagua y J.A. Piqueras, eds. (1998): $11-52$.

- (1998e), «La renta colonial cubana en vísperas del 98", en J.A. Piqueras, coord. (1998): 47-70.

- (1998-99), «Competir en la colonia. Intereses, relaciones de poder y decisiones políticas (Cuba, 18781895)», en M.T. Cortés et al., eds. (1998-99).

- coord. (1998), Construvendo la nación: Cuba en el cambio de siglo, dossier de Tiempos de América, 2.

-, ed. (1998), Diez nuevas miradas de la historia de Cuba, Castellón de la Piana, Univ. Jaume I.

PIZARRo, F.J. (1998), «La gráfica política del 98: la otra guerra", en Estudios de Historia Social... (1998).

PLACER, G. (1997a), «Las acciones navaies en el teatro cubano de la Guerra de 1898», en L.E. González Vales, ed. (1997): 143-60.

- (1997b), Guerra hispano-cubano-norteamericana, La Habana, Ciencias Sociales.

- (1998a), «1898: los escenarios de la guerra y su interrelación», en Cuadernos... (1998): 121-30.

- (1998b), La explosión del Maine. El pretexto, La Habana, Política.

PlanOS, C. (1995), «Proceso de definición y asentamiento de las bases del dominio neocolonial», en A. García Álvarez y C. Planos (1995): 45-137.

PlaZA, J.A. (1997a), Al infierno con España, Madrid, Temas de Hoy.

- (1997b), El maldito verano del 98. Los 112 días de la guerra con los EE.UU., Madrid, Temas de Hoy.

La población cubana (1976), La Habana, Ciencias Sociales.

PONTE, FJ. (1944), Historia de la Guerra de los Diez Años, La Habana, Siglo XX.

PORTELA, F. et al. (1998), El ejército y la armada en el 98 , Madrid.

PORTELL VILÁ, H. (1941), Historia de Cuba en sus relaciones con los Estados Unidos y España (4 vols.), Madrid, J. Montero.

- (1949), Historia de la guerra de Cuba y de los Estados Unidos contra España, La Habana, Ofic. del Historiador de la Ciudad.

PORTUONDO, J.A. (1937), La inmigración france sa. Fomento de capital. Las nuevas ideas, monográfico de Cuadernos de Historia Habanera (1937), 10.

PORTUONDO, O. (1998), «Mentalidad y religión en la alborada de la República de Cuba», en Estudios de Historia Social... (1998).

POTTHAST-JUTKEIT, B. (1998), «The Slave Family in the Caribbean: a Research Review", en Race, Society... (1998): 279-302.

POUMIer, M. (1975). La vida cotidiana en Cuba en 1898, La Habana, Ciencias Sociales.

- (1986), Contribution à l'étude du banditisme social à Cuba, Paris, L'Harmattan.

- (1993), Abufar-Abdala. Aspect tragiques de la cubanité, I820-1880, París, Equipe de Recherche de L'Univ. Paris VIII.

PoYo, G.E. (1989), With All and for the Good All: the Emergence of the Popular Nationialism in the Cuban Communities of the United States, 1848-1868, Durham, Duke Univ. Press. 
PRADOS, L. (1988), De imperio a nación. Crecimiento y atraso económico en España, Madrid, Alianza.

- y S. AMARAL, eds. (1993), La independencio americana: consecuencias económicas, Madrid, Alianza.

La presencia española en Cuba (1868-1895) (1996), monográfico de CDESEN, 14.

PRÉSTAMO, F.J. (1996), "The Architecture of American Sugar Mills: the United Fruit Company», en Cuba Theme... (1996): 62-81.

PRUNA PM (1997), «La ciencia en Cuba en la segunda mitad del siglo XIX», en C. Almodóvar. comp. (1997): 9-16.

Puell, F. (1997), «El Grito de Baire: frustración de una vocación europeísta», en J.P. Fusi y A. Niño, eds. (1997): 101-14.

Puerto Rico ante el 98 visto desde España (1996), Madrid, Casa de Puerto Rico en España y Banco Central Hispano.

PUIG-SAMPER, M.A. (1995), «La historia de la ciencia en Cuba: algunas reflexiones críticas», en J. Opatrný, ed. (1995): 143-52.

- (1998-99) «La polémica de la ciencia española en el fin de siglo», en M.T. Cortés et al., eds. (1998-99).

- y C. Naranjo (1998), «Pensamiento científico y revolución en Cuba a finales del siglo XIX en la Revista Cubana», en Ibero Americana Pragensia (1998): 9-27.

- y - (1999), «Fernando Ortiz: herencias culturales y forja de la nacionalidad», en $C$. Naranjo y $C$. Serrano, eds. (1999).

Pujol, J. et al., eds. (1996), Cambio institucional e historia económica, Barcelona, Univ. Autónoma.

PUPO, R (1997) «Cultura, política e identidad nacional en Juan Marinello", en En busca... (1997): 23-8.

QuifaDA, M. (1997), «Latinos y anglosajones. El 98 en el fin de siglo norteamericano», en Hispania (1997): 589-609.

- (1998), «El 98 en la construcción nacional argentina», en El 98... (1998): 173-86.

QUINTERO, A.G. (1988), Patricios y plebeyos: burgueses, hacendados y artesanado obrero: la relación de clase en el Puerto Rico del cambio de siglo, Río Piedras, Huracán.

Quiroz, A.W. (1998a), «Coste socioeconómico de la Guerra de los Diez Años: insurrección cubana independentista y represión oficial española (18681878)», en J.G. Cayuela, coord. (1998): 245-282.

- (1998b), «Loyalist Oyerkill: the Socioeconomic Cost of 'Repressing' in the Separationist Insurrection in Cuba, 1868-1878", Hispanic American Historical Review, 72/8: 261-305.

QUIROz, J.C. (1998), «Los grupos políticos mexicanos ante la guerra hispano-norteamericana", en El 98 visto... (1998): 59-72.

QuizA, R. (1998), «Fernando Ortiz y su Hampa afrocubana», en J.A. Piqueras, ed. (1998): 227-46.

Rábida, 17 (1998) (monográfico sobre el 98).

Race, Society and Culture in Afro-Latin America (1998), monográfico de Ibero-Amerikaniche Archiv,
24, 3/4. (coordinador por R. Liehr, M. Röhrig Assuncao y M. Zeuske).

Raices históricas del pueblo cubano (l y II) (1991 y 1993), monográficos de Arbor, 547-548 y 567.

RAMfREZ, J. (1998), «lmpactos del 98 en el campo religioso cubanom, en El 98 (1998): 34-4l.

RAMOS, A. (1988), La sociedad del azúcar en Puerto Rico, San Juan, Univ, de Puerto Rico.

RaMoS, A.G. (1987), Las ideas anexionistas en Puerto Rico bajo la dominación norteamericana, Río Piedras, Huracán.

Ramos, D. (1997), «Lo que hubiera supuesto el triunfo de la revolución de Martí para Cuba y Puerto Ricom, en L.E. González Vales, ed. (1997): 221-44.

RAMOS, R. (1994), «Los fondos del Archivo Nacional para la historia de Cuba en los siglos XIX y XX», en C. Naranjo y T. Mallo, eds. (1994): 65-74.

REMESAL, A. (1998), El enigma del Maine. 1898. El suceso que provocó la guerra de Cuba. ¿Accidente o sabotaje?, Barcelona, Paza \& Janés.

La República Neocolonial I y II (1975 y 1979), monográfico de Anuario de Estudios Cubanos, 1 y II.

Revista Española del Pacífico (1997 y 1998), VII/7 y VIII/8, (monográficos sobre 1898)

RiCHARD, M.T. (1999) «mages de vie: Cuba et la canne à sucre», en M. Guicharnaud-Tollis, ed. (1999); 323-34.

RiverA, B. (1998), «El puerto de San Juan en la coyuntura de 1898", en S. Álvarez Curbelo et al., eds. (1998): 95-118.

Rivero, A. (1972), Crónica de la Guerra Hispanoamericana en Puerto Rico, San Juan, Inst. de Cultura Puertorriqueña.

RIVERO MUÑIZ, J. (1958), Los cubanos en Tampa, La Habana.

- (1961), El movimiento obrero durante la primera intervención, Santa Clara, Univ. Central de Las Villas.

- (1962), El primer partido socialista cubano, Santa Clara, Univ. de Las Villas.

- (1964), Tabaco: su historia en Cuba (2 vols.), La Habana, IHC

ROBLES, C. (1996), «España y Europa durante la crisis cubana (1896-1897)", en C. Naranjo et al., eds. (1996): 729-54.

- (1997), «España y las alianzas europeas en 1898», en Hispania (1998): 479-514.

Rodó, J.E. (1900), Ariel, Lima, Peisa.

RoDriGo, M. (1996), Antonio López y López (1817-1883), primer Marqués de Comillas. Un empresario y sus empressas, Madrid, Fund. Empresa Pública.

- (1997), «Els condicionaments de la política colonial espanyola a Cuba (1868-80)m, en J. Casanovas, coord. (1997): 28-33.

- (1997-98), «La politica naval antes del 98», en S. Juliá, dir. (1997-98): 126-7.

- (1998a), «El Banco Hispano Colonial y Cuba (1876-1898)m, en Ibero Americana Pragensia (1998): $111-28$

- (1998b), «Colonias, negocio y poder en la Restauración (1875-1898)», en J. Paniagua y J.A. Piqueras, eds. (1998): 81-112.

R. I., $1999, \mathrm{n}^{\circ} 215$ 
RoDrígueZ, J.J. (1998), «El nacionalismo radical en la fase de maniobra: Pedro Albizu Campos y el mito de la nación perfectas, en Op. Cit. (1998): 25-60.

Rodríguez, A.R. (1996), «La situación de la Armada en 1894 a través de los informes parlamentarios», en J.P. Fusi y A. Niño, eds. (1996): 199-210.

- (1997), El desastre naval de 1898, Madrid.

- (1998a), La guerra del 98. Las campañas de Cuba, Puerto Rico y Filipinas, Madrid.

- (1998b), Operaciones de la guerra de 1898 Una revisión crítica, Madrid.

RODRfGuez, E. (1998), «Semblanza de una estadística radical, mi padre y el $98 \%$, en S. Álvarez Curbelo et al., eds. (1998): 11-8.

RODRfGUEZ, E.L. (1996), «The Architectura Avant-Garde: from Art Deco to Modern Regionalism», en Cuba Theme... (1996): 254-77.

RodrfGUEZ, M.R. (1996), «El resurgimiento del destino manifiesto en la década de los 90 'sm, en C. Naranjo et al., eds. (1996): 809-18.

- (1998-99), «El proyecto geopolítico norteamericano de fin de siglo», en M.T. Cortés et al., eds. (1998-99).

-, coord. (1997), 1898. Entre la continuidad y la ruptura, Morelia, Univ. Michoacana San Nicolás do Hidalgo.

RODRIGUEz, P.P. (1998), «Moderninidad y 98 en Cuba: alternativas y contradicciones», en El 98 (1998): 13-8.

- y R. de ARMAS (1996), «El inicio de una nueva etapa del movimiento patriótico de liberación nacional», en IHC (1996): 318-79.

RODRIGUEZ, R. (1997), «El 98, epifanía de un nuevo imperialismo", en La sociedad... (1997): 99-103.

- (1998), «La disolución del Ejército Libertador el gran objetivo de los Estados Unidos», en El 98 (1998): 42.7

- (en prensa), Cuba: la forja de la nación, $\mathrm{La}$ Habana.

RODRÍGUEZ CASTRO, M. (1998), «El '98: los arcos de la memoria», en S. Álvarez Curbelo et al., ed. (1998).

RODRíGueZ PIÑA, J. (1990), Guerra de castas. La venta de los indios mayas a Cuba, 1848-1861, México, CONACA.

ROHRIG ASSUNÇAO, M. y M. ZEUSKE (1998) «Ethnicity and Social Structure in 19th Brazil and Cuba», en Race, Society... (1998): 375-444.

RorG, E. (1961), Cuba no debe su independencia a los Estados Unidos, La Habana, La Tertulia.

- (1973), Historia de la Enmienda Platt, La Habana, Ciencias Sociales.

Rojas, R. (1997-98a), «José Martí», S. Juliá, dir (1997-98): 49 .

- (1997-98b), «Una guerra entre cuatro», en $S$. Juliâ, dir. (1997-98): 43-8.

- (1998), «Cuba mexicana: el último proyecto de anexión (1896-1898)», en El 98. (1998): 161-72.

ROLDÁN, I. (1990), La Hacienda en Cuba durante la Guerra de los Diez Años, 1868-1878, Madrid, Inst. de Estudios Fiscales.

- (1991) La Unión Constitucional y la política de España en Cuba, 1868-1898, Ph. D., Madrid, Univ. Complutense.
- (1994), «El fracaso de las reformas en Cuba: la cuestión electoral», en C. Naranjo y T. Mallo, eds. (1994): 223-38.

- (1995), «El Banco Español de La Habana (18561881)m, Revista de Historia Económica, 2: 281-310.

- (1996), «Cuba entre Romero Robledo y Maura», en C. Naranjo et al., eds. (1996): 377-90.

- (1997a), «España y Cuba. Cien años de relaciones financieras», en A. Bahamonde, coord. (1997): 35-69.

- (1997b), «Guerra y finanzas en la crisis de fin de siglo, 1895-1900", en Hispania (1997): 611-75.

- (1998), Bibliografía sobre historia económica cubana en el siglo XIX, Madrid, Fund. de Empresa Pública (título provisional).

Rosario, C. (1997), «El '98 puertorriqueño en tres tiempos: ensayo historiográfico», en L.E. González Vales, ed. (1997): 43-80.

Rosario, J.C. y G. SIERra (1997), «El Patronato festivo y la evocación ritual de San Juan en Contramaestre», en J.A. Galbán, ed. (1997): 125-30.

ROSARIO, M. (1998), «Reclamos de identidad social en las narraciones protestantes: transformaciones de un proyecto civilizatorio», en $O p$. Cit. (1998): 153-74.

RoviRA, J.C. (1999), «La imagen reflejada en $E s$ pejo de Paciencia de Silvestre Balboam, en C. Naranjo y C. Serrano, eds. (1999)

RuANO, A. (1993), Biografia de Hostos, Moca, Centro Cultural.

RUIZ, J.B. (1998), «Los Estados Unidos hacia 1898», en A. Gutiérrez y M.L. Laviana, coords. (1998): 43-62.

RUIz ACosTA, M.J. (1996), Sevilla e Hispanoamérica. Prensa y opinión pública tras el desastre del 98, Sevilla, Esc. de Estudios Hispano-Americanos, (CSIC).

- (1998), «Entre la estima y el reproche. Visión periodística de los contactos entre España e Hispanoamérica (1898-1903)m, en Estudios de Historia Social.. (1998).

SAGARDIA, A. (1998), «La Carta Autonómica y las Actas Foraker y Jones: análisis comparativo", en J.E. Hernández, ed. (1998): 59-70.

SÁINZ, L. (1989), Historia de la literatura hispanoamericana, Sevilla, Esc. de Estudios Hispano-Americanos, (CSIC)

SAIZ PASTOR, C. (1990), Liberales y esclavistas. El dominio colonial español en Cuba, 1833-1868, Alicante, Univ. de Alicante.

- (1994), «El colonialismo español en el Caribe durante el siglo XIX: el caso cubano", en C. Naranjo y T. Mallo, eds. (1994): 213-22.

- (1998), «El imperio de Ultramar y la fiscalidad colonial», en S. Palazón y C. Saiz Pastor, eds. (1998) $77-93$.

SALOM, J. (1967), España en la Europa de Bismark, Madrid, CSIC, 1967.

- (1988), «La Restauración y la política exterior de Españan, en La monarquía española en la historia de las relaciones internacionales, Madrid, Esc. Diplomática. 
SÁNCHEZ, A.P. (1996), "Maten canarios hasta que se les canse el brazo: la presencia canaria en Cuba hasta la crisis de 1933», en Cuba/España (1996): 20-2.

SÁNCHEZ, 1. (1998), «La prensa como fuente de información en torno al $98 \%$, en J.G. Cayuela, coord. (1998): 75-112.

SÁNCHEZ, J.B. (1998), «Narraciones de esclavos afrocubanos y afroamericanos», en J.G. Cayuela, coord. (1998): 703-16.

SÁNCHEZ, J.J. (1998), «El intervencionismo cultural norteamericano en Cuba a travês de la imagen», en A. Gutierrez y M.L. Laviana, eds. (1998).

SÁNCHEZ-ALBORNOZ, N. (1998), «A propósito de Cuba en el año 1897. Una especulación con la rivalidad del marco internacional», en J.G. Cayuela, coord (1998): 33 I- 44

- comp. (1988), Españoles hacia América. La emigración en masa, 1880-1930, Madrid, Alianza.

SÁNCHEZ Alonso, B. (1990), «Una nueva serie anual de la inmigración española, 1882-1930», Revista de Historia Económica. VIII/1: 133-70.

- (1995), Las causas de la emigración española a América, 1880-1930, Madrid, Alianza.

SANCHEZ ANDRÉS, A. (1996a), La política colonial española (1810-1898). Administración central estatuto juridico-político antillano, $\mathrm{Ph}$. D., Madrid, Univ. Complutense.

- (1996b), «El proceso de toma de decisiones en la política colonial española», en J.P. Fusi y A. Niño, eds. (1996): 253-62.

- (1997a), «La alternativa federal a la crisis colonial. Las colonias en Ios proyectos de organización federal del Estado (1972-1873), Revista Complutense de Historia de América, 23: 193-208.

- (1997b), «Los presupuestos de Filipinas y las Antillas (1863-1898)», en Revista Española del Pactíco (1997): 11-29.

- (1998a), «El 98 en la coyuntura imperial (Michoacán, 1997)», en J.A. Piqueras, coord. (1998): 151-52.

- (1998b), «La crisis de 1898 y las relaciones hispanoamericanas", en $E l 98$ visto... (1998): 45-58.

- (1998-99), «La frustrada integración de las Antillas en el Estado liberal: el debate en torno al estatuto jurídico-político colonial entre 1808 y 1898 », en M.T. Cortés et al., eds. (1998-99)

SÁNCHEZ BAENA, J.J. (1998), «Aproximación a la historia del imperialismo editorial de Estados Unidos en la etapa preindependentista cubana: entre la necesidad y el exilio», en En torno al 98 (1998): 81-102.

Santamaría, A. (1993), «El legado filosófico de Ortega en América Latina. José Gaos y el Movimiento de Historia de las Ideas», Anuario de Estudios Americanos, L/2: 279-308.

- (1994a), «Los ferrocarriles de servicio público de Puerto Rico (1870-1990)", Revista Complutense de Historia de América, 20: 207-28.

- (1994b), «La historia de Cuba en el Siglo XIX a través del debate de investigadores cubanos y españoles», Revista de Indias, 200: 221-31.

- (1995a), «Los ferrocarriles de servicio público cubanos (1837-1929). La doble naturaleza de la dependencia azucarera», Revista de Indias, 204: 485-515.
- (1995b), La industria azucarera y la economía cubana en los años veinte y treinta, Ph. D., Madrid, Univ. Complutense (I.U. Ortega y Gasset).

- (1996a) «Caña de azúcar y producción de azúcar en Cuba. Crecimiento y organización de la industria azucarera cubana desde mediados del siglo XIX hasta la finalización de la Primera Guerra Mundial», en C. Naranjo et al, eds. (1996): 225-50.

- (1996b), «Cuba, evolución socio-económica y formación nacional», Revista de Indias, 207: 505-38.

- (1998a), «La ambigua capacidad explicativa del azúcar. Historia económica y fin de siglo en Cuba. Resultados, carencias, perspectivas y bibliografían, en Estudios de Historia Social y Económica... (1998).

- (1998b), «Canales, cafetales y banano. Historia del ferrocarril de servicio público en Centroamérica y Panamá», en J. Sanz, coord. et al. (1998b): 249-88.

- (1998c), "Cuba", en J. Sanz, coord. et al. (1998a).

- (1998d), «El ferrocarril en las Antillas españolas, Cuba, Puerto Rico y la República Dominicana (18301995)», en J. Sanz, coord. et al. (1998b): 289-34

- (1998e), «Puerto Rico», en J. Sanz, coord. et al. (1998a)

- (1999), "Auge, alteración y crisis y ajuste de una economía de exportación. Cuba, 1898-1939», en E. Cárdenas et al., eds. (1999).

- (inédito-a), «Análisis de los costes de producción del azúcar en Cuba, 1804-1912», Oxford.

- (inédito-b), «Precios, sector externo y crecimiento económico en Cuba, 1872-1912», Oxford (en evaluación por la Revista de Historia Económica).

- y L.M. GARCIA MORA (1998a), «Colonos.

Agricultores cañeros, iclase media rural en Cuba?, 1880-1898", en A. García Álvarez y C. Naranjo, coords. (1998): 131-62.

$-y-(1998 b)$, «A propósito de la industria azucarera en Cuba. Mano de obra y tecnología (18601877)», en J.G. Cayuela, coord. (1998): 283-98.

- y C. NARANJo (1999), «La historia social, 1868-1914. Aportaciones recientes y perspectivas», Historia Social, 33.

SANTANA, J. (1997), «Las ideas en Cuba al cese del dominio colonial. Una aproximación crítica», en C. Almodóvar, comp. (1997): 73-82.

SANTIAGO, A. (1996), «Contrapunto boricua: Ponce y San Juan ante la Ilegada de los americanos», en C. Naranjo et al., eds. (1996): 559-66.

SANZ, J., coord. et al. (1998a), Guía histórica de los ferrocarriles en lberoamérica (1837-1995) (CDRom) Madrid, Minist. de Fomento (CEDEX/CEHOPU) y Fund. de los Ferrocarriles Españoles.

-, coord. et al. (1998b), Historia de los ferrocarriles en lberoamérica (1837-1995), Madrid, Minist. de Fomento (CEDEX/CEHOPU) y Fund. de los Ferrocarriles Españoles.

SCARANO, F.A. (1984), Sugar and Slavery in Puerto Rico: the Plantation Economy of Ponce, Madison, Winconsin Univ. Press.

- (1990), «El colonato azucarero en Puerto Rico, 1873-1934», Historia y Sociedad, 3: 143-67.

- (1993), Puerto Rico. Cinco siglos de historia, San Juan, McGraw-Hill.

R. I., $1999, \mathrm{n}{ }^{\circ} 215$ 
- (1998), «Liberal Pacts and Hierarchies of Rule: Approaching the Imperial Transition in Cuba and Puerto Rico", en Hispanic... (1998).

- et al. (1981), Inmigración y clases sociales en el Puerto Rico del Siglo XIX, Río Piedras, Huracán.

SCHMidT-NowARA, Ch. (1995), The Problem of Slave in the Age of Capitalism: Abolitionism, Liberalism and Counter-Hegemony in Spain, Cuba and Puerto Rico, 1833-1886, Ph. D., Michigan, Univ. of Michigan.

- (1997), «Reforma entre revolucionaris: Puerto Rico i els límits de la política», en J. Casanovas, coord. (1997): 43-7.

- (1998a), «Imperio y crisis colonial», en J. PanMontojo, coord. (1998): 31-89.

- (1998b), «National Economy and Atlantic Slavery: Protectionism and Resistence to Abolitionism in Spain and the Antilles, 1854-1874», en Hispanic.. (1998).

SCHOONOVER, T. (1998), «Columbus, the SpanichCuban-American War, and the Advance of the U.S. Liberal Capitalism in the Caribbean and Pacific Region», en W.L. Bernecker, ed. (1998): 61-76.

SCHWARTD, R. (1989), Lawles Liberators: Political Banditry and Cuban Independence, Durham, Duke Univ. Press.

SCoTr, R.J. (1985), Slave Emancipation in Cuba: the Transition to Free Labor, 1860-1899, Princenton, Princenton, Univ. Press.

- (1987), «La dinámica de la emancipación y la formación de la sociedad post-abolicionista», Santiago, 66: 49-77.

- (1995), «Relaciones de clase e ideología raciales: la acción rural colectiva en Louisina y Cuba, 1865 1912», Historia Social, 22: 89-111.

- (1996), «'The Lower Class of Whites' and 'the Negro Element': Race, Social Identity and Politics in Central Cuba, 1899-1909», en C. Naranjo et al., eds. (1996): 179-92.

- (1997a) «Raza, clase y acción colectiva en Cuba, 1895-1902: la formación de alianzas interraciales en el mundo de la caña», en A. Díaz Quiñones, ed. (1997): 131-56.

- (1997b), «Visiones retrospectivas de la guera de 1895-98: la documentación del Spanish Treaty Claims Commission y del Army of Cuban Pacification (U.S. National Archives)», en M.R. Rodríguez, coord. (1997): 83-91.

- (1998), «Race, Labor, and Citizenship in Cuba: A View from the Sugar District of Cienfuegos, 1886 1909», en Hispanic... (1998).

SEOANE, M.C. (1997-98), «El desastre en los diarios españoles», en S. Juliá, dir. (1997-98): 138-9.

SEPÚl VEDA, I. (1996), « Viva Cuba Libre!: análisis crítico del nacionalismo martiano», en J.P. Fusi y A. Niño, eds. (1996): 85-98.

SERGE, R. (1998), «La revolución confiscada: Teodoro Roosevelt y el racimiento de la república de Cuba», en En tomo al 98 (1998): 61-72.

SERRA, S. (1996), «La política emigratoria en la primera etapa de la Restauración. Las Islas Baleares y las Islas Canarias», en J.P. Fusi y A. Niño, eds. (1996): $133-42$.
Serrano, C. (1996), «Cuba: los inicios de una guerra gráfica», en C. Naranjo et al., eds. (1996): 675-84. - (1999), «Vara del Rey y los héroes de Caney: un mito de doble cara», en C. Naranjo y C. Serrano, eds. (1999).

SERRANO, J.M. (1987), El viraje proteccionista de la Restauración. La Política comercial española, 1878-1895, Madrid, Siglo XXI

SERRANO DE HARO A (1996), "Tres notas sobre Rafael María de Labra», en C. Naranjo et al., eds. (1996): 49-64

SEVILLA, R. (1996), La Guerra de Cuba y la memoria colectiva. La crisis del 98 en la prensa sevillana, Sevilla, Esc. de Estudios Hispanoamericanos. (CSIC).

- (1998a), «España-Cuba 1898: prensa y opinión pública», en A. Gutiérrez y M.L. Laviana, coords. (1998): 31-42.

- (1998b), «La imagen de los Estados Unidos en España», en A. Gutiérrez y M.L. Laviana, eds. (1998).

- (1998c), «¿Opinión pública frente a opinión publicada? 1898: la cuestión cubana», en A. Garcia Álvarez y C. Naranjo, coords. (1998): 255-76.

SICARD, A. (1999), «Lorca y Lezama a la luz de Góngora», en C. Naranjo y C. Serrano, eds. (1999).

SilveSTRINI, B.G. y M.D. LUQUE (1992), Historia

de Puerto Rico: irayectoria de un pueblo, San Juan, Cultural Panamericana.

Simón, M.C. (1986), Rafael María de Labra, Madrid, Inst. de Estudios Madrileños.

SMITH, A. y E. DÁvila, eds. (1998), The Crisis of 1898. Colonial Redistrution and Nationalism Mobilization. Londres.

SMITH, R.F. (1960), The United States and Cuba. Business and Diplomacy, New Haven, Borkman Ass.

La sociedad cubana más allá del 98 (1997), monográfico de Debates Americanos, 4.

SOLANO, F. Y A. GIMERÁ, coords. (1990), Esclavitud y derechos humanos, Madrid, CSIC.

SOMMER, D. (1997), «Puerto Rico a flote: desde Hostos hasta hoy», en A. Díaz Quiñones, ed. (1997): 253-62.

SONESSON, B. (1995), Catalanes en las Antillas. Un estudio de casos, Colombres, Archivo de Indianos. SOSA, E. (1998), «La literatura cubana de entresiglos», en J.G. Cayuela, coord. (1998): 693-702.

SoTO, L.D. (1981), Apuntes sobre la historia de la minería en Cuba, Santiago, Univ. de Oriente.

STEWARD, J.H. et al. (1974), The People of Porto

Rico, Chicago, Univ. of Illinois Press.

STOLKE, V. (1992), Racismo y sexualidad en la Cuba colonial, Madrid, Alianza.

StubBs, J. (1989), El tabaco en la periferia. El complejo agro-industrial cubano y su movimiento obrero, 1860-1959, La Habana, Ciencias Sociales.

- et al., comps. (1996), Cuba, World Bibliographical Series, 75, Oxford, Clio Press.

SuÁrez-GalBáN, E. (1996), «El bufete del diablo: polémica de la poesía puertorriqueña en inglés». en Puerto Rico... (1996): 211-30.

SUBiRATS, E. (1997), «España 1898: decadencia y modemidad», en A. Díaz Quiñones, ed. (1997): 325-44. 
TABARES, J. (1997), «Estados Unidos, la sociedad política norteamericana y el $98 »$, en La sociedad... (1997): 21-32.

TEDDE, P., ed. (en prensa), Antecedentes y consecuencias económicas del 98, Madrid, Síntesis.

THOMAS, H. (1973), Cuba, la lucha por la libertad (3 vols.), Barcelona, Grijalbo.

- (1997-98), «La explosión del 'Maine'», en S. Juliá, dir. (1997-98): 101-6.

- (1998), Historia de la trata de esclavos, Barcelona, Planeta.

Thomson, L. (1996), «Estudiarlos, juzgarlos y gobernarlos: conocimiento y poder en el archipiélago imperial norteamericano», en C. Naranjo et al., eds. (1996): 685-94.

- (1997), «Las fundaciones culturales del imperio: un estudio comparativo de la política estadounidense en Puerto Rico, Hawai y Filipinas», en M.R. Rodríguez, coord. (1997): 192.

Tío, A. (1973), «Breve historia de los ferrocarriles de Puerto Rico», Boletín de la Academia Puertorriqueña de la Historia, 10: 105-16.

TOLEDO, L. (1997a), «1898 en el desconcierto del mundo», en La sociedad... (1997): $91-4$.

- (1997b), Cesto en llamas. Biografía de José Marti, La Habana, Ciencias Sociales. 89-99.

- (1998a), «95 vs. 98», en Casa de las... (1998):

- (1998b), «La literatura cubana hacia/desde 1898\%, en A. Gutiérrez y M.L. Laviana, coords. (1998): 115-40.

- (1998c), «De la guerra y otros vínculos entre Cuba y Españas, en A. Gutiérrez y M.L. Laviana, eds. (1998).

- (1998d), «En vísperas de otro 98 y a propósito de Espartaco», en A. Gutiérrez y M.L. Laviana, coords. (1998): 63-72.

TORNERO, P. (1996), «Estados Unidos y Europa ante el 98 cubano, pasado y presente», en C. Naranjo et al., eds. (1996): 575-84

- (1998a), «Desigualdad y racismo. Demografia y sociedad en Cuba a finales de la época colonial», en A. García Álvarez y C. Naranjo, coords. (1998): 25-46. - (1998b), «La guerra y la población en Cuba», en A. Gutiérrez y M.L. Laviana, eds. (1998).

$-(1998 \mathrm{c})$, «El peso del colonialismo. Integración y racismo en la Cuba de 1898m, en Rábida (1998): 5-10.

En torno al 98 (1998), monográfico del Anuario de Estudios Americanos, LV/1.

En tomo al 98: Cuba, Puerto Rico y Filipinas, 1880-1910 (1995), monográfico de Cuadernos Rayuela, 6 .

TORO, C. del (1997), «EJ movimiento obrero cubano, 1898-1909», en C. Almodóvar, comp. (1997): $50-61$.

- (1998), «El movimiento obrero en Cuba: dos décadas de historiografía (1973-1995)», en EI 98 (1998): 216-25.

TORO, R.J. (1982), Historia económica de Puerto Rico, Cincinatti, South-Western.

TORRE, M. de la (1985), «Veinticinco años de historiografía cubanam, Revista de la Biblioteca Nacional José Martí, 27/1:90-110.
- (1997a), «Els derechs politics $\mathrm{i}$ el problema electoral a Cuba (1878-1898), en J. Casanovas, coord. (1997): 34-37.

- (1997b), «Ideología y cultura política en 1898 », en M.R. Rodríguez, coord. (1997): 123-8.

- (1997c), «El Partido Liberal Autonomista: estructura y etapas, 1878-1898», en C. Almodóvar, comp. (1997): 97-109.

- (1998a), El autonomismo cubano, 1878-1898, La Habana, Ciencias Sociales.

- (1998b), «El debate en tomo a los planes Romero-Abárzuza y Autonómico", en Cuademos... (1998): 39-56.

- (1998c), «Las elecciones en La Habana», en M.C. Barcia et al. (1998): $71-133$.

TORRE, R. de la (1988), Inglaterra y España en 1898, Madrid, Eudema.

- (1997a), «1895-1898: Inglaterra y la búsqueda de un compromiso internacional para frenar la intervención norteamericana en Cuba», en Hispania (1997): 515-49.

- (1997b), «La situación internacional en los años 90 y la política exterior española», en J.P. Fusi y A. Niño, eds. (1997): 163-72.

- (1997-98), «El Tratado de París», en S. Juliá, dir. (1997-98): 165-69.

- (1998-99) «La seguridad del estrecho de Gibraltar como condicionante de la política exterior española en la crisis internacional de 1898 », en M.T. Cortés et al., eds. (1998-99).

TORRECH, R.A. (1997), «La gestión de gobierno del gabinete autonómico en Puerto Rico», en M.R. Rodríguez, coord. (1997): 186.

- (1998-99), «De propaganda a gobierno: la ocupación autonomista de la administración pública puertorriqueña», en M.T. Contés et al., eds. (1998-99).

TORRES, L. (1998), «La autonomía y sus efectos políticos en la ciudad de San Germán», en J.E. Hernández, ed. (1998): 29-36.

TORRES, S. (1997), «Hacia una identidad racial alternativa en la sociedad dominicana», en A. Díaz Quiñones, ed. (1997): 235-52.

TORRES, V.M. y C. ButrRaGo (1998), «Dos Estados y un pueblo: la redefinición de un centenario en Adjuntas, 1869-1902», en S. Álvarez Curbelo et al., eds. (1998): 69-77.

TORRES-CUEVAS, E. (1993), «Patria, pueblo y revolución: conceptos base para la historia de la cultura en Cuba», en ACI (1993): 1-22.

- (1997), «En busca de la cubanidad (III)», en En busca... (1997): 3-10.

- (1999), «El azúcar y la formación de los complejos económico-sociales regionales», en M. Guicharnaud-Tollis, ed. (1999): 51-70.

- (inédito), Historia de la Iglesia Católica en Cu$b a$, La Habana.

- et al. (1996), «La Revolución del 68. Fundamentos e inicion, en IHC (1996): I-55.

- y E. REYES (1986), Esclavitud y sociedad. Notas para el estudio de la esclavitud negra en Cuba, $\mathrm{La}$ Habana, Ciencias Sociales.

R. I., $1999, \mathrm{n}^{\circ} 215$ 
TORTELLA, G. (1964), «El desarrollo de la industria azucarera y la Guerra de Cuba», Moneda y Crédito, 91: 131-63.

- (1997-98), «Lo que se perdió en Cuba», en S. Juliá, dir. (1997-98): 197-202.

TOUSSAINE, M. (1998-99), «De Blaine a Prelinghuysen: el Departamento de Estado y el interés estratégico en Centro América (1881-1885)», en M.T. Cortés et al., eds. (1998-99).

TRASK, D.F. (1997a), «La guerra cubano-hispanoamericana durante el año 1898», en M.R. Rodríguez, coord. (1997): 66-82.

- (1997b), «The Influence of International History on the U.S. Historians of the Cuban-SpanishAmerican War», en L.E. González Vales, ed. (1997): 97-110.

TRIBIN, G. (1996), «Reafirmación del idioma español en Puerto Rico y defensa de su identidad iberoamericana», en Puerto Rico... (1996): 231-6.

Tusell, J. y F. PORTERO, eds. (1998), Antonio Cánovas y el sistema político de la Restauración, Madrid, Biblioteca Nueva y Congreso de los Diputados.

UBIETA, E. (1997), "La independencia no es un valor abstracto», en Contracorriente (1997): 3-5.

UCELAY-DA CAL, E. (1997), "Cuba y el despertar de los nacionalismos en la España peninsular», en A. Bahamonde, coord. (1997): 151-92.

Un último amor 1898. Imágenes de la inmigración española a Cuba (1998), Madrid, AECI.

URía, J., ed. (1994), Asturias y Cuba en torno al 98, Barcelona, Labor.

URIBE, J.A. (1995), «La historiografía minera en Cuba: carencias y perspectivas», en J. Opatrný, ed. (1995): 161-76.

- (1998-99), «Depreciación de la plata y ciencia de los metales en la coyuntura de fin de siglo», en M.T. Cortés et al., eds. (1998-99).

URRUTIA, M.R. (1996), «Reconstruyendo la nación: la idea del progreso en el discurso anti-alcohol, 1898-1917», en C. Naranjo et al., eds. (1996): 585-94.

- (1998), «La claúsula prohibicionista de la Ley Jones, ficha de tranque a las aspiraciones autonomistas, 1915-1917», en J.E. Hernández, ed. (1998): 71-84.

VALDES, M. (1998), «Desmontando discursos: el nuevo orden forestal en el imaginario colonial, 1898 . 1925», en S. Álvarez Curbelo et al., eds. (1998): 78-94.

VALLE, A.R. del (1998), «El marco bibliográfico y archivístico general para el estudio del 98», en J.G. Cayuela, coord. (1998): 61-74.

VÁSQuEZ, C. (1999), «La novela de la caña en Puerto Rico», en M. Guichamaud-Tollis, ed. (1999): 335-46.

VELASCO, R.N. (1998), «La construcción legal de la familia en el Puerto Rico de entresiglos", en $S$. Álvarez Curbelo et al., eds. (1998): 158-77.

VENEGAS, C. (1996), «Havana between Two Centuries», en Cuba Theme... (1996): 12-35.
VENEGAS, H. (1980), «Consideraciones en tomo a la economía remediana colonial», Islas, 67 (1980): 63-91.

- (1995), «Acerca del proceso de concentración y centralización de la industria azucarera en la región remediana a finales del siglo XIX», Islas, 73: 103-46.

VIAÑA, E. (1998), «¿Pantanos o acorazados? Economía y defensa en la España del novecientos», en J.G. Cayuela, coord. (1998): 311-28.

VICENTE, U. (1992), Don Rafael María de Labra y Cadrana. Reformador de la educación nacional, Granada, Univ. de Granada.

VIEIRA, A., coord. (1996), Escravos com e sem açucar, Coimbra, Centro de Estudios de Historia do Atlántico.

VilleNA, R. (1998), «Estados Unidos y el Caribe en el siglo XIX», en J.G. Cayuela, coord. (1998): 401-18.

VINAT, R. (1998a), «Accionar político de las cubanas durante la etapa de entreguerras», en M.C. Barcia et al. (1998): 272-353.

- (1998b) «A cien años de una experiencia (participación femenina en la lucha independentista cubana, 1895-1898», en Cuadernos... (1998): 107-20.

VITIER, C. (1997), «Martí y el 98 de ayer y hoy», en $L a$ sociedad ... (1997): 104-5.

- (1998), "Nuestro hombre del 98», en Casa de las... (1998): 38-45.

VIVoni, E. (1998), «San Juan de Puerto Rico: de plaza fuerte a ciudad bella», en S. Álvarez Curbelo et al., eds. (1998): 19-37.

WALLICH, H.C. (1953), Problemas monetarios de una economía de exportación. La experiencia cubana. 1914-1947, La Habana, Banco Nacional.

WRIGHT, P.H. (1931), The Cuban Situation and Our Treaty Relations, Washington, Brookings Inst.

XIXIREY, C. y J.R. CAMPOS (inédito), Los Centros Gallegos en América, Ourense, Diputación Provincial (título provisional)

YAÑNEZ, C. (1994a), La emigración española a América (siglos XIX y XX). Dimensión y características cualitativas, Colombres, Archivo de Indianos.

- (1994b), Saltar con red. La emigración catalana a América, Ph. D., Barcelona, Univ. Autónoma.

YGLESIAS, T. (1977), Cuba: primera República, segunda ocupación, La Habana, Ciencias Sociales.

ZANETTI, O. (1975), «El comercio exterior de la República Neocolonial», en La República Neocolonial I, (1975): 45-183.

- (1985), «La historiografia de temática social», Revista de la Biblioteca Nacional José Martí, 27/1: 111-36.

- (1989), Los cautivos de la reciprocidad, La Habana, EMPES

- (1994), «Realidades y urgencias de la historiografía social cubana», Historia Social, 19: 99-112.

- (1997), «El factor comercial en la crisis colonial», en C. Almodóvar, comp. (1997): 40-9. 
- (1998a) «1898: comercio, reciprocidad, modernización», en El 98 (1998): 48-61.

- (1998b), «El camino al 98: Cánovas y el problema económico de Cuba (1878-1881)», en A. García Álvarez y C. Naranjo, coords. (1998): 195-214.

- (1998c), Comercio y poder. Relaciones cubanohispano-norteamericanas en tomo a 1898, La Habana. Casa de las Américas.

- (1998d), «Cuba y 1898», en Rábida (1998): 33-50.

- (1998e), «Nación y modernización; significados del 98 cubano», Debates Americanos (1998).

- (1998f), «Política comercial de la Restauración: el caso del comercio cubano», en Cuadernos... (1998): $11-26$.

- (1998g), «Las relaciones comerciales hispanocubanas en el siglo XIX», en S. Palazón y C. Saiz Pastor, eds. (1998): 95-117.

-, M.C. BARClA et al. (1997), "Significación del 98... Mesa redonda entre historiadores cubanos acerca de un centenario de entre siglos", en La sociedad.. (1997): 179-94.

- y A. García Álvarez (1976), United Fruit Co.: un caso de dominio imperialista en Cuba, La Habana, Ciencias Sociales.

- y - (1987), Caminos para el azúcar, La Habana, Ciencias Sociales.

- y - (1998), Sugar and Railroads, Chapel Hill, North Carolina Univ. Press.

ZAPATERo, J.M. (1996), «San Juan de Puerto Rico. La perla fortificada del Caribe», en Puerto Rico... (1996): 257-70.

ZEA, L. (1979), Precursores del pensamiento latinoamericano contemporáneo, México, Sep Setentas Diana.
ZEUSKE, M. (1996), «1898. Cuba y el problema de la 'transición pactada'. Prolegómeno de una historia de la cultura política en Cuba (1880-1920)», en C. Naranjo et al., eds. (1996): 131-49.

— (1997), «Dier diskrete marcht der sklaven. Zur politischen partizipation von afrokubanene während des kubanischen unabhängigkeitrieges under ersten jahre republic (1895-1905)-eine regionales perspective», en M. Zeuske, ed. (1997): 32-98.

- (1998a), «El cimarrón y las consecuencias de la guerra del 95. Un repaso de la bibliografía de Estaban Montejo», en A. García Álvarez y C. Naranjo, coords. (1998): 65-84.

- (1998b), «Estructuras, movilización afrocubana y clientelas en un hinterland cubano: Cienfuegos, 1895-1906», en J.A. Piqueras, coord. (1998): 93-116.

- (1998-99), «Un Caribe alemán? El imperio guillermino y Cuba hacia 1898», en M.T. Cortés et al., eds. (1998-99).

- (en prensa), Estructuras regionales, movilización afrocubana y raza en un hinterland cubano: Cienfuegos entre colonia y República (1895-1912), Mainz.

--..- ed. (1997), Nach der sklaverli grundprobleme amerikanischer postemanzipationsgesellchaften, monográfico de Comparativ, 7/1.

ZULUeTA, E. (1998), «Los Estados Unidos y la Guerra del 98», en El 98 visto... (1998): 141-58.

ZULUETA, R. (1995), «Las fuerzas armadas de los Estados Unidos en la Guerra Hispano-Norteamericana en el teatro de operaciones militares en Cuba», en $\mathrm{O}$. Loyola, coord. (1995): 101-14.

R. I., $1999, \mathrm{n}^{\circ} 215$ 